Portland State University

PDXScholar

10-24-1995

\title{
American Deaf Students in ENNL Classes: A Case Study
}

Janice Elisabeth Ruhl

Portland State University

Follow this and additional works at: https://pdxscholar.library.pdx.edu/open_access_etds

Part of the Bilingual, Multilingual, and Multicultural Education Commons Let us know how access to this document benefits you.

\section{Recommended Citation}

Ruhl, Janice Elisabeth, "American Deaf Students in ENNL Classes: A Case Study" (1995). Dissertations and Theses. Paper 4920.

https://doi.org/10.15760/etd.6796

This Thesis is brought to you for free and open access. It has been accepted for inclusion in Dissertations and Theses by an authorized administrator of PDXScholar. Please contact us if we can make this document more accessible: pdxscholar@pdx.edu. 
THESIS APPROVAL

The abstract and thesis of Janice Elisabeth Ruhl for the Master of Arts in

Teaching English to Speakers of Other Languages were presented October 24,1995 , and accepted by the thesis committee and the department.

COMMITTEE APPROVALS:

Marjorié Terdal, Chair

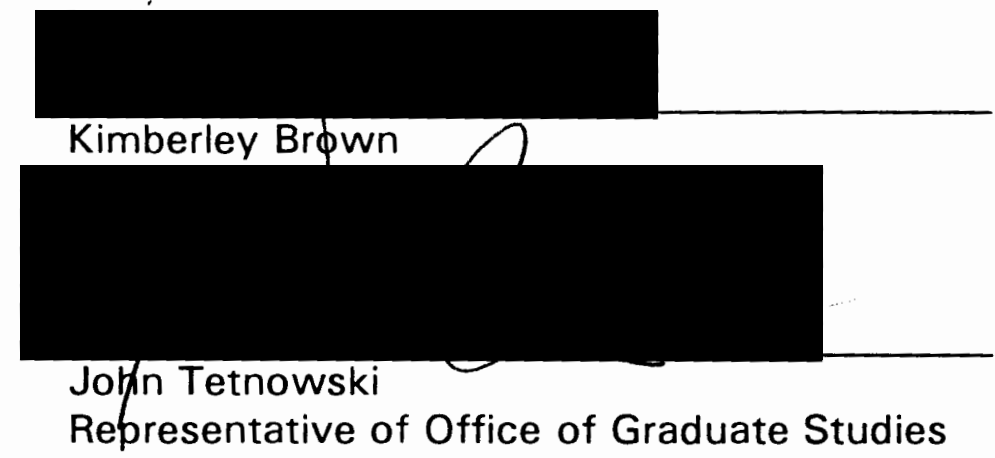

DEPARTMENT APPROVAL:

Beatrice Oshika, Chair

Department of Applied Linguistics

ACCEPTED FOR PORTLAND STATE UNIVERSITY BY THE LIBRARY

by

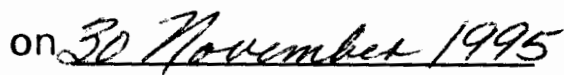




\section{ABSTRACT}

An abstract of the thesis of Janice Elisabeth Ruhl for the Master of Arts in Teaching English to Speakers of Other Languages presented October 24, 1995.

Title: American Deaf Students in ENNL Classes: A Case Study

Many deaf students who seek post secondary education need some sort of developmental education in reading and writing to ensure success in college. These students often end up in college preparatory or remedial classes that are designed for native speakers of English. For many of the deaf students entering college, English is a second language or a first language that they have failed to achieve fluency in.

This study describes the experience of two deaf students enrolled in English as a Non-Native Language classes for the first time at an Oregon community college. The Office of Students with Disabilities and the ENNL department cooperated in this trial to determine whether the ENNL program is an appropriate place for American deaf students needing developmental education in English. Observations, interviews and writing sample analysis were used to provide a multi-layered description of the experience from several perspectives. 
The deaf students were found to display similar errors in their writing samples as traditional ENNL students at the same level and benefited from instruction geared to non-native speakers of English. The rehabilitation counselor and ENNL instructors agreed that placement of the deaf students in ENNL classes is appropriate and the program continues in fall term. The deaf students of this study stated that they were better served by ENNL classes than by Developmental Education Classes.

Curriculum and methodology used in ENNL classes were found to meet the educational needs of the deaf students, and only minor modifications were made to accommodate the students. The experience from these classes has convinced the ENNL department to continue accepting deaf students to the program and enrollment of deaf students in ENNL classes is expected to increase. 
AMERICAN DEAF STUDENTS IN ENNL CLASSES:

A CASE STUDY

by

JANICE ELISABETH RUHL

A thesis submitted in partial fulfillment of the requirements for the degree of

\section{MASTER OF ARTS \\ in \\ TEACHING ENGLISH TO SPEAKERS OF OTHER LANGUAGES}

Portland State University

1995 


\section{TABLE OF CONTENTS}

PAGE

\section{CHAPTER}

I INTRODUCTION .....................

Statement of the Problem . . . . . . . . . . . . . 1

Background .....................

Research Questions . . . . . . . . . . . . . . . 8

Definition of Terms .................. 10

II REVIEW OF THE LITERATURE . . . . . . . . . . . 11

Orientation to Deafness . . . . . . . . . . . . . . . . 11

Language Use in the Education of Deaf Children . . . 14

Deafness and Language Acquisition . . . . . . . 19

English as a Second Language of the Deaf . . . . . . . 22

The ESL Approach to Teaching English to the Deaf . . 24

III METHODOLOGY ....................30

Subjects ................... 30

American Deaf Students

ENNL Instructors

Interpreter

Office of Students with Disabilities Rehabilitation

Counselor

ENNL Department Chair

Interpreter Training Instructor 
ENNL Students

Data Collection

Observations

Interviews

Writing Samples

Procedures

Interviews and Observations

Writing Samples

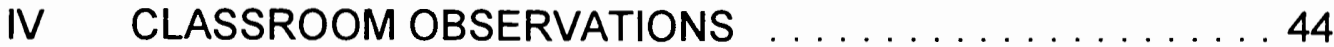

Intermediate Writing Class . . . . . . . . . . . . . 44

Upper Intermediate Reading Class $\ldots \ldots \ldots \ldots . \ldots 53$

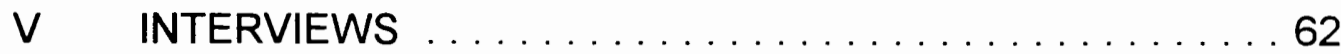

Susan .........................62

Nancy . . . . . . . . . . . . . . . . . . . . . . 65

Paula .....................67

Maya ......................... . 75

George ...........................85

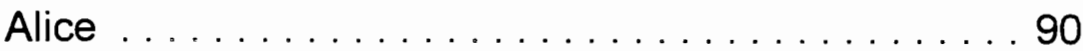

Peter . . . . . . . . . . . . . . . . . . . . . 96

Sharon ........................98

VI WRITING SAMPLE ANALYSIS . . . . . . . . . . . . . . 101

Placement Samples . . . . . . . . . . . . . . . . . . . . . . 101

In-Class Essays . . . . . . . . . . . . . . 107 
VII DISCUSSION ...................... 110

A Return to the Guiding Questions . . . . . . . 110

Other Issues . . . . . . . . . . . . . . . . 126

Limitations and Suggestions for Future Research . . 131

Implications for Teaching ENNL Classes with

American Deaf Students . . . . . . . . . . . . 133

Conclusion . . . . . . . . . . . . . . . . . 136

Epilogue . . . . . . . . . . . . . . . . 138

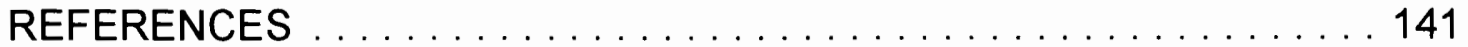

\section{APPENDICES}

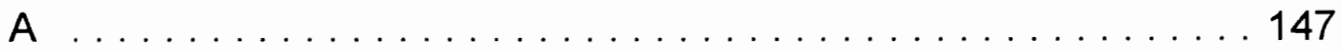

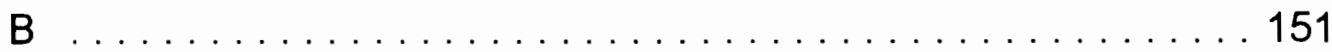

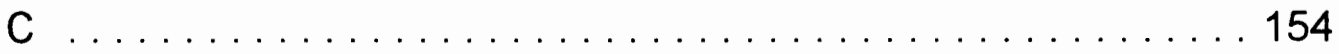

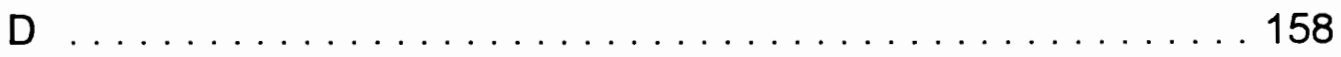




\section{LIST OF TABLES}

TABLE

PAGE

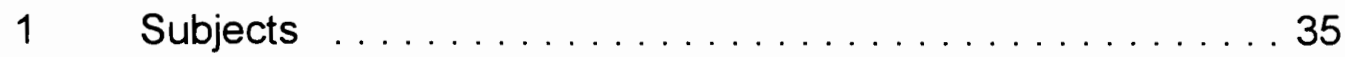

2 Matrix of Guiding Questions and Data Collection Methods . . 38

3 Classification of Writing Errors . . . . . . . . . . . 42

$4 \quad$ Classification of Errors of Nine ENNL Intermediate Level Writing Placement Samples . . . . . . . . . . . . . 102

$5 \quad$ Global and Local Errors in Nine ENNL Intermediate Level Writing Placement Samples . . . . . . . . . . . . 105

6 Global and Local Errors in 64 Intermediate Writing In-class

Paragraphs .................... 108 


\section{CHAPTER I}

\section{INTRODUCTION}

\section{STATEMENT OF THE PROBLEM}

This study describes the experience of two deaf students enrolled in English as a Non-Native Language classes for the first time at an Oregon community college. Observations, interviews and writing sample analysis were used to provide a multi-layered description of the experience from several perspectives.

English language instruction programs for speakers of other languages in this country often carry titles such as English as a Second Language (ESL) or English as a Non-Native Language (ENNL). These terms are not always clear to those outside of the Teachers of English to Speakers of Other Languages (TESOL) field. When discussing their jobs, ESL instructors are often asked, "What's the first language?" or "How many languages do you speak?" because it is commonly assumed that we must know the languages of our students in order to teach them English. Generally speaking however, most people can identify an ESL student as being someone who was born in another country; grew up speaking a language other than English; is a 
refugee, recent immigrant, international student, or visitor; and is learning English.

The college level or adult ESL teacher might question the term "recent" immigrant. Some students have been here for a long time. The elementary school ESL instructor might object to defining students as foreign born. Some pupils were born in the U.S. to parents who use a language other than English in the home. Those of us who teach ESL sometimes have U.S. citizens (children born here and immigrants who have gained citizenship) in our classrooms, but how many of us have had a student who was born in the United States to a family that has been in this country for generations? Is it possible that a second or third generation American who went to public school in this country would need to take an ESL class? For some deaf people, the answer may be "yes".

The majority of deaf people are born to hearing parents (Rawlings \& Jensema, 1977). At a time when hearing children are sailing through the various stages of language acquisition, many children who were born deaf or were deafened at an early age find themselves in a period of language deficit. They receive little or no spoken language input and often experience only rudimentary gestural communication with hearing family members, caretakers and peers who either do not know or are not fluent in sign language. These children may reach school age with very little language.

Approximately $10 \%$ of deaf children are born to deaf parents 
(Hoffmeister \& Wilbur, 1980; Rawlings \& Jensema, 1977). Unlike the deaf children of hearing parents, a majority of these children are exposed to a sign language early in life and may reach school age with sign as their first and only language (Strong, 1988).

School is often a frustrating experience for a deaf child who is struggling with English as a first or second language. Studies indicate that the average deaf high school graduate has a third to fifth grade reading level (Allen, 1986; DiFrancesca, 1972; Trybus \& Karchmer, 1977). Many deaf students who seek post secondary education need some sort of developmental education in reading and writing to ensure success in college. These students often end up in college preparatory or remedial classes that are designed for native speakers of English. But is this the appropriate place for them?

\section{BACKGROUND}

"How can someone who went to school in this country not read and write English?" "I can't imagine an American in an ENNL reading class. They'd be so bored with the content, the American culture and history." "I'm worried about it taking something away from the non-native students." These were some of the reactions to the idea of allowing American deaf students to take ENNL classes at an Oregon community college, when ENNL instructors were discussing the idea at an in-service meeting during Winter term in 1995. 
As the technical assistant to the ENNL department chair, I knew that the department had recently been approached by Alice (a pseudonym, as are all the other names in this study), a rehabilitation counselor in the Office of Students with Disabilities (OSD) at the same community college. She proposed that selected American deaf students be allowed the choice of taking classes in the ENNL program. The term "American deaf student" is used in this study to describe a young adult who grew up in the United States (where English is the native language of the dominant hearing community) and was born deaf or became deaf at an early age. Such individuals are to be distinguished from deaf students from another country, where a language other than English is the native language of the hearing community. I learned later that Alice had first contacted the ENNL department in the spring of 1994 but a decision had been deferred until the position of ENNL department chair changed hands.

All students desiring admission to the community college take a placement test that assesses English and math skills. Non-native speakers of English may substitute the ENNL placement test for the English skills test. Students who do not meet basic reading and writing requirements are steered toward the Developmental Education (DE) and the Adult Basic Education $(A B E)$ departments which offer classes designed to meet those requirements. Students who do not qualify for DE classes take ABE courses first. Sometimes non-native speakers of English take the general placement test. If 
they receive scores that place them at the DE level, they are advised to enroll in the ENNL program because ENNL classes are designed for students whose first language is not English, while $D E$ and $A B E$ classes are designed for native speakers of English. ENNL and DE classes can be taken for college credit. ABE classes are non-credit only.

Students who place in ABE move into DE once they successfully complete their $A B E$ classes. In the past, deaf students who completed $A B E$ also moved into DE. Concerns about the difficulty many of the deaf students faced in DE led Alice to develop an English course specifically for deaf students. The Comprehensive English Development for the Deaf (CEDD) course is a one-term class offered to deaf students as a transition between $A B E$ and $D E$. The CEDD course design is grounded in deaf education and language acquisition theory, and some ESL materials and methodology are used by Alice, who teaches the course. In part, her experience with teaching this course has convinced Alice that the ENNL program may be a better place for American deaf students than DE.

The ENNL program consists of courses at four sequential skill levels: Intermediate, Upper Intermediate, Advanced, and Upper Advanced. The program is academic in nature and offers courses in Reading, Writing, Speaking, Pronunciation, and Supplementary Writing. Most sections of ENNL are five-credit, college transfer courses. Pronunciation and upper-level speaking classes are two to three credit courses. Speaking, writing, and 
reading are taught separately. Students in the ENNL program may be at different levels in different skill areas but students enrolled for one skill must be placed at least at the previous level in the other skills. For instance, a student with an Upper Advanced Reading placement may enroll in that class only if his or her writing and speaking placement is at the Upper Advanced or Advanced level.

Although American deaf students have never taken ENNL classes at the community college before, Peter, the department chair, did some research on deafness and language acquisition and talked to colleagues at another community college that had had American deaf students in ENNL classes. He became convinced that the ENNL program might be the right place for some deaf students and agreed to allow deaf students who passed the reading and writing portions of the ENNL placement test to register for spring term classes. The decision was contingent on the agreement that Alice would screen deaf students and recommend those that had successfully completed her Comprehensive English Development for the Deaf Course and that she considered ready for the program. ENNL faculty were advised of the possibility of American deaf students entering the program in the spring term. The research was made available to them and some instructors met with Alice to discuss questions and concerns.

The ENNL placement test consists of a speaking, reading and writing portion. A retired revision of the Michigan Test of English Language 
Proficiency is used for reading placement. The possible levels for placement are: ESL (too low to start ENNL, the college has an ESL program that is nonacademic, free and geared toward the beginning English learner), Intermediate, Upper Intermediate, Advanced, Upper Advanced, and no ENNL (too high for the ENNL program). For writing placement, students are given twenty minutes to write on a given topic. Essays are rated holistically and students are placed in one of the following levels: ESL, Intermediate, Upper Intermediate, Advanced, Upper Advanced, Writing 115, Writing 121. The last two levels are regular prerequisite writing classes in the college curriculum. The rater judges the writing sample impressionistically and takes everything into account using criteria that are outlined in the ENNL course content guidelines to assign the samples to an appropriate level. A summary of the course content guidelines for Intermediate Writing can be found at the beginning of Chapter IV.

During Winter term 1995, Alice advised three deaf students to take the ENNL placement test. Two of the students had taken the CEDD course while one had not. The two who took CEDD placed into Intermediate Writing and Upper Intermediate Reading and enrolled for Spring term. The scores of the third student placed her at the ESL level. She plans to take the CEDD course and take the ENNL placement test again. 


\section{RESEARCH QUESTIONS}

The main inquiry for this study is:

Given that for many of the deaf students entering the community college English is a second language or a first language that they have failed to achieve fluency in, is it possible that the ENNL program is an appropriate place for American deaf students needing developmental education in English?

Following are guiding questions:

1. How do the ENNL placement test writing samples of the deaf students compare to those of the non-native English speakers?

2. Does the ENNL reading and writing curriculum meet some or all of the needs of the two American deaf students who need developmental education in these skill areas?

3. What similarities and differences exist in the writing errors of American deaf students and other ENNL students?

4. What modifications, if any, in teaching methodology, style, materials, and testing do ENNL instructors report they make to accommodate American deaf students in the classroom?

5. How much, if any, of the American culture incorporated in the content of the ENNL classes is new to the deaf student?

6. What difference, if any, does the interpreter for the deaf students find in interpreting in ENNL classes as opposed to other classes, such as 
biology, math, or literature?

7. Do the writing and reading skills of the deaf students improve by the end of the term?

8. Is there any classroom interaction between the deaf students and the other ENNL students and what is the nature of this interaction?

9. How does the presence of American students in the classroom impact the other ENNL students?

10. How will the ENNL department chair and the OSD counselor evaluate the experience of having American deaf students in the ENNL program?

11. What criteria will be used to determine whether ENNL classes be recommended for American deaf students in the future?

This is a descriptive case study of the first term that American deaf students have been enrolled in ENNL classes at the community college. It is based on observations of the ENNL classes, student writing samples, interviews of key participants, placement test information, course content guidelines and class texts and materials. Data collection will be discussed more fully in the "Methods" chapter. 


\section{DEFINITION OF TERMS}

ESL English as a Second Language

ENNL English as a Non-Native Language

TESOL Teachers of English to Speakers of Other Languages

OSD Office of Students with Disabilities

CEDD Comprehensive English Development for the Deaf

DE Developmental Education

ABE Adult Basic Education

ASL American Sign Language

OE Oral English

MCE Manual Coded English

SEE I Seeing Essential English I

SEE II Seeing Essential English II

LOVE Linguistics of Visual English

PSE Pidgin Sign English

LAD Language Acquisition Device

GED General Equivalency Degree 


\section{CHAPTER II}

\section{REVIEW OF THE LITERATURE}

The review of the literature is divided into five sections: Orientation to deafness, language use in the education of deaf children, deafness and language acquisition, English as a second language of the Deaf, and an ESL approach to teaching English to the Deaf.

\section{ORIENTATION TO DEAFNESS}

Paul and Jackson (1993) note that defining deafness is really a matter of perspective, and audiologists, sociologists, educators and psychologists may view deafness differently. Quigley and Paul (1984a) consider a child deaf when "hearing impairment is so great, even with good amplification, that vision becomes the child's link to the world and main channel of communication" ( $p$. 1). For the purpose of educational treatment, Rodda and Grove (1987) distinguish between the deaf child and the hard-of-hearing child but categorize both as hearing impaired. Hearing impairment is characterized by "disorders of communication" brought on by hearing loss ( $p 1)$.

Though society uses the term "deaf" somewhat indiscriminately, the general tendency in the literature is to use "hearing impaired" as a collective 
term for people with varying degrees and types of hearing loss, which includes the hard-of-hearing (able to receive some speech input) and the deaf (unable to receive speech input) (Rodda \& Grove, 1987; Scheetz, 1993). However, ?

language used to refer to differently abled people is constantly evolving and in some circles the term hearing impaired is not favored. (Swisher 1989).

Even though there are an estimated 15 million hard-of-hearing people in the United States (Sacks, 1989), deafness has always been a low incidence handicap (Streng, Kretschmer Jr., \& Kretschmer, 1978). According to Moores and Meadow-Orlans (1990), early profound deafness occurs only in one child per thousand.

The distinction made between the words "deaf" and "Deaf" is also related to perspective. From a clinical perspective, the word "deaf" with a lowercase letter refers to a physical condition. The use of the word "Deaf" with an uppercase letter reflects a cultural perspective that refers to a community of people who share language, interests and attitudes. Within this community, deafness is not viewed as a pathology or handicap. However, being deaf does not necessarily mean that an individual is a member of the Deaf culture (Rodda \& Grove, 1987; Scheetz, 1993; Swisher, 1989). As Scheetz notes, membership in the Deaf community is based on several factors. First, one must want to identify with the Deaf subculture; second, he must be able to relate to experiences that are shared by other members; and third, he must share a similar communication base in order to facilitate the exchange of ideas. (p. 20) 
Many factors make the deaf population a diverse one, such as age of onset of hearing loss, degree and type of hearing loss, parental hearing status and educational background. Age of onset refers to the age at which hearing loss occurred. People who are born deaf or experience hearing loss before developing language are termed prelingually deaf, while those who lose their hearing after some development of language are postlingually deaf.

Degree of hearing loss varies and is categorized by audiologists into five levels, ranging from mild to profound (Scheetz, 1993). The degree of hearing loss affects the amount of auditory input the individual receives, which in turn determines whether the individual's main channel of communication is auditory or visual. Type of hearing loss is related to the location of impairment and determines what, if any, amplification methods can be employed to increase reception of auditory input.

Parental hearing status can affect the age at which deaf children begin to acquire language and often determines the type of language they learn. Educational background may vary considerably. The parent of a deaf child faces a myriad of decisions when selecting the best learning environment for that child. Choices include the mode of communication to be used, residential vs. day programs, self-contained vs. mainstreamed settings, and whether activities should focus on Deaf culture or on integration with hearing students (Scheetz, 1993, p.74). 


\section{LANGUAGE USE IN THE EDUCATION OF DEAF CHILDREN}

Controversy has surrounded the education of deaf children for centuries. Lou (1988) notes that in the history of deaf education in the United States there have been "almost exactly one and a half sweeps of the pendulum between American Sign Language (ASL) and manual approaches at one end of the arc and oral English at the other end" (p.75). Manual approaches, dominant in the early part of the nineteenth century, were replaced by oral-only approaches in the late 1800 s. Oralism peaked in the early 1900 s and, according to Lou, the pendulum has swung slowly back to a midpoint where manual approaches are back in favor and both oral and manual systems are used, sometimes in combination (p. 76). Total communication, which incorporates oral and manual communication modes is the most widely used approach today (McAnally, Rose \& Quigley, 1987). In its ideal form, which is not always practiced, this approach considers the capabilities and needs of each individual child and provides the best combination of communication modes (Lou, 1988).

Quigley and Paul (1987) categorize the language options available for the education of deaf children as follows:

There are two distinct languages, American Sign Language and English, and two distinct communication forms, oral and manual . . . (that can be) combined in a variety of ways to produce a number of systems or approaches, which can be classified into three general categories: Oral English (OE), Manually Coded English (MCE), and American Sign Language. (P. 182) 
Stokoe (1960) was the first linguist to analyze the structure, signs and constituent parts of American Sign Language (ASL), a manual language that developed in part from the French Sign Language brought to this country in the early 1800 s by Thomas Gallaudet and Laurent Clerc (Lane, 1984). ASL is now considered a fully-developed complex language with a rule-governed grammar (Klima \& Bellugi, 1979). It is a visual-gestural language that uses shapes, positions and movements of body parts. Signs represent words and non-manual cues are used to express grammatical functions (Scheetz, 1993). There is no more correlation between English and ASL than there is between English and Japanese, they are two distinct languages.

Manually Coded English (MCE) systems such as Signed English, Seeing Essential English (SEE I), Linguistics of Visual English (LOVE), and Signing Exact English (SEE II) are invented manual communication systems that manipulate ASL signs and finger spelling to conform to the structure of English. They were devised to present the English language manually to help deaf children acquire that language. They are also useful in facilitating communication between hearing and deaf people, because parents and teachers are more apt to learn one of the MCE systems than ASL.

Though they consider it a "linguistically natural language", Quigley and Paul (1984a) classify Pidgin Sign English (PSE) as a form of MCE. PSE, like any pidgin, developed through the interaction of two language groups. As described by Scheetz (1993), PSE is used for communication between deaf 
users of American Sign Language and hearing people who know ASL signs but not ASL grammar. PSE varies depending on who is using it and "can assimilate strong characteristics of ASL or reflect a more English base" (P.113). Some deaf people use "Contact Variety" as an alternative term for PSE to reflect the variation that can occur. Pidgin Sign English and the Manually Coded English systems can be viewed as a continuum between American Sign Language and the English language. They differ in how much they diverge from American Sign Language and how close they approximate English (Quigley \& Paul, 1984a).

It should be noted that there are deaf and hearing people who object to the linguist's categorization of sign languages, but even within this group there is disagreement. There are those who propose that the term American Sign Language should be used to cover all variations of sign language used by the deaf, including Manually Coded English (Andersson, 1990; Bragg, 1990, H. Goodstein, 1990; Kuntze, 1990; L. Stewart, 1990). Others object to invented sign systems being labeled as a form of American Sign Language (Mather, 1990; Newell, 1990; Valli, 1990).

Oral English as a communication system for deaf children emphasizes the use of auditory-vocal mechanisms, and children are trained to use residual hearing, speechread (lipread), and monitor their own speech (McAnally, Rose \& Quigley, 1987). 
There is a movement today in the deaf education field to provide deaf children with a bilingual education. Not everyone is in agreement as to what this means. Strong, Woodward and Burdett (1987) implemented an experimental program for deaf children who were taught ASL as a first language, which then was used as the medium for teaching English as a second language. As with many spoken language bilingual programs, they advocate that ASL and English be given equal importance and value.

Many support the idea of providing young deaf children with early access to ASL and using it as the sole language of instruction in content areas for the first few years of school (Christensen, K., Goodstein, A., Humphries, T., Kuntze, M., Titus, A. \& Strong, M., 1990; Johnson and Liddell, 1990; Paul, 1990; Quigley \& Paul, 1984b; Strong, 1990). After the child has developed academic skills in the first language, English would be introduced as a second but equal language. Christensen $(1989,1990)$ and Christensen et al., (1990) however, caution against relying too heavily on research of bilingualism involving two spoken languages to make generalizations about bilingualism involving a spoken language and a visual-spatial one. She points out that for many deaf children without access to ASL, a bilingual approach would more likely involve a parallel acquisition of ASL and English, because there would be no first language to help with the acquisition of a second. She advocates more research on deaf families to provide insights into how deaf children of deaf parents acquire $A S L$ and English. 
Not everyone favors ASL as a deaf child's first language. L. Stewart (1990) cautions against the assumption that teaching ASL to deaf children will be the cure-all for their language and educational problems and considers the idea that all deaf people use and understand American Sign Language a myth. Cornett (1990) proposes that a deaf child's first language should be the language of his or her parents. He supports the teaching of ASL to deaf children but thinks that deaf children of hearing parents should learn English first. Bosso (1990) argues that while ASL may not be the native language of deaf children born to hearing parents, neither is spoken English.

Others support the teaching of ASL but do not rule out the use of various forms of Manually Coded English in the classroom and at home. Bragg (1990) proposes that deaf children be exposed to ASL at home and in school and then gradually be exposed to forms of Manually Coded English in school because "seeing English in print is not sufficient. Deaf children need to see it on someone else's hands and lips and feel it on their own hands" (p. 11). D. Stewart (1990) also sees value in using Manually Coded English as well as ASL in the classroom and hypothesizes that a common element in future bilingual programs for deaf children "will be the mutual coexistence between ASL in the sign modality, and English in the sign, speech, and print modalities" (p. 5). 


\section{DEAFNESS AND LANGUAGE ACQUISITION}

For the deaf, the task of acquiring the language of the dominant hearing majority is not easy. Prelingual, profoundly deaf children face unique problems that require early recognition and intervention (Rodda \& Grove, 1987; Sacks, 1989). Without it they risk delayed language development. The impact of living with little or defective language is poignantly described by Sacks:

To be defective in language, for a human being is one of the most desperate of calamities, for it is only through language that we enter fully into our human estate and culture, communicate freely with our fellows, acquire and share information. If we cannot do this, we will be bizarrely disabled and cut off - whatever our desires, or endeavors, or native capacities. (p. 8)

Hearing children seem to acquire language unconsciously and effortlessly, which Chomsky (1972) attributes to an innate predisposition for language acquisition. A Language Acquisition Device (LAD) allows children to induce and master most of the grammatical rules of their native language by the age of five, in spite of the degenerate input Chomsky considers they receive. Snow (1977) disagrees with the premise that language input available to children is degenerate. Her studies found mothers' language to children well-formed and clear. Bohannon and Warren-Leubecker (1985) see meaningful interaction with mature language learners as an important factor in normal language acquisition. 
Swisher (1989) discusses the limited linguistic input available to the prelingually deaf child learning English whose family does not know or use a natural sign language. The primary channel for children acquiring language is the auditory one. Input reaching the deaf child through the primary channel and the secondary visual channels is often reduced and fragmented. Amplification may increase the amount of auditory input a deaf child receives but because English sounds have different frequencies and the stress of English words varies, what gets through to the deaf child may be distorted. Lipreading is the process by which deaf individuals "read" shapes and movements of the speaker's lips as they articulate speech sounds. Evans (1982) notes that the term speech reading is more accurate, as the process also involves "reading" facial expressions and linguistic cues. The input received through lipreading is limited because not all English speech sounds are visible on the lips. In addition, some phonemes that sound different, such as $/ \mathrm{p} /, / \mathrm{m} /$, and $/ \mathrm{b} /$ look the same on the lips.

Manually Coded English systems were developed in part to allow simultaneous communication in oral English and manual English. However, Swisher (1989) points out that it is simply not possible to map out every word and inflection of an auditory language onto a signed one and retain a natural rate of delivery. Many of the signs invented to show English structure end up being omitted during rapid communication, and the deaf student receives 
degraded input that may affect his or her ability to acquire the language (Strong, Woodward \& Burdett, 1987; Swisher, 1989).

Print alone cannot provide the communicative interaction that typifies successful first language acquisition. Hearing children are generally fluent in aural-oral communication by the time they learn to read (King \& Quigley, 1985). They bring developed cognitive and linguistic abilities to the task of reading. Lane (1990) notes that "written text is more complex, coherent, integrated, decontextualized, and emotionally detached than face-to-face communication" (p. 84).

Deaf children of deaf parents are generally exposed to language early in life in the form of American Sign Language which they learn in the home (Goldberg \& Bordman, 1975; Quigley \& Paul, 1984a; Strong, 1988). The majority of deaf children are born to hearing parents, most of whom do not use a natural sign language (Swisher, 1989). Some deaf children of hearing parents learn ASL in residential schools for the deaf and ASL becomes their first language. Deaf children who attend mainstream schools and have no opportunity to learn ASL learn English as a first language but do not always achieve native-like fluency. Acquisition of English is especially problematic for these children in that it

becomes neither their first language, in the sense that they may never achieve native-like grammatical competence in the language, nor in traditional terms, a second language, in the sense that they may not be exposed in early life to any other language they can readily acquire. (Swisher, 1989, p. 239) 


\section{ENGLISH AS A SECOND LANGUAGE OF THE DEAF}

Strong (1988) considers English the second language of a deaf child who learned ASL as a first language at home. Many prelingual, profoundly deaf students from hearing families struggle with English language proficiency. Deaf students seeking secondary education are a diverse group for whom ASL may or may not be a first language, and they have been compared to the adult learner of English as a second language (A. Goodstein, 1983; Walworth, 1989).

In recent years, professionals in the fields of linguistics, TESOL and deaf education have begun to draw parallels between the problems deaf students and ESL learners experience. Berent (1983a) notes that "despite differences in degree or persistence, the language problems of prelingually deaf learners of English resemble those of second language learners in many respects" (p. 12).

Errors common in writing samples of deaf students resemble those found in the writing of ESL students. Such errors include verb errors; confusion of singular and plural nouns; ungrammatical strings of adjectives; absence of adverbs; omission, or misuse of pronouns; repetition of nouns, rather than use of pronouns; wrong function words; idiom errors; article misuse or omission; wrong word choice; short, choppy, monotonous sentences; garbled sentences; incorrect word choice; and errors in 
grammatical conceptualization, where writing is grammatical but the concept expressed is foreign to English (Goldberg, Ford \& Silverman, 1984, p. 8).

Quigley and King (1980) found similarities in written errors produced by ESL learners and deaf students. These include confusing "be" and "have", mixing verb tenses in sequence, and placing negatives outside the sentence. Magrath (1985) noted that writing samples of deaf students resembled ESL student compositions and exhibited "the lack of possessive endings, missing relative pronouns, wrong word forms such as depression for depressed, and incorrect verb usage" (p. 498).

In a study by Langston and Maxwell (1988), English compositions of deaf students who sign, deaf students who do not sign, and ESL students at the same level of proficiency could not be easily distinguished by a group of audiologists, speech pathologists, educators of the deaf, and ESL instructors. Berent (1983b) tested the judgements of prelingually deaf adults and adult ESL learners on infinitive complement structures. Both groups tended to overextend the nearness principle when identifying logical subjects in infinitive complements. Berent notes that first language studies show that children acquiring English use this same strategy.

Goidberg, Ford and Silverman (1984) draw parallels between the cultural situation of some deaf students and the adult ESL students who may be barely literate in their own languages; who are from native backgrounds completely unfamiliar to the teacher; and who live in ethnic enclaves where they are immersed in their native 
language and culture, almost devoid of communication with users of English. (p. 5)

THE ESL APPROACH TO TEACHING ENGLISH TO THE DEAF

Connections between the fields of TESOL and deaf education have been growing. A. Goodstein (1983) notes that the Gallaudet College English Department publication, Teaching English to the Deaf has been renamed Teaching English to Deaf and Second Language Students. There is a special interest group in the TESOL organization called Teaching English to Deaf Students (TEDS). Some think that their training and experience make ESL instructors good candidates for teaching English to deaf students (Berent, 1983a; A. Goodstein, 1983; Magrath, 1985).

Goldberg and Bordman (1975) contrast the difference between the methodology of ESL and remedial English and believe that ESL is better for deaf students because

the assumption underlying ESL methods is not that students need correcting of the language they already have, but input of language they do not yet have ... ESL methodology is based on the fact that any person who wants to acquire use of a language he did not grow up hearing must (1) have a reliable model to follow, (2) follow the model in expressing his own ideas, and (3) practice a very great deal. (p. 22)

Meath-Lang and Albertini (1984) see value in borrowing the functionalnotional curriculum from the ESL field for use in teaching English to deaf students. According to Finocchario and Brumfit (1983), such a curriculum is centered around the language learners and their communicative purposes for 
the second language. Meath-Lang and Albertini note that deaf students are often frustrated in their struggle with English and sometimes question the time and effort that goes into the study of the language. A functional-notional curriculum provides them with a rationale for learning English. They outline a functional-notional curriculum model for deaf students that involves assessing student language skills and identifying typical communication situations they encounter; describing the activities involved in those communication situations; and designing a set of language experiences relevant to those situations.

Magrath (1985) advocates the use of dialogue journals with deaf students, a technique often used in ESL that involves teacher and student exchanging written communication. The goal is not to correct the students' English but rather to provide a model of the language being acquired. Cannon and Polio (1989) analyzed the dialogue journals of deaf students and one hearing student at a community college. They found that the instructor used questions, especially yes/no questions more frequently when writing to the deaf students than when writing to the hearing student. In addition, the instructor employed many more communication devices such as comprehension checks and clarification requests when writing to the deaf students. In other words, the instructor's written communication with the deaf students paralleled the "foreigner talk" sometimes employed by instructors communicating in spoken language with non-native speakers of English. 
Cannon and Polio also discovered that over the course of a term, even the minimally English proficient deaf students improved in their ability to use written English communicatively.

Many people are enthusiastic about using an ESL approach to teach English to deaf students (Berent, 1983a; Goldberg \& Bordman, 1975; Goldberg, Ford, \& Silverman, 1984; A. Goodstein, 1983; Magrath, 1985; Walworth, 1989). However most acknowledge that ESL methods and/or materials may have to be adapted. A. Goodstein (1983) notes that most mass produced ESL material is usable but must be supplemented because deaf students do not get the constant reinforcement of the language that ESL students do by listening to their instructor. She suggests that maximum use be made of visuals, and that additional material should provide extra opportunity to practice, apply, and review language structures. She does not think that deaf students need material covering the social mores of American culture often found in ESL texts, and proposes that materials that deal with language problems unique to deaf students would be beneficial, although she does not identify these problems.

Goldberg, Ford and Silverman (1984) also see the need for adapting ESL methodology when teaching deaf students, and they note that methods that have fallen out of fashion in the ESL field can actually benefit those students. They advocate more explicit teaching of grammar and structure and more pattern practice than occurs in many ESL classrooms. In addition, they 
believe in limiting the practice of free writing, another staple of many ESL writing curriculums. They note their reasons for these recommendations as follows:

Prelingual deaf students . . left completely to their own devices ... will not move rapidly in the direction of good grammar and structure control. Rather, we see again and again that the language of these students fossilizes, and with relatively few exceptions becomes relatively fixed (except for some increases in vocabulary)... . Our aim is not to unfetter them, but quite the opposite, to help them get their expression under control. (p. 7)

Not everyone embraces the use of ESL methodology to teach English to deaf students, although it should be noted that most of the people with reservations are referring to teaching deaf children, not young adults.

Christensen et al. (1990) caution against making broad generalizations comparing deaf and non-native speaking students and importing methods meant for students whose first language is sound based. Second language acquisition theories such as order of acquisition and the need for comprehensible input appeal to Humphries in Christensen et al. (1990), but he prefers to develop his own methods from such theories for use in teaching English to deaf children.

A. Goodstein (1983) discusses the possibility of deaf students in ESL classes. She and Goldberg, Ford and Silverman (1984) mention the enrollment of deaf students in the ESL program at the Community College of Philadelphia, but no details are given. Goldberg et al. list changes in classroom operations that are useful when a deaf student enrolls in an ESL 
class, but their suggestions of how to speak and where to stand are not specific to an ESL class and would be appreciated by many non-ESL instructors who had never had deaf students in a class.

There did not appear to be any case studies of deaf students in ESL classes in the literature. Adaptations to ESL methodology and materials were primarily made by deaf education teachers in English programs for the Deaf, like the one at Gallaudet University or the Comprehensive English Development for the Deaf course developed at the community college where this study takes place. There were no descriptions of actual changes in methodology made in an ESL class. No articles were found that had been written by ESL teachers who have taught deaf students in their classes or by deaf students who have taken an ESL class.

Despite the many connections being made between TESOL members and deaf educators, it is safe to assume that many ESL/ENNL instructors have limited knowledge in this area, and little or no experience with American deaf students in their classrooms. There may even be some consternation among instructors facing the prospect of having deaf students in their class. The purpose of this study is to describe the experience of deaf students in ENNL classes at a community college, with the intent of determining whether that is an appropriate placement for them. Given the fact that the Americans with Disabilities Act has opened up all public classrooms to deaf students, the question, "Do American deaf students belong in ESL/ENNL classes?" is 
perhaps more aptly replaced with the question, "When are they arriving?" It is hoped that the results of this study will contribute to existing research that will be useful when that time comes. 


\section{CHAPTER III}

\section{METHODOLOGY}

This is primarily a qualitative study of the experience of two American deaf students in ENNL classes. Observations and interviews were conducted to provide a description of this experience from several perspectives. Writing samples were analyzed to provide quantitative data about the writing errors of deaf students and ENNL students. Details concerning methodology can be found in the Data Collection and Procedures sections.

\section{SUBJECTS}

\section{American Deaf Students}

Two deaf students passed the ENNL placement test during Winter quarter 1995 and became the first American deaf students to enroll in the ENNL program.

Susan is a profoundly deaf woman in her late twenties who was born deaf as a result of the rubella her mother contracted during pregnancy. Her deafness was not discovered until she was two years old, and her family never learned a sign language. Susan attended both mainstream and deaf schools and started oral training when she was about three and a half years old. She 
did not learn sign language until she was ten years old. At that time she became exposed to forms of Manually Coded English through total communication instruction, and American Sign Language from other deaf children. Susan dropped out of high school and completed her General Equivalency Degree (GED) at the age of 22 . She relies primarily on sign language, both American Sign Language and Pidgin Sign English for communication. She tends to vocalize as she signs, but her speech could not be easily understood by the researcher or the two ENNL instructors. She enrolled in Developmental Education Reading and Writing classes and the Comprehensive English Development for the Deaf course during Fall quarter 1994. She finished the Comprehensive English Development for the Deaf course but dropped out of the Developmental Education classes. In Winter quarter 1995, the Comprehensive English Development for the Deaf class was canceled due to a lack of enrollment, and Susan repeated the Developmental Education classes but dropped out again before the end of the term. She took the ENNL placement test that quarter and placed into Intermediate Writing and Upper Intermediate Reading. Susan enrolled in these classes in Spring quarter 1995. She started missing ENNL classes during the fifth week of the term and by the 7th week she dropped both classes.

Nancy is a 19-year-old profoundly deaf woman who lost her hearing at the age of 23 months after a high fever. Her deafness was diagnosed immediately and her family learned Pidgin Sign English. Her sister is an 
interpreter for the deaf. Nancy does not remember learning sign language.

She believes she learned it at about age 3 from her parents and a teacher. She also met a deaf girl when she was around three or four years old. Nancy began oral training at the age of six but quit after two years. She attended public school until the fourth grade and then switched to the Washington School of the Deaf, where she completed high school. She learned American Sign Language at the Washington School of the Deaf and uses American Sign Language and Pidgin Sign English for communication. She began attending the community college Fall quarter 1994 . She took the Comprehensive English Development for the Deaf class that term and Developmental Education Reading and Writing during Winter quarter 1995. She took the ENNL placement test at the same time Susan did, and also placed into Intermediate Writing and Upper Intermediate Reading. She enrolled in these classes in Spring quarter 1995 and completed them.

\section{ENNL Instructors}

Paula taught the Intermediate Writing class. She is a full-time instructor who has taught at the community college for twenty years. She has taught English composition as well as Adult Basic Education classes and she has been teaching ENNL since 1980.

Maya taught the Upper Intermediate Reading class. She is a full-time instructor who taught ESL at another community college from 1968 to 1974. 
She began teaching ENNL at the school where this study took place in 1976 and has been there ever since. Neither Paula nor Maya know sign language.

\section{Interpreter}

George was the primary interpreter for Nancy and Susan. As the only hearing member of his immediate family, he learned Pidgin Sign English at home and has used it all his life. He has not had any formal interpreter training. At the start of the quarter, George had been working as an interpreter for the deaf for nine months and had interpreted in a computer assisted design class, a grammar class and a Math lab. He signs Pidgin Sign English and some American Sign Language but does not consider himself fluent in American Sign Language.

\section{Office of Students with Disabilities Rehabilitation Counselor}

Alice has worked at the community college for 18 years as a rehabilitation guidance counselor with the Office of Students with Disabilities and as an English instructor for the Deaf. Over the years she has designed and developed several courses and she currently teaches the Comprehensive English Development for the Deaf course every term, as long as there are a minimum of five students. She is hearing and a fluent American Sign Language, Pidgin Sign English, and Manually Coded English signer. 


\section{ENNL Department Chair}

Peter is a full-time ENNL instructor who is currently the ENNL department chair. The full-time instructors in the department rotate this position every two years.

Interpreter Training Instructor

Sharon is an administrator and instructor in both the sign language studies program and the sign language interpreter training program at the community college. She is deaf and communicates with sign language.

\section{ENNL Students}

Seventeen non-native speaking students took the ENNL placement test on the same day that the deaf students did. Seven of these received Intermediate Writing placement, as did the deaf students. Twenty five "traditional ENNL" students ( $a$ term coined by Maya to distinguish them from the American deaf students) enrolied in the Intermediate Writing class, while 18 enrolled in the Upper Intermediate Reading class. Fifteen of the Upper Intermediate Writing students agreed to share their essays with the researcher.

See Table 1 for a summary of the subjects. 
Table 1

Subjects

\begin{tabular}{|l|l|}
\hline Susan & American deaf student \\
\hline Nancy & American deaf student \\
\hline Paula & Intermediate Writing Instructor \\
\hline Maya & Upper Intermediate Reading Instructor \\
\hline George & Interpreter \\
\hline Alice & OSD Rehabilitation Counselor \\
\hline Peter & ENNL Department Chair \\
\hline Sharon & $\begin{array}{l}\text { Administrator/Instructor for Sign Language Studies and } \\
\text { Interpreter Training Program }\end{array}$ \\
\hline S1-S7* & $\begin{array}{l}\text { Non-native English speakers who took the ENNL placement } \\
\text { exam on same day as Susan and Nancy }\end{array}$ \\
\hline W1-W15 & $\begin{array}{l}\text { Intermediate Writing students who shared their essays with } \\
\text { the researcher }\end{array}$ \\
\hline
\end{tabular}

Note. One of the placement subjects (S1) is also the Intermediate Writing subject (W14)). The other placement subjects enrolled in Intermediate Writing did not share their writing class samples with the researcher. 


\section{DATA COLLECTION}

\section{Observations}

Each ENNL class (Intermediate Writing and Upper Intermediate Reading) was observed 13 times between the fourth and tenth week of classes. Extensive field notes were taken during each 50-minute class period. Appendix $A$ includes a sample of the field notes. Copies of the writing class text, (Focus on grammar: An intermediate course for reference and practice) and the reading class text, (Reflections) were obtained. Class syllabi, handouts, and exams were collected from the instructors. Course curriculum guidelines for both classes were collected from the ENNL department.

\section{Interviews}

Subjects were interviewed during the period between the fourth and tenth week of classes. Nancy, Maya, and Paula, were interviewed three times. Susan was interviewed once before she dropped the classes. Alice and George were interviewed twice, and Peter and Sharon were interviewed once. All interviews were audiotaped and all tapes were transcribed. See Appendix B for samples. 


\section{Writing Samples}

The ENNL placement test includes a 20 minute writing sample on a given topic. At the time that Susan and Nancy took the test, the essays of seven other students were also judged to be at the Intermediate level. All nine Intermediate level placement samples were collected from the ENNL department. Writing samples can be found in Appendix C.

During the period of observation, four in-class paragraphs were written in the writing class. Nancy and 15 ENNL students (Susan's attendance had become sporadic at this point) agreed to allow the researcher to make copies of these paragraphs.

\section{PROCEDURES}

Interviews, observations and the collection of student writing samples and other classroom material were used to answer the guiding questions of the study. Table 2 presents a matrix of guiding questions and data collection methods.

\section{Interviews and Observations}

Both ENNL instructors introduced me to their students as a TESOL MA student researching American deaf students in ENNL classes. The first three observations were made from the back of the room. The remaining observations were made from the front of the room facing the deaf students in order to view communication between them and the interpreter. (The two deaf 


\begin{tabular}{|c|c|c|c|c|c|c|c|c|c|c|}
\hline & 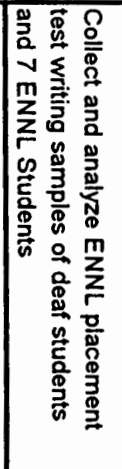 & 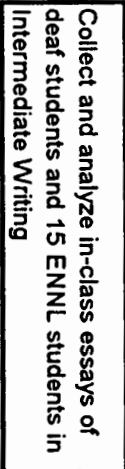 & 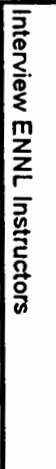 & 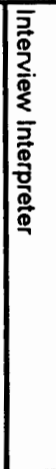 & 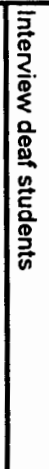 & 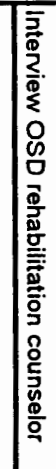 & 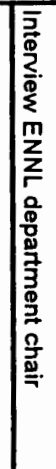 & 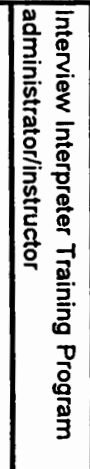 & 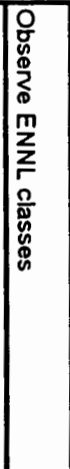 & 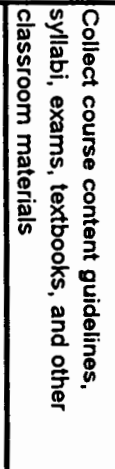 \\
\hline $\begin{array}{l}\text { How do the ENNL placement test writing samples of the deaf students compare to those of the other } \\
\text { ENNL students? }\end{array}$ & & & & & & & & & & \\
\hline $\begin{array}{l}\text { Does the ENNL reading and writing curriculum meet some or all of the needs of the two American } \\
\text { deaf students who need developmental education in these skill areas? }\end{array}$ & & & & & & & & & & \\
\hline $\begin{array}{l}\text { What similarities and differences exist in the writing errors of American deaf students and other ENNI } \\
\text { students? }\end{array}$ & & & & & & & & & & \\
\hline $\begin{array}{l}\text { What modifications, if any, in teaching methodology, style, materials, and testing do ENNL instructor } \\
\text { report they make to accommodate American deaf students in the classroom? }\end{array}$ & & & & & & & & & & \\
\hline $\begin{array}{l}\text { How much, if any, of the American culture incorporated in the content of the ENNL classes is new to } \\
\text { the deaf student? }\end{array}$ & & & & & & & & & & \\
\hline $\begin{array}{l}\text { What difference, if any, does the interpreter for the deaf students find in interpreting in ENNL classes } \\
\text { as opposed to other classes, such as biology, math, or literature? }\end{array}$ & & & & & & & & & & \\
\hline Do the writing and reading skills of the deaf students improve by the end of the term? & & & & & & & & & & \\
\hline $\begin{array}{l}\text { Is there any classroom interaction between the deaf students and the other ENNL students and what } \\
\text { is the nature of this interaction? }\end{array}$ & & & & & & & & & & \\
\hline How does the presence of American students in the classroom impact the other ENNL students? & & & & & & & & & & \\
\hline $\begin{array}{l}\text { How will the ENNL department chair and the OSD counselor evaluate the experience of having } \\
\text { American deaf students in the ENNL program? }\end{array}$ & & & & & & & & & & \\
\hline $\begin{array}{l}\text { What criteria will be used to determine whether ENNL classes be recommended for American de } \\
\text { students in the future? }\end{array}$ & & & & & & & & & & \\
\hline
\end{tabular}


students always sat in the front row on one side of the room. The interpreter sat directly in front of them facing the class. I sat in the corner next to the interpreter and slightly behind him). During small group work in the reading class, observations were made of the group that included the deaf student(s) and the interpreter.

During observations of the reading and writing classes, the general classroom procedure was recorded but the primary focus was any and all interactions of the deaf students. Notes were made of any communication that occurred between the deaf students and each other, the interpreter, the teacher, and other students. Any discussion between the instructor and the interpreter was also noted. Because I do not know sign language, I did not always know what was being said between the deaf students and or their interpreter. When I was unsure of what was happening I made a note to ask one or more of the subjects about it during the interviews.

Interviews with the deaf students took place separately in any rooms that happened to be free in the Office of Students with Disabilities. Susan, Nancy or I would put in a request for an interpreter who was provided by the OSD. Sharon arranged for an interpreter for her interview which took place in a faculty conference room. Peter, Alice, Maya, and Paula were interviewed in their offices. George was interviewed in enclosed study rooms in the library. Interviews were both structured and open-ended. Many of the questions in the first interview resembled the guiding questions of this study. As the term 
progressed, subjects brought up many issues during interviews. In addition, as mentioned, part of the interview time was used to clarify things seen during observations.

\section{Writing Samples}

The ENNL Intermediate placement writing samples of nine peoplewere collected. The ENNL placement test is given at regular intervals throughout the quarter. There are 20 placement essay topics that are rotated. On the day that Susan and Nancy took the ENNL placement exam, students were given twenty minutes to write a letter responding to a friend or relative who has asked the student to take a trip around the world. The letters ranged in length from 6 to 13 sentences.

Sixty-four in-class paragraphs of 16 students in the Intermediate Writing class were collected. The paragraph assignments were designed to give the students controlled practice with the tenses and grammatical structures being learned in class. Rewrites were done at home.

For the first paragraph, students wrote about their favorite room using the simple present tense, focusing on subject-verb agreement and placement of prepositions. The second paragraph involved describing three favorite things to do in order of importance, using the simple present and present progressive tenses and focusing on sentence patterns. The third paragraph, entitled "A frightening experience" called for the use of the past and past progressive. For the fourth paragraph, students looked back on the past year 
and described their busy life using the previously mentioned tenses as well as future, present perfect and present perfect progressive, and other structures including adjectives, adverbs, gerunds, and participles.

The average length of the first two, third and fourth paragraphs was 12 , 16 , and 14 sentences respectively. See Appendix C for samples of student writing.

The placement samples and in-class paragraphs were fairly short and many of them were unsophisticated in terms of content, organization and vocabulary. For this reason student writing was analyzed by classifying the types of errors made and comparing the errors of the deaf student(s) to those of the traditional ENNL students. The error classification system of Lane and Lang (1993), found in Writing clearly: An editing guide was used. In this grading system a distinction is made between global and local errors. Global errors are those that operate at the sentence or discourse level and are apt to interfere with the intelligibility of the essay. Local errors are less serious errors that involve part of a sentence and do not interfere with intelligibility. A classification of writing errors is shown in Table 3. 
Table 3

\section{Classification of Writing Errors}

\begin{tabular}{|c|c|}
\hline ERRORS & DEFINIION \\
\hline GLOBAL & more serious, usually impede understanding \\
\hline vt & incorrect verb tense \\
\hline vf & verb incorrectly formed \\
\hline modal & incorrect use or formation of a modal \\
\hline cond & incorrect use or formation of a conditional sentence \\
\hline ss & incorrect sentence structure \\
\hline wo & incorrect or awkward word order \\
\hline conn & incorrect or missing connector \\
\hline pass & incorrect formation or use of passive voice \\
\hline unclear & unclear message \\
\hline LOCAL & less serious, do not impede understanding \\
\hline sv & incorrect subject-verb agreement \\
\hline art & incorrect or missing article \\
\hline num & problem with singular or plural of a noun \\
\hline we & wrong word choice, including prepositions \\
\hline wf & wrong word form \\
\hline nonidiom & nonidiomatic (not expressed this way in English) \\
\hline
\end{tabular}

Note. From Writing Clearly: An Editing Guide (p. xx-xxi), by J. Lane and E. Lange, 1993, Boston: Heinle and Heinle.

Nine Intermediate placement writing samples (Susan, Nancy and nonnative speakers S1-S7) were analyzed using this classification. The in-class 
paragraphs of 16 Intermediate Writing students (Nancy and ENNL students W1-W15) were also analyzed using this system.

Results of the observations, interviews and writing sample analysis are given in Chapters IV, V, and VI and discussed in Chapter VII. 


\section{CHAPTER IV}

\section{CLASSROOM OBSERVATIONS}

Observations of 26 fifty minute periods of ENNL classes attended by two American deaf students were made. The first section of this chapter contains observations of the Intermediate Writing class followed by a second section covering the observations of the Upper Intermediate Reading class.

\section{INTERMEDIATE WRITING CLASS}

As stated in the ENNL course content guide for Intermediate Writing, this course is designed to improve students' writing skills. The course focuses on the writing of single paragraphs, beginning with a topic sentence and followed by relevant details. Tenses (simple and continuous present, simple and continuous past, future), sentence patterns, capitalization, punctuation and spelling patterns are reviewed and the present perfect tenses and adverb clauses of time are introduced. Instructional goals include reviewing and introducing phrase and clause structures, verb tenses and related structures, specific parts of speech, mechanics of writing, elements of the writing process (such as brainstorming); requiring students to write weekly paragraphs using selected rhetorical styles; and introducing thinking skills (such as 
distinguishing between description and narration) as part of the writing process.

There were 27 students enrolled in the Intermediate Writing class. Susan withdrew from the class during the seventh week, leaving 26 students by the end of the term. Observations usually began as the previous class was leaving the room and the Intermediate Writing students were arriving. Nancy, Susan and George, the interpreter, usually came in separately. If Nancy and Susan were there first, they would chat with each other in sign language. If George was there, Susan signed with him while Nancy "listened."

As the term progressed, the traditional ENNL students got to know each other and visited and talked with each other before class, but there was very little interaction between the deaf students and the ENNL students. After Susan dropped the class, Nancy talked with George in sign language before class and occasionally she would greet her neighbor behind or to the side of her with a nod and a smile.

The objectives of the class, as presented to the students by the instructor, were to learn and use basic structures and vocabulary of English in writing. Verb tenses, English sentence patterns, modals, adjective and adverb clauses, the sound-spelling system, and writing controlled paragraphs were listed as topics to be covered. Class time was structured around grammar and writing style presentations, in-class essay writing and grammar and structure practice, and review of in-class exercises and homework 
assignments. No pair or group work was observed. All students were called on regularly to give answers to written exercises.

Paula, the instructor, has an informal, humorous style that is infectious. Hers was a comfortable classroom with lots of joking and laughing at oneself as well as others. At the beginning of the period when she passed back homework and writing assignments, she often took a moment to single out a student or two and talk with them. She included the deaf students in this routine and George interpreted everything, including the jokes, so that it was not uncommon to see the deaf students laughing a few seconds after everybody else and turning around to look at the student Paula was talking to.

Susan and Nancy sat next to each other in the first row in the seats closest to the right wall when one is facing the class. George sat directly in front of the deaf students, facing them and the class. Paula generally sat or stood at the center front of the room slightly behind or parallel to George. He appeared to interpret everything that was said in the classroom, silently mouthing words as he signed. He would interpret even when Paula was reading from a handout or book that the deaf students had in front of them. During the early part of the term, Paula would frequently look at George and stop or slow down as if to gauge whether or not he was keeping up. This was less common as the term progressed. By the fourth week of class when observations began, the ENNL students no longer paid any attention to George and his signing. If both deaf students were looking down at their 
papers or books, he stopped signing and waited until they looked up again, unless Paula was giving an assignment or instructions, in which case he would wave in the deaf students' direction or extend his foot towards them to get their attention. George tried to sign everything that the traditional ENNL students said, but sometimes he would stop in mid-air, looking puzzled. He would continue when Paula restated the comment or question, which she frequently did.

George would stop Paula when one of the deaf students had a question or when he himself needed clarification of a point. When a general question was thrown out to the class as a whole by Paula, sometimes the deaf students, usually Susan, would sign the answer and George would say it quietly. The one time George was absent during the thirteen observations, another interpreter filled in and was much more forceful in calling out the deaf students' answers than George was. Sometimes Paula did not hear George. Susan usually asked a lot of questions in class. In addition, there was a lot of signing going on between George and Susan, but the majority of this communication did not get passed on to Paula. Subsequent observations revealed class periods during which Susan would "talk" almost nonstop to George. Nancy, on the other hand, hardly signed at all in the earlier part of the term, participating only when called upon. Later, after Susan dropped the class, Nancy's participation in class slowly picked up. She began to volunteer answers to questions and became much more involved in the classroom even 
to the point of making jokes. Once, when Paula announced on the Friday before Memorial Day that she would see everyone on Monday, Nancy, who rarely vocalized, was the first to shout out, "No!", to the delight of her classmates.

George was accepted as a class member by the other students and by mid-May, they sometimes approached him before class to ask him a grammar question. Paula was very comfortable with George's presence in class and they often chatted quietly when students were writing or working on exercises. Some of this was informal social conversation, but often Paula would use this time to ask about certain aspects of interpreting and to make sure that there were no problems. George became Paula's native speaker informant when she was searching for a word as well as the occasional target of one of her jokes. When running out of time towards the end of the class period one day, Paula began to read answers to the previous homework assignment very quickly. She looked over at George's rapid signing and asked if his fingers were getting tired. When Susan began missing classes and no one had heard from her, Paula often asked George what he had heard about her, although he either did not know or did not want to say much.

Once when class started before George got there and once when there was a substitute interpreter who had to leave halfway through the period, the deaf students had no interpretation. Paula appeared unfazed by the lack of an interpreter. She is a kinetic speaker who normally employs many hand 
gestures and exaggerated facial expressions when teaching ENNL students. During a class discussion with an interpreter present, Paula was asked by a traditional ENNL student what the word "hubcap" meant. She described it for the hearing students using gestures that were very similar to the sign used by the interpreter. Paula often used facial expressions to explain states or emotions such as confusion, puzzlement, boredom and excitement.

When there was no interpreter, she stood directly in front of the deaf students, slowing and enunciating her speech somewhat so that they could read her lips. When she wrote on the board, she did not speak until she finished. On the day that the substitute interpreter left early, Paula ran her fingers across her face to demonstrate the meaning of wrinkles. Later that same period when a student had written the sentence, "He shakes his hand," on the board, Paula shook her own hand after determining that the student had meant to say, "He waves his hand." Susan and Nancy laughed along with their classmates.

George usually left as soon as class ended, and occasionally Susan and Nancy would stay behind to clarify a point or show work to Paula. Susan would resort to speech when having difficulty communicating with a hearing person, but she was difficult to understand. Nancy tended to write or point to things to communicate with Paula.

Class met five days a week. Susan and Nancy were absent more often than the other students. Nancy was absent eight times during the term. 
Susan was absent several days during the fourth week and during the fifth and sixth weeks she missed half of the classes. By the seventh week, she was no longer attending. As her absences became more frequent, Paula would try to bring her up to date during the first few minutes of class, but it became difficult to do this. Paula made herself available to students after class and during office hours, but arranging for an interpreter for Susan and Nancy usually took at least twenty-four hours, so extensive meetings between Susan and Paula after class were not an option.

Susan was erratic in her contact with Paula during her absences.

Paula knew that I was in contact with Alice, Susan's counselor in the Office of Students with Disabilities, and asked me on three different occasions if I had heard anything about Susan. She also asked George about her and had George ask Nancy.

Nancy, on the other hand, usually contacted Paula, through the TTY, the telephone system used by deaf and hearing-impaired people, to let her know when she was going to be absent. Nancy did not appear to ask for or keep track of work assignments that she missed during her absences. On four observed occasions, she returned to class without completed homework exercises. At the beginning of another observed class period, she appeared puzzled when Paula asked students to turn in the folktale they had written at home. Paula summarized the assignment assuming that Nancy had forgotten 
it, but Nancy, George and Paula finally realized that she had never received the assignment because she was not in class the day it was given.

The Intermediate Writing class was teacher-fronted and interaction between students was minimal. Homework was assigned by the instructor every day and review of in-class and homework exercises took up a large portion of time in class. Each chapter of the class text, Focus on Grammar, is divided into four sections; contextualization, presentation, focused practice, and communication practice. The focused practice exercises were often assigned for homework. These exercises provided students with a chance to practice structures (such as present, past, future and present perfect tenses; adjectives and adverbs; and gerunds and infinitives) they had already seen in natural contexts (contextualization) and studied in class and in the text (presentation). Preliminary focused practice exercises called for students to recognize the form or meaning of the structure without producing it.

Contextualized secondary focused practice exercises included: fill-in-theblanks, matching, multiple choice, question and sentence formation, and error analysis. Students were also given material in the form of handouts with explanations and exercises covering sentence classification, patterns, and combining; word order; affirmative and negative statements; and tenses.

During six of the 13 observations, seventy percent of the 50 minute period was used to go over homework and in-class exercises as a class. Exercise review took up approximately $30 \%$ of an additional six observed periods. Other 
activities during those six periods included presentations of grammar structures and the mechanics of paragraph writing, pre-writing exercises in preparation for in-class writing, and one spelling test. The other observation took place on a day when the class was held on the college commons so that students could watch a display of Native American dancing during a collegewide arts fair.

When Nancy had not done the assignment because of an absence, it was difficult for her to watch George and write down all the answers as the class went through them together. On these days, Paula would sometimes have Nancy do the exercises on her own while the rest of the class read their answers aloud. During this time, George would stop interpreting and read a book or magazine. If Paula began to cover something she wanted Nancy to know about, she would have her stop working and George would return to interpreting. Paula would check Nancy's work after class or later during office hours.

Observations of the Intermediate Writing class resulted in several questions about recorded behavior. In addition, because I do not know sign language, it was not always clear what interactions between Nancy, Susan and George were about. The following questions were noted and asked of various subjects during interviews: 
-- What is Susan talking about with George during class? Is George clarifying and answering her rather than passing the questions on to Paula?

-- Why does George mouth words when he signs?

-- Can Susan and Nancy read lips?

-- How does Paula feel about communicating to the deaf students without an interpreter?

-- Is it hard for George to understand the non-native speaking students?

-- Does George have some sort of policy about not discussing the deaf students' absences with the instructors?

\section{UPPER INTERMEDIATE READING CLASS}

As stated in the ENNL course content guide for Upper Intermediate Reading, this course is designed to improve students' prose and non-prose reading and to develop their understanding of the reading process. The course focuses on developing ability in content comprehension, language analysis, textual analysis, critical thinking, and study skills. Instructional goals include reviewing and introducing content comprehension skills (such as identifying topic, themes, main idea), textual features (such as paragraph and essay structures), critical thinking skills (such as making inferences, drawing conclusions), study skills (such as previewing, skimming, scanning), and 
review or introduce language features (such as subordinate clauses and phrases, pronoun reference) to aid in text comprehension.

There were 20 students enrolled in the Upper Intermediate Reading class including Nancy, Susan and one traditional ENNL student who was also in the Intermediate Writing class. After three students, including Susan, dropped the class, there were 17 students left.

Many of the things observed in Intermediate Writing held true for the reading class as well. The seating arrangements were similar, although Susan and Nancy sat in the front two seats on the left-hand side of the room as one faces the class and Maya, the instructor, usually stood forward from George rather than parallel or slightly behind him. During the first few observations, Susan asked questions constantly. She and George also did a lot of signing back and forth throughout the period. Nancy was fairly quiet until about the time Susan dropped, and then she began to participate more.

George was the interpreter during all 13 observations, but he was occasionally late to this afternoon class and Maya would begin without him. In four observed instances, Maya started class a few minutes before the hour, and George arrived on the hour. She generally faced the class during these times without an interpreter, but did not speak specifically to the deaf students or change her manner of speaking. As in the writing class, George was not very forceful in calling out answers that the deaf students volunteered. Maya rarely seemed to hear these answers. 
In the early part of the term, Maya and George would talk briefly after class. Maya would discuss ideas with him or check to see how something had gone. Unlike in the writing class, there was little time for this during the class period. Later in the term, George tended to leave the room as soon as class was over and there appeared to be less communication between him and Maya.

As with the writing class, observations began when the previous class was leaving. As the term progressed, there was much more interaction between Nancy and the other ENNL students than occurred in the writing class. Sometimes, while waiting outside, traditional ENNL students would watch George and Nancy sign and ask what they were talking about. Once inside the classroom, several of Nancy's neighbors would become involved in a conversation with her if George was there to interpret, and students in other parts of the room would watch the pre-class signing intently.

The objectives of the reading class, as presented to the students by the instructor, were to expand basic silent reading skills, to develop and refine skills in receptive listening, to improve vocabulary and develop the skill of using context clues, to expand thinking and reasoning skills, to develop skills in comprehension, and to use grammatical structures as a key to understanding meaning.

The reading class had a more serious feel to it, but was much more intimate than the writing class because of the smaller number of students. 
There was also more variety to the classroom routine. The class was structured around learning reading skills and strategies such as skimming and scanning, using context clues, and making inferences as well as regular readings of the text and newspaper articles provided by the instructor. Other topics of study included dictionary usage, finding the main idea, sentence study and word analysis. There was pair or small group work two or three days a week for 15 to 25 minutes of the class period.

Maya and the students did a lot of reading aloud. George would interpret all the reading. Class discussion often called for verbal reflection on the part of the students. George appeared to have difficulty interpreting extended ENNL student discourse, and it was often too long for Maya to repeat, although she sometimes paraphrased the student comments.

During one observation, students were discussing, as a class, a story they had read about a Vietnamese refugee. There were several traditional ENNL students in the room who had escaped from Vietnam by boat. One student, whose pronunciation was difficult to understand, spent about five minutes telling the story of how he had escaped from Vietnam. George tried to interpret what the student was saying, but often stopped. Nancy would shrug and George appeared to let her know that he was having a hard time understanding the student. He continued to sign intermittently when he was able to understand something. The student's account was compelling and obviously emotional for him to recount, and the other students were very quiet 
and attentive. In this case, Maya did not paraphrase what the student had said.

Before Susan dropped the class, she and Nancy were partners during pair work. During the first two observations of group work, they were in the same group. All subsequent observations of group work were of Nancy in a group with two or three other traditional ENNL students. All observations of group work revealed that Maya suggested that particular traditional ENNL students work with the deaf student(s), and that she rotated the ENNL students so that each one had a chance to work with them.

During the first observation of small group work, Susan and Nancy worked with two other ENNL students. Their task was to examine words in context and determine what part of speech they were and what kind of context clue was given. George clarified a point with Maya and then waited for the students to begin. Nothing happened. George asked the students, speaking and signing, what the answer to number one was. The students began working separately, writing down answers. One of the ENNL students finally attempted an answer for the first word and George interpreted what he said, but there was no response from anyone. The two traditional ENNL students began discussing the sentence together. They asked George if their answer was correct and as he was explaining that they needed to ask the deaf students, Susan began signing to him. George did not see it and Susan went back to working alone. One of the ENNL students asked what Susan and 
Nancy thought and George interpreted this. There was a brief discussion about what part of speech the first word was. The two ENNL students and Nancy thought it was an adjective. Susan disagreed, checking her electronic dictionary. George began to moderate the group asking for the context clue and then moving onto the next word. The ENNL students and Susan continued to work alone, while Nancy waited until George started a discussion again. When Susan expressed confusion about the use of a synonym as a context clue, George reviewed the classifications of context clues with her, while Nancy and the traditional ENNL students worked separately on the exercise. By the end of the session George was giving the students the answers.

My second observation of group work was very similar. On this day, Susan was absent and Nancy worked with two traditional ENNL students with whom she had not yet worked. George continued to play the role of group leader, facilitator and sometimes tutor. By the third observation George had started to pull back from the group. He seemed to be making an effort to act solely as an interpreter, but the ENNL students often asked him for answers or help in finding the answers.

By the end of the term, George was completely out of the group except as a conduit between Nancy and the other group members. As he pulled out, ENNL students began to rely more on Nancy as the "native-speaker and cultural informant." During one small group session in which Nancy worked 
with two classmates, students were given ten questions about the civil rights movement to discuss and answer. As soon as the group was formed, one of the ENNL students looked at George and me and jokingly asked for the answers. We both shook our heads and the student turned to Nancy and said, "You know all the answers, don't you? You studied it in school." Nancy tended to eschew the role of cultural informant and in this particular instance laughed and explained that she did not know that much. The same ENNL student asked Nancy who Rosa Parks was and George interpreted her answer: "A black woman who refused to leave the front seat in the bus. She got arrested." "Good," said the student, "Write it down. What about the next one. Who is Martin Luther King Jr.?" George laughed before he gave Nancy's answer, but Nancy appeared serious. "Martin Luther King's son." Then Nancy told the other students that those were the only two questions she knew the answers to.

Though she did not take on the role of cultural informant, Nancy did begin to act more frequently as group recorder and monitor. She often wrote down the group's conclusions for later class discussion and in one instance when the group was given a set of 20 definitions and asked to match them with the correct word on a list containing more than 20 words, Nancy chided other students for resorting to their electronic dictionaries.

During an observation early in the term, the class period was taken up with a test that dealt primarily with sound/symbol correspondence, and Susan 
and Nancy were excused early after completing the dictionary part of the test. Later in the term, the class spent two periods viewing a movie that had no closed captioning. Nancy watched the first part, but left early because she did not understand it and was excused from the second part the next day.

Nancy sometimes looked bored in the reading class. She rarely took notes and usually put her notebook, text and pen away before class was over. As the term progressed, the class often ran over the 50-minute period, but Nancy was ready to leave at ten minutes before the hour.

Observations of the reading class resulted in a number of questions which were addressed in interviews with the subjects. These questions included:

-- Is Maya aware that Susan and later Nancy are volunteering answers during class discussions?

-- Has George ever interpreted in small groups before?

-- Have Susan and Nancy ever worked in small groups before?

-- Is Maya aware of the role that George has in the small groups?

-- What led to the change in George's behavior in small groups by the end of the term?

-- What does Nancy think about being seen as a native-speaker and cultural informant by other ENNL students in group work?

-- Is Nancy bored with the reading class? Why does she take so few notes? 
Questions that emerged during the course of observing both classes were brought to subject interviews as they arose, and the results of these interviews can be found in Chapter V. A discussion of the observations of the ENNL writing and reading classes can be found in Chapter VII. 


\section{CHAPTER V}

\section{INTERVIEWS}

Sixteen guided but open-ended interviews were conducted with eight subjects: Two deaf students, two ENNL instructors, the primary interpreter for the deaf students, the ENNL department chair, a rehabilitation counselor from the Office of Students with Disabilities, and an administrator in the Interpreter Training Program. When possible, subjects were interviewed two or three times during the course of the term. Interview questions consisted of guiding research questions found in Chapter I and the questions that emerged during classroom observations. (See Chapter IV).

\section{SUSAN}

Susan, a deaf student, was interviewed one time before she dropped the ENNL classes because of personal problems. She missed the first interview appointment and was unable to get an interpreter for the rescheduled interview so Alice, the Office of Students with Disabilities rehabilitation counselor, interpreted. The interview lasted 60 minutes. Susan had a lot to say about her language learning experiences and the ENNL program and tended to give long answers to interview questions. 
She expressed a great deal of frustration with her educational history and her struggle with learning English. She remembers being taught to communicate in elementary school but says "they didn't teach me about English." She said by the time she reached high school she was a "lousy writer" and behind in reading development.

Susan struggled with her Developmental Education classes at the community college, sometimes putting in five hours a day on her homework assignments and still not understanding the material. She was very excited about the ENNL classes and felt that she was learning a lot.

I just didn't understand in those developmental courses. . . But now in ENNL I really understand. It's so much better than Reading and Writing 80 [DE classes]. . . . DE is only good for hearing people, not deaf, because those students grew up hearing English and those students are very skilled at writing. . . . The reading teacher [ENNL] is always telling what a word means. . . And also l'm learning that one word doesn't have one meaning but they have so many different meanings so l'm learning something and its really making me understand better. .

.. It's about time for me to learn!

One of the concerns that had been expressed by ENNL faculty members is that American students would be bored with the American history and culture that infuses the content of some of the classes, especially reading. Susan strongly disagreed and said that she needed to learn exactly what foreign students need to learn, "They don't have a lot of history about America and neither do I."

I asked Susan about her lipreading skills. She said that it depended on the speaker and how clearly they speak. I reminded her about the day I had 
observed the writing class without an interpreter and she said that she had been able to understand most of what Paula said because Paula also wrote it down on the blackboard. There was a short quiz on sentence structure at the end of that class period, and I had observed Susan clarifying the directions with Paula. Paula repeated the directions while standing directly in front of the deaf students. Susan said this had helped her understand what she was supposed to do.

When I asked Susan what she and George talked about during class, she was concerned that I thought they were visiting and assured me that this was not the case, "Sometimes l'Il ask the interpreter, like, what the teacher said and what does that word mean and kind of to clarify for me ... sometimes I need something repeated or I misunderstood a sign." Susan also explained that she did this sometimes for Nancy's benefit. Although she admitted that Nancy rarely asked for her help, Susan still felt that she should help her.

There was nothing that Susan disliked about the ENNL classes and she stressed how different learning was for her in those classes:

I'm understanding and I'm improving so much and I'm not forgetting. I remember a time, before - I had difficulty. I'd get very confused. I wouldn't understand and everything was just blah and I would look and I didn't understand the teacher. I would try to figure it out and do my homework and I just struggled the whole time and the language seemed so weird because I hadn't really learned it. I would talk to other students and struggle and try but still it wasn't working well ... I repeated 80 [DE] and still I didn't get it and this is the first time l've tried ENNL and now I'm smiling and now I'm happy. 
When she dropped the ENNL classes because of personal problems, Susan informed Alice, the rehabilitation counselor, that she would take them again in the Fall of 1995. Alice felt that it would be inappropriate to share the reasons for Susan's withdrawal from classes with anyone else.

\section{NANCY}

Nancy, a deaf student, was interviewed three times over the course of the term. An interpreter provided by the Office of Students with Disabilities interpreted during the first two interviews. George was the only interpreter available at the time of the third interview. I did not plan on asking Nancy any questions about George during the third interview and did not see his presence as a problem. While Susan gave lengthy, somewhat rambling answers to interview questions, Nancy's answers were direct. Each interview lasted approximately twenty minutes.

Nancy reported less frustration and struggle with learning English than Susan did. Unlike Susan, she feels that she has steadily improved her English over the years; however, she did say that she had trouble understanding a lot of what went on in the Developmental Education classes. When asked to compare the DE classes to the ENNL classes, she tended to compare the ENNL and DE teachers:

The [DE] teacher didn't really help a lot with the problems and things that you were weak on, but in ENNL they seem to focus more. . . . The teacher from DE was more kind of old fashioned and strict and cold in manner. Not really hmm-l didn't kind of fit what was going on, but now 
with Paula and Maya I really fit better. It's more comfortable... The teachers seem to be more flexible and I like that.

Nancy felt that the DE Reading class was too advanced for her and dealt with history and politics that she was unfamiliar with. She said that the tenses that were being covered in Intermediate Writing had not been talked about in DE Writing. Nancy's first impression of her ENNL classes was that they were too easy for her, but after the first few days she changed her mind:

When I first came in, the teacher had some basic things and I knew some of that and later on they were explaining things more deeply. It felt better cause the basic stuff - it's like I already knew that, you know. So that's review and after that it was fine.

She denied feeling bored with the content of the ENNL reading class: "I know some things about history, but l'm learning a lot from going through thisthe stuff that I don't know." In fact, Nancy felt that many of the ENNL students knew more about American politics than she did and she didn't think she had much to offer as "the American" in a small group: "Sometimes I don't know what they're talking about because of politics and stuff that I don't know about so I can't answer their questions, but it doesn't bother me."

Nancy was familiar with small group work, having been exposed to it in her Developmental Education classes. She shrugged when asked if she liked working in small groups. I asked her about her meager note-taking in the reading class and she said that she has a very good memory and does not have to take many notes. Nancy reported that she can lipread, but stressed that it is important for the speaker not to speak too quickly. She had no 
trouble communicating with either Paula or Maya when there was no interpreter. She said both instructors wrote on the board for her or wrote notes to her, and generally she got the information she needed. She said that it was easier to lipread Paula's speech than Maya's.

Nancy said that she likes to write sometimes, but admitted that she does not do much writing outside class. She said she does check her work over and make changes before turning it in. I asked her what kind of fiction she likes to read and she said: "Science fiction, horror movie books, true stories. Really anything except romance. I can't stand romance."

I asked Nancy if she thought ENNL classes were a good place for some deaf students. She said they were and that she had recommended them to a deaf friend of hers "because deaf have problems with English and stuff and I think it's a good idea to take a class for them to get better and stuff, quicker." When I asked Nancy if she planned to continue on to Upper Intermediate Writing and Advanced Reading, she said that she was definitely going to take the writing class but had not decided about the reading class. She thinks writing is her weaker skill and that she may not need more reading classes.

\section{PAULA}

Paula, the Intermediate Writing instructor, was interviewed three times during the term. Each interview lasted 30 to 35 minutes. I started my interviews with both instructors by asking them what, if any, concerns they had 
experienced when first hearing that the deaf students had enrolled in their classes. Paula reported very few reservations. After discussions with someone in the interpreter training program, she had come to believe that deaf students might be better placed in ENNL than in remedial classes. Her main concern had been with the interpreter:

I was concerned about that intrusion, I guess, in the regular flow of the class. .. . I thought, well l'll be nervous, you know, more nervous than I usually am in the first week or so of classes because how is she or he going to interpret what I say? I have to be careful about how I say things.

Paula was also concerned that the material might be too elementary for the deaf students, and she was afraid that they might be bored. Paula reported that neither of these concerns lasted long. During the first few days of the term, George told her that sign language was his first language and that he struggled with writing in college. This revelation along with the rapport that quickly developed between George and Paula eased her nervousness. After an early in-class writing assignment, Paula found that the deaf students made the same kinds of errors that the traditional ENNL students did: "Verb tense errors . . subject-verb agreement errors . . . missing helping verbs . . and prepositions are a major problem."

During the first interview, Paula described Susan as very interested in class. She mentioned that she seemed particularly curious about everything and was always "signing away." Paula was concerned that she might not be answering all of Susan's questions and asked George to let her know if this 
was the case. At this time, Paula found Nancy harder to "read." She did not appear as engaged as Susan. Paula felt that both Susan and Nancy "have more language" than the traditional ENNL students and considered them both high Intermediates:

The ideas that they're trying to present are more complicated. . . Their vocabulary is more typical of their age and experience which of course, the other non-native students at the intermediate level-they're not going to have the same kind of vocabulary.

Paula found Nancy's writing to be that of "a very young innocent girl" written in an "innocent style using non-collegiate words." Initially, Paula was more concerned about Nancy's chances of passing the class. She wondered if some of her errors might be fossilized and noted that she was "less cautious, careful and cognizant of her mistakes" than Susan.

During the first interview, Paula discussed her plans to have the students write six in-class paragraphs, using grammatical structures covered in class over the course of the term:

They want to write complex sentences, but l'm really asking them to control their writing, not just write the way they want to write, but the way I ask them to write. . . The reason I do that [in-class writing] is because I see what their real work is, rather than what they may have been helped with. I just want to see what they can do themselves which means that they're not very deep obviously, but they are representative of their real writing-I mean of their real sentence construction.

In each of the three interviews with each instructor, I asked them to describe any changes in teaching methodology or style they made to accommodate the American deaf students in their classroom. During the 
second interview, Paula told me there had been a problem with the first spelling test. She had not given George the list of words in advance so he had to, as she put it, "sign blindly." Not every English word can be expressed with a sign and some words and grammatical morphemes are communicated through finger spelling. George was concerned that this was like giving the deaf students the answers to the test. For subsequent spelling tests, Paula gave George the list in advance so that he could review it and see which words might pose a problem. Paula did not see a problem with his finger spelling an "ing" or "ed" ending. She had no other changes to report.

Paula said she had no problems communicating with the deaf students when there was no interpreter. Nancy sometimes came to her office to make up a test or an assignment, and Paula would point to written directions or give her a written example of what she wanted Nancy to do.

In the period leading up to the time that Susan dropped the ENNL classes, Paula became concerned with the amount of signing Susan did in class. There was also an increase in the number of questions that Susan asked, and a tendency for her to over clarify every little point. On her last day in the writing class, Susan was very agitated and Paula said that Susan had been somewhat disruptive in class. According to Paula, Susan often wanted to know the definition of every word used in class. From discussions with George, Paula had discovered that this was the reason there was so much signing between Susan and George. On Susan's last day, Paula used the 
word "entails" during a presentation on a grammatical structure. During the course of the lesson, Susan returned again and again to this word trying to clarify its meaning, and George interrupted Paula's presentation with each one of Susan's queries.

When Susan dropped the class, for other reasons, there was no longer a problem but during the second interview, I asked Paula how she would have handled the situation if Susan had stayed. She and George had talked about it and he had suggested that she talk to Alice about it. Paula considered it to be

a classroom behavior issue which we would deal with like any other person. We do not talk out of turn, we do not get off the subject, we usually stay on the subject and if we want to talk about something we just save it till the end of class. That's something that we were going to talk to Alice about and we would hope that she would have talked to Susan about it and I think she would have. I'm just so sorry she's gone because I think she has lots to benefit from and she was so enthusiastic about it in the beginning. I think it [classroom behavior] would have been a very easy adjustment. I don't think that Susan exhibits that behavior except during times when she is under stress.

After Susan left, Paula noticed changes in Nancy. She speculated that Susan, being a more dominant person overshadowed Nancy, who somehow got "lost in the shuffle." Paula realized that she and Nancy interacted much more after Susan left. Susan had needed so much attention and asked so many questions that Paula did not feel she focused on Nancy very much. Paula also noticed that Nancy began to volunteer more answers in class after Susan left. I asked Paula if she thought one deaf student in a class would be 
preferable to more, but she saw it more a matter of personalities than numbers.

Nancy was absent from the writing class eight days during the term.

Paula became less concerned with these as the term progressed:

I think that truly in most cases, it doesn't make that much difference if the student is bright enough. If the student is already at a low-at a disadvantage in the class, then absences are absolutely disadvantageous, but Nancy is bright to begin with.

Paula thought that higher absences on the part of the deaf students might be cultural and reflect an American attitude towards school attendance. She said that it was rare for her non-native students to be absent so much. She also mentioned that she was used to traditional ENNL students wanting and working for "A"s. By midterm, Paula thought it was possible for Nancy to get an A but noted that Nancy seemed happy working at a "B/B-" level.

Paula saw some improvement in Nancy's writing as the term progressed. Her homework and in-class exercise work improved greatly, but Paula had the impression that Nancy does not like to write. Exercise work was generally at the sentence level and Paula said Nancy began to master several concepts such as tense inflection and question formation, things that she did not appear to understand when first introduced in class. Nancy continued to make mistakes at the text level when writing in-class, and she postulated that her carelessness may have to do with not rereading her work once she's written it. As Paula described it, 
Nancy hasn't found the value in what she's learning yet. She . . hasn't or cannot yet apply what she has learned in grammar, which I think is much more than she's ever learned before, to her writing. In terms of her knowledge of grammar, I think she's gone a lot farther. In terms of writing, she hasn't because she is still making those fossilized errors and I think that just takes time. And it takes a light bulb going off . . . I've seen her apply it some to the tenses because she'll say something and then she'll think about it and then she'll say 'oh no-I think I'm supposed to do this.'. . . I think the grammar and the compositions have not melded yet.

Paula was quick to note that the same could be said for many of the traditional ENNL students, and while she could think of several who had made that connection during the term, there were many like Nancy who had not reached that point yet.

During the third interview, I asked Paula whether there had been a support system in place during this trial period of having deaf students in ENNL classes. Paula did not feel the need for much communication or support from Alice or Peter, the ENNL department chair. She was satisfied with her communication with Nancy and George, and she viewed George as the most supportive person in the experience. She talked to Alice only once, but noted that they exchanged several voice mail messages about Susan's absences. She considered her experience with deaf students in the classroom successful, but thinks that a lot depends on the interpreter. She talked with Maya during the term, but even without that contact, she thought that having deaf students in a reading class would pose more challenges than having them in a writing class. 
Paula does think there should be no more than two deaf students and one interpreter per ENNL class. She assumes that interpreting would become difficult with more deaf students because of the constant interaction between teacher and students that takes place in ENNL classes. We discussed Alice's gatekeeper role of screening appropriate deaf students and sending a limited number to the ENNL program. I asked Paula if she thought that role could be maintained:

Yes, I think it can. I don't know if it's the right thing to do but certainly not all of the instructors in the ENNL faculty are enthusiastic about having deaf students in their classes and I think it's mostly a fear factor. Or a newness-something again that has to change. And I can certainly assure them that I'm not very much changed. If any thing it was for the better. I think my students gained something from it.

I told Paula that in my interview with Sharon, the instructor in the college's Interpreter Training Program, the question of hearing children of deaf parents needing ENNL classes had come up. Paula said that George told her he was getting a lot out of her class, and I was curious to know what she thought of the idea of people like George enrolling in ENNL classes:

I think it all depends on the kind of instruction they've had. I don't think linguistically it's the same issue. Because if they had been taught and if they can hear the nuances and tenses then I don't think ENNL is the place for them. If they haven't learned English in the same way as other students learn English then I would say yes, I guess I don't mind. I think that anyone who wants to, ought to have the opportunity to learn. If it's something that they think they can learn from, then let them try it.

When asked if she would have done anything different, knowing what she did by the end of the term, Paula said she was glad that she had not known anything. "Innocence is bliss. . . I I wasn't tense. I was perhaps a little 
nervous but not tense. . . I went about teaching Intermediate Writing rather than worrying about having these deaf students in my class."

\section{MAYA}

Maya, the Upper Intermediate Reading instructor, was interviewed three times during the term. The interviews generally lasted an hour. Maya had a lot to share about the experience of having American deaf students in the Upper Intermediate Reading class. A reflective instructor, Maya kept a diary of the experience and would often tell me in class or in the hallway that she had something to discuss at our next interview. She admitted to fairly negative feelings when first approached about having deaf students in ENNL classes: "My initial reaction was 'No, this won't work.' We're not trained to work with deaf students. We don't know American Sign Language. We don't know enough about the diversity within the deaf population. We are simply not equipped to do this." Maya noted the concerns brought up at a staff meeting, whether the students who were born in this country and [who] have a much higher cultural literacy rate than the students who were born outside of the U.S. would be able to work in the same classroom. . . . There were also concerns voiced about whether you could get communication between the non-native student population which is generally quite reticent to participate.

After talking to Alice and reading some of the research that Peter had gathered, Maya began to understand why ENNL classes might be appropriate for deaf students. Maya found it interesting that Alice uses a text in the Comprehensive English Development for the Deaf class that Maya herself has 
used in ENNL classes. She said that talking to Alice had made her realize that many deaf students have not been exposed to the cultural literacy many of us take for granted. Maya said that as long as it was considered an experiment and Alice maintained control over the selection of deaf students, she was comfortable with the idea of deaf students entering ENNL classes.

Maya said she did not change her style of teaching to accommodate the deaf students, but during our first interview she spoke of a change in methodology. She usually spends one or two class periods teaching the phonetic alphabet and sound/symbol correspondence. Maya was not comfortable teaching these lessons with the deaf students in class and was equally uncomfortable about excusing them for those days, so she spread the lesson out over many days, doing a short portion at the beginning of each class.

Maya was very concerned about the lack of interaction between the deaf students and the traditional ENNL students during the early group work sessions:

I don't want to take away the opportunity for students to talk about what they've read. . . . The discussion of the readings and inference making and critical thinking strategies seem to work best in small groups. . . . I let them go at it for a while and come back into the larger group. . . I can see that the majority of class members benefit from it and I think Susan and Nancy . . . benefit from it. But l'm feeling there's still a need for modification in getting the two groups to communicate more.

Initially, she accepted George's facilitator role in the small group because she thought it was important for him to do what felt comfortable for 
him. She thought the traditional ENNL students could benefit from the interaction with a native speaker but also realized they might be more assertive in their English language use if he just interpreted. She admitted to, "riding the fence here! I just feel like he [George] needs to be comfortable with it. He needs to feel that he is doing what's best for them [the deaf students] because that's why he's here."

Maya said she made a point of rotating students so that everyone worked with Susan and Nancy, but she expressed some frustration at not being able to separate the deaf students occasionally, ". . it's a combined package and I can't separate them from George." Later, she said she did separate them and sat in on a group made up of several ENNL students and Nancy while George and Susan worked in another group. Maya and the traditional ENNL students wrote notes and used gestures to communicate with Nancy, and Maya said this experience was instrumental in breaking the barrier that she felt had existed between herself and Nancy.

Because most of the writing in Maya's class was done at the sentence level, she did not feel she could compare traditional ENNL and deaf student writing in depth, but did note that in a paragraph assignment Susan and Nancy made errors similar to those of the other ENNL students, "missing articles, wrong preposition, missing preposition, word order problems and word form problems are very common." 
During the first interview, Maya said that Susan was the better student and thought she would "probably pass with flying colors." She noted that Nancy seemed,

less involved. I don't feel like l've gotten through to her yet. I don't feel like we have a personal relationship, teacher-student relationship yet . . . .Nancy is just more reserved, shy and, as George has reported, just less involved as a student in the learning experience.

Maya reported having a difficult time in the first week of the term because eye contact with students is very important to her. Until the traditional ENNL students got used to George's presence, all eyes were on him. Although this changed with time, Maya said she continued to feel the lack of eye contact with Susan and Nancy because they had to watch George. One day when Susan and Nancy were both absent from class, Maya said she took some time at the beginning of the period to talk to the traditional ENNL students about the deaf students. She wanted to know how they thought things were going. She pressed them to be specific and feel comfortable about sharing their thoughts. Most of the comments had to do with wanting to be able to communicate more with Nancy and Susan. They talked about different ways to do that and Maya said that several students had had communication with the deaf students outside of class through writing notes. Several students expressed a desire to learn some sign language, and when Nancy returned she and George taught the class how to welcome Susan back after a long absence. Maya said several students found it interesting to work in a small group with the deaf students. In describing her talk with the 
ENNL students, Maya noted, "There weren't really any negatives. It was more like 'this is working pretty well, but we'd like it to be working even better' . . I told them that I too was concerned about having more communication between the two groups." After Susan dropped the class, Maya said that interaction between the traditional ENNL students and Nancy improved:

I think it's less daunting to . . . the traditional ENNL students . . if there's just one deaf student and the interpreter. . . . Otherwise it seems to me that they feel like they're kind of a visitor. The main focus is in helping the deaf students and they're (the ENNL students) just kind of observing and visiting the scene where when there's just one deaf student, they're more equal participants."

After Susan dropped the class, Maya also noticed changes in Nancy and in her own relationship with Nancy. Although she conceded that personality may play a role, Maya felt strongly that one deaf student was better than two in an ENNL reading class.

By the second interview, Maya was no longer concerned that the deaf student(s) might be bored with the class content. "It is true that Nancy would recognize FDR, for example . . but she wouldn't necessarily know that much about him and about his policies." She described a day when the class was discussing European unity and working with maps. Maya noticed that Nancy had finished her task:

I had her help the non-native student that was having a lot of difficulty finding France. And then after I left the class, I thought, 'well what's wrong with that?' She probably felt great that day, you know? I mean you look at it as a teacher and say, 'Oh, l've got to be teaching new things every minute of every hour of every week.' But when I look at it from her standpoint, she was probably having a glorious day.... If she already knew all the in-depth concepts that we're trying to get at 
through the reading of historical and cultural happenings and events, then I would be concerned. But she has just basically a superficial knowledge of it and still needs to know as the others need to know about it, in more depth.

Maya told of another change in her methods during the second interview. When teaching a story about a music box, she usually plays music for the class. She likes classical music and she noted, "I've always found in my twenty years of teaching that when I share something I love with the class, it builds a bond." Maya was at the library selecting records and tapes, planning on how she would give students rating sheets to evaluate the music when she realized,

Oh my God, I can't do this . . . my colleagues and I talked about this before we started to have deaf students. My colleagues said, 'just do everything exactly the way you would do it without deaf students', and I thought that was very, very naive.

Maya said she talked to George about playing music in class. During this time, she often discussed ideas, concerns and doubts with him and used him as her Deaf culture informant. She said that George felt she might "lose" the deaf students during the time that she played music. Maya decided to tell the class about the record and tape collection in the library and leave it at that. She said she would have loved to play the music,

but I didn't want to hurt her [Nancy's] feelings, but I wouldn't avoid the story entirely just because the story is about music. I think that would be hypersensitive to her deafness. In the long run that kind of attitude could do more harm.

Maya also uses film in her reading classes and was disappointed that Nancy was unable to participate in the two-day viewing of a film that related to 
a story the class was reading. She sees a need for more close captioning of videos and films in the library collection.

Maya reported that she continued to modify her emphasis on sound/symbol correspondence throughout the term. She said that when students trip over a word during reading aloud, she usually stops and works on a phonetic transcription with the class. Though she said she was continuing that practice, she was conscious of its being a waste of time for Nancy and tried not to spend too much time on it. She was also concerned about the amount of reading out loud she and the other students do and reported decreasing this somewhat as well. Maya said that George had difficulty understanding the traditional ENNL students when they read, and it was not feasible for him to read text and sign at the same time, so she adapted by doing more of the in-class reading aloud herself.

I asked Maya if she felt she gave less to the traditional ENNL students by adapting her methodology to accommodate the deaf student:

In all honesty, you are giving them less because if you have the ability to give them, let's say, your background information about music and bring that to a story, but you don't want to do it because of hurting someone - yes you are giving the students less, but you have to look at what they're getting in return. They're seeing that in this system, in this new culture in which they are living, that even a person who is deaf or blind or disabled in some other way is welcome into the fold and that's so much more valuable than what they might be losing . ... Just their sensitivity to difference in general, I hope, will be much keener than it would have been without this experience, so yes l'm giving them less, but I'm giving them more - not I, but the opportunity is giving them so much more than they're losing. So, I feel very strongly that it's the right place for them to be. It's the right thing for us to do. 
At midterm Maya and I discussed Nancy's progress in class. Maya was not too concerned about Nancy's absences. She was quite sure that Nancy would pass the class, but wished that she would come up with spontaneous comments and questions more often as the traditional ENNL students do.

I told Maya that I often observed Nancy doing that but that it appeared that Maya did not hear George when he called the answers out. Maya related the experience she had with another interpreter when Susan was still in the class. The substitute interpreter (the same one I had observed for half a period in Intermediate Writing) had broken into the discussion constantly with questions and comments primarily from Susan, and Maya had found it unnerving. Maya said she would try looking in Nancy's direction after asking a question and adjust her position in relation to George in an effort to catch more of Nancy's comments.

By the end of the term, Maya reported that her relationship with George had soured somewhat. She conceded that afternoons might be the low point of his day but felt his flagging energy and enthusiasm were taking a toll on the small group work. I spoke with her the day after a class period that she described as trying:

The attitude of the interpreter toward that particular class that day and the class in general obviously has an enormous impact on the students' attitude toward the activity and the class in general. And there were times when I felt George was preoccupied, that he wanted out of there. . . particularly on a Friday afternoon . . . and frankly I feel that's somewhat unprofessional. ... So, that adds another complexity to the 
equation. You're not only trying to keep students at various levels and various personalities interested in what you are doing for that 50 minutes, but your mind is somewhat occupied with entertaining the interpreter, making sure that he is in touch with what you're doing, that he's connecting with your activity.

Maya was also frustrated because George was no longer talking to her after class and he wasn't communicating his problems with small group work. Maya was also concerned that George's "down time" in her class might be affecting the interpretation of her instructions to Nancy, which was reflected in her work. Toward the end of the term, Maya asked the students to choose one of the short stories or newspaper articles the class had read and to write a summary of it. Nancy wrote a summary of a former ENNL student's essay about one of the short stories that Maya had handed out as an ancillary item. Maya found this odd and wondered if there had been a misunderstanding through interpretation. One of the things she would pass on to colleagues who have deaf students in their classes is that "a key element of importance is that the interpreter have a positive attitude and communicate enthusiasm."

Maya described Nancy as a student who "puts in the time" but thought that "she may not be doing what's in her best interest during the time that she's putting in." She told of a time when a small group definition activity was extended to a second period. Nancy finished the activity at home, copying long complex definitions from the dictionary rather than winnowing them from the context of a story she and her small group members were reading. Towards the end of the term, Maya felt that there had been some growth in 
Nancy's vocabulary and critical thinking skills. She said that Nancy's work had become neater, less simplified and more complete and predicted that she would get a " $\mathrm{B}$ " or " $\mathrm{C}$ " in the class.

Discussions with Paula have convinced Maya that American deaf students pose more challenges to the ENNL reading instructor than to the writing instructor. Maya thought that Nancy may have been able to start at an even higher reading level because she exhibited few problems with reading comprehension and did not need the sound/symbol correspondence work. Maya noted that,

... the problems she seemed to be having in reading have more to do with her ability to write or her ability to communicate what she understood ... when you looked at her during the process of something that you read or you asked her something, she almost always knew what was going on. When she wrote about the stories, she didn't show the depth of understanding .... Now that has a lot to do with her maturity, her age, limited experience compared with people who have lived through horrors. Very protected. Very limited experience.

Maya said that during a small group activity about a story concerning Vietnamese refugee methods of departure, Nancy and her Vietnamese group members discovered that they all had relatives who had fought in the Vietnam war. Maya was encouraged by what she perceived as the first emotional. connection Nancy had made to a story they had read, but felt that Nancy's written responses to questions about the story reflected her lack of maturity.

She wrote, 'I think it's good for them if they can come here, but I wish they wouldn't all come to the U.S. I understand that they need a place to live, but do they all have to come here?' And that is pretty much a high schooler's response to reading the tragedy of refugee status-the 
tragedy of the expatriate who can't go back. It's going to take years of growth before she can see in these stories [from Reflections] and stories like them, the things that most of the other students could see.

Maya said she felt she got the most support from Alice. She also talked to Peter on several occasions but mainly to keep him informed on how things were going: "I wanted him to know that my initial reservations were somewhat assuaged after I worked with them [deaf students] for a while."

Maya said that she would like to see Alice maintain strict control over referring deaf students to the ENNL program. She thought it would be interesting for ENNL programs to create a class for hearing children of deaf parents, but could not envision someone like George as a student in her class: "I think people with that background would tend to be somewhat frustrated that things weren't going fast enough, that we're spending too much time listening to this person [traditional ENNL student] trying to get this idea out."

l asked Maya, what she would have done differently, knowing what she did at the end of the term. She said she would have used dialogue journals because that would provide an additional avenue of communication between the deaf students and herself.

\section{GEORGE}

George, the interpreter for the deaf students, was interviewed two times during the term. The first interview lasted 30 minutes and the second one lasted 45 minutes. George often spoke to me before class and would 
volunteer information or answer my questions as issues arose. Initially, George was the subject most uncomfortable with my observations. He thought I was evaluating him in some way and was relieved to learn that I did not know sign language. After our first interview, he had a better understanding of what I was doing and became more relaxed.

George refers to the people he interprets for as clients. During spring quarter, he was interpreting for six other clients besides Susan and Nancy. George said that he generally signs Pidgin Sign English when he is interpreting in a classroom. He does know some ASL, but tends to use it for informal conversation outside of the classroom. He said his clients often ask him to move his lips while signing so that they have two sources of information.

George reported a big difference between interpreting for ENNL classes and other classes because of "the way the classes [ENNL] are structured. The teachers are a lot more interactive, a lot more slower paced, a lot more flexible." George explained that an interpreter is supposed to imitate the style of the speaker as well as interpret the message. He considers the message in ENNL simpler because it is not highly technical but thought that other interpreters might be intimidated by the interactive style of an instructor like Paula.

During the first interview, I asked George about the large amount of signing that he and Susan did in class. Was he answering her questions? 
Yes, I do answer the question, but I don't give her the - you know, it's just like $98 \%$ of what Susan wants is an affirmation of her mental thinking that she communicates through her hands. She does a lot of it and so I will sit there and just affirm her . . . most students don't need clarification for every little thought they have but she does.

I told George that from my observations it looked like he had trouble understanding the speech of the traditional ENNL students. He confirmed this:

Oh, yea! ... We're required to do both what the teacher says and what the students say.... I've given up to the point that I don't really try to catch initially what the student says. I will just translate what the teacher will say because Paula and Maya tend to repeat the comment. It is really, especially with a lot of students, very difficult and unrealistic actually to try to do it so I just wait till the teachers says it.

In the early part of the term, I asked George how he felt about the small group work in the reading class. I asked him if he was comfortable with the group leader role he played in small group work in the reading class. He said he liked what he did, but thought that other interpreters might not take on the role of facilitating a group because they are not required to. He noted:

I do it [facilitate] because it furthers their [Susan and Nancy's] education. I mean they would literally just be sitting there . . they would just sit there ... and so finally I just said, 'Why don't I just try to pull this together and try not to lose any essence by just taking over.'

George said he had interpreted in small groups in other classes and in those situations acted solely as a conduit for the deaf students, but did not feel this was possible in the reading class: "You have deaf clients not doing anything and you have your foreign exchange students not doing anything. Nothing happening! So, that's an exceptional situation." 
Before our second interview, George told me that there had been some changes that he was anxious to talk about. When we met, I asked about Susan's last day in writing class because I had heard about it from Paula. George said that it had been a difficult day and it had made him realize that he is still in the process of learning to be an interpreter. He had talked with people in the Office of Students with Disabilities a few days before the incident and decided that he needed to stop answering so many of Susan's questions during class. As he put it, "I needed to pull back and quit being such a buffer for her [Susan] and allow the teachers to address the problem and kind of get out of that dependence on the interpreter kind of thing." On Susan's last day he put his plan into action and vocalized absolutely everything that Susan signed to him:

I wanted the teachers to realize this was going on . . they weren't taking any action on it. ... If they had a class leader that was monopolizing all the time, they would do two things, either pull them aside or they would ignore them and they weren't really doing either one of those things with Susan and I think it's because they really didn't know or they thought, 'Oh, George will take care of it' . . it wasn't like a big malicious thing. Just more of 'O.K., this is what's going on'.... Paula got the front end of it.

I asked George why he started pulling out of his facilitator role in small groups as the term progressed. Again, after discussions with Office of Students with Disabilities personnel, he had decided to change his role in small group work in the reading class:

If I'm leading the group, it's sure beneficial to the class, but it's not beneficial to the student because they're not learning small group dynamics, they're not learning how to become a group leader, they're 
just sitting there and being passive and I'm pulling it out of them and so I'm slowly trying to withdraw.

But he still felt some frustration about the group work experience and noted that sometimes "they're just going to be quiet . . . it must drive some kids crazy because they hate going into small groups . . . they'd just rather do it themselves and Nancy is a very individual person and she'd be fine doing it herself."

I asked George if he was comfortable with the amount of consulting about deafness, Deaf culture, activities and interpreting Paula and Maya did with him. He said that was fine and that he considered himself a resource, but thought that they should deal with the Office of Students with Disabilities counselors when there was a problem with a student rather than involving him. He said he really did not know what Susan's story was when she began to be absent so much, but would probably have not said anything if he had known.

I had tried to get Nancy to talk about the difference in her experience in the ENNL classes before and after Susan left, but she was reluctant to do so. George said that he thought that Susan had overshadowed Nancy. He mentioned that Nancy had complained to him several times:

She was kind of bugged. She told me several times that Susan needs to be in control, you know, I need to put her into some kind of control situation ... she was frustrated . . because l'd be spending time with her and stuff like that. 
I asked George if he usually interpreted for more than one student at a time and he said he did. When asked if it was more difficult interpreting for two students, he said it depended on the individuals.

On the whole, George liked interpreting for ENNL classes and said that if he returned to the college to interpret, he would ask for those classes. He thought it was a very good idea for deaf students to take ENNL:

I'm speaking from personal experience because by being raised in a deaf family and the struggles I had in English and l'm learning volumes now and to think if I would have had a chance to learn this when I was younger and got based that way, I think it would have done eons for me.

\section{ALICE}

Alice, a rehabilitation counselor with the Office of Students with Disabilities, was interviewed twice during the term and each interview lasted 90 minutes. Alice has known Nancy and Susan for over a year. She has been their counselor as well as their instructor when they both took the Comprehensive English for the Development of the Deaf class. During our first interview, Alice said that Susan and Nancy were extremely happy with the ENNL classes and that she got most of her feedback from them by running into them in the hallway at the Office of Students with Disabilities, because they were not coming to see her anymore. Alice noted that as a counselor

I set time aside for each student . . . to be available to them, to support or give input or whatever to help them. . . I used to see them [Susan and Nancy] every single week, two or three times a week when they were in Developmental Education classes. They were coming to me, 
'Alice, I need help.' and since they've started the ENNL classes, they have not come in for help once .... They also were much more uncomfortable seeking out the instructor [DE] for assistance. . . They came to me for help a lot for explaining things or what certain terms meant ... and they literally have not come to me once for help which to me is just right away a real indicator . . . something really neat is happening. I absolutely love not being needed!

Alice noted that Susan characteristically had more to say about her experience in ENNL classes than Nancy, who can "come off as seeming flatter." She said that Susan is "much more active and expressive," while Nancy tends to be "more withdrawn," but she said that Nancy also spoke positively about the ENNL program.

Alice mentioned that both students were enjoying being in classes with people from other cultures and that Susan described her experience as being like a huge door opening. Alice did not think that deaf students would be bored with the American culture content of the reading class because "there are so many gaps in their education." She said that for many deaf students this gap is the result of parents trying to meet the educational needs of their son or daughter:

Often times you'll find the deaf students have been moved from school to school to school. They've tried oral approach and then they've gone to a program that uses sign language and then they've been moved to this program and that ... especially the kids that were put in oral programs for a long time and not allowed to sign; during that period you find that there are just huge educational gaps where they've really missed out on a lot of information.

I asked Alice what she knew about Susan's last day in class and she said she had spoken to both Paula and Maya about it. She said she would 
have talked to Susan about her classroom behavior but she dropped out before that happened. She thought part of the problem had to do with Susan's personality:

I know that in her case she can tend to be very enthusiastic and very excited and she wants to understand and/or she may want clarification but she gets stuck. She sort of gets into this little gully and it's sometimes kind of hard to get her wheels out of the gully.

Alice said that some deaf students assume that signing is not a distraction. In addition they may "have a sense that they have this kind of linkage with the interpreter and their dynamics or their behavior is not in tune with the rest of the group." Alice notes that some deaf people "just don't have the social etiquette awareness that many other people pick up." She said this can sometimes be seen in classrooms when a late student begins to sign greetings to other students while the lesson is in progress. Alice was quick to say that none of this holds true as a general rule for deaf people, but she has found that

among some students there really is this social immaturity and I call it immaturity not in a negative sense, but it's just that they haven't yet fine-tuned or developed that social awareness in working with groups. . .. It might be lack of experience in a mainstream setting . . it could be that these behaviors have never been pointed out to them.

Alice wondered whether Susan's constant interaction with George might have been detrimental to Nancy: "It concerns me . . if there was dialogue going on between the interpreter and Susan, the information that the instructor was talking about was not getting to Nancy." I asked Alice if she thought there was a problem with having two deaf students in a class. She 
said she saw it more as a personality issue than a number problem. She noted that it is not unusual for a class to have two deaf students, ". . and of course from our perspective it helps tremendously, as a department, when we can group students because of the cost of interpreters and the availability of interpreters ...."

Alice did not know George and did not meet him during the term, but had gotten the impression that he was very flexible. I asked her if it was common for interpreters to act as consultants for instructors trying to plan appropriate activities. She said that there is a natural tendency among instructors who have not had experience with deaf students in their classrooms to turn to interpreters for information and reassurance. She noted that some interpreters, like George, are willing to help out in any way they can but that means stepping out of the role of just an interpreter and many interpreters will not do that: "Some interpreters are going to back out and not willingly participate in that type of dialogue and they'll probably recommend that the instructor talk directly to the student."

I asked Alice how she planned to evaluate the deaf students' success in ENNL classes and what criteria she will use to refer students to the program in the future. When Susan and Nancy first came to Alice, she tested their reading and grammar skills and had them do a writing sample. She did not think that she would see a measurable gain in these areas after one term of ENNL and said she planned to wait and test again after two or three terms. 
She said she also places a great deal of importance on the input both students give her about their experience in the classes and will use this "informal" feedback as well.

Alice stressed that she is still learning about the ENNL program and will be using the information she gains from evaluating Susan and Nancy's progress to help her in future referrals to the program:

This is all really a learning process for me and on down the road, I can almost guarantee there are going to be other deaf students coming along that may be really appropriate for ENNL, but I want to be able to have a pretty good handle on when it's the right time to refer, what types of things to anticipate ... especially now that I'm a little more familiar with the placement testing for ENNL, it helps me . . to better gauge some students that need more work at Adult Basic Education or even at my level [Comprehensive English Development for the Deaf] . . . so I'm just going to continue to feel my way through . . . to try to get a better idea what students is this approach most suitable for.

When Alice told me that news of Nancy and Susan's participation in ENNL classes had spread among the deaf student population, I asked if she would be able to maintain control over which students got referred to the ENNL placement test. She had mixed feelings about the issue of control and conceded that some students might be adamant about taking the placement test.

I think ideally it would be wonderful if any person in the community, any deaf person, if they wanted to further their English development ... . could just make their arrangements with the testing office and see if they can get placed . . . there would be no screening on my part or anybody's part. ... I certainly don't like being in the position of having to have any control . . . because this is so new .... I sort of feel, at this point in time, it's experimental. . . One of the things I don't want to do is refer a bunch of students blindly and have them all be turned down. They've had such horrible experiences in studying English for so many 
years that to send them to take the test and then have them denied access to the program - it's another one of those negatives . . and this is all new for Peter, new for Paula, new for Maya, for the entire department, this is so new - working with a population you're not used to. ... And if it does work - if it does appear to the ENNL department and from my perspective that, yes, this is a great viable option for these students, again maybe not all students, then ideally it would be nice for me not to have to play gatekeeper.

Alice noted that although both Nancy and Susan had taken her Comprehensive English Development for the Deaf class as well as

Developmental Education classes, they still placed at the lowest writing level in the ENNL program (Intermediate Writing):

That indicates to me that a lot of the students that come to the college . .. will probably need more developmental work prior to accessing ENNL. So l'm sort of seeing ENNL for the upper level deaf students. . . My concern is that students think its [ENNL] going to be a cure-all . . . because there are so many students that come in at second or third grade level and they really need very intensive, basic English and those students are not going to be able to handle ENNL.

Alice reported that she had contact with Maya, Peter and Paula during the term and planned to be available for anyone in the ENNL department who wanted to talk to her. She stressed that it was vital that Paula and Maya share their experience with other faculty members.

I would be more than happy to talk to instructors. . . My hope though is that Paula and Maya might have an opportunity to share their experience because my assumption is there may be instructors in that program . . . that have reservations or fears, not knowing, 'How am I going to do this?' - just having that reassurance that maybe it wasn't perfect for Maya or Paula, maybe there were things that they were uncomfortable with or things they had to change in order to accommodate and maybe that frustrated the hell out of them. Maybe they felt it was an imposition on the other students, whatever the case may be. But I think by sharing those concerns openly and the things 
that did work and the positives as well as the negatives, I think would be really helpful for the other instructors.

\section{PETER}

Peter, the ENNL department chair, was interviewed formally once during the last week of classes for 40 minutes, As his technical assistant, I was involved in several informal discussions concerning enroliment of deaf students in ENNL classes prior to and during the term.

During my interview with Peter, he related some of the events that led up to the decision to allow American deaf students in ENNL classes and discussed the initial objection and his own decision about it:

Some full-timers (instructors) were reluctant . . . and their objections were that mainly it would be a lot of work for them. I don't think there were any objections ever that this might not be an appropriate place for them, for some of these students. . . I guess my approach was, not just because of the disabilities act, if this is the type of instruction that they need then I don't see how we should be able to turn them back.

Peter felt that the term had gone reasonably well. "It's been the absences, I think, that bothered people ... you kind of hope that it will work well to start off with and that's been a little disappointing." I asked him how he planned to evaluate the experience of having deaf students in ENNL and he said he was inclined to wait: "I would rather wait until the middle of next year. We may get a couple more deaf students in next year and be able to evaluate ... as a larger group." To Peter, the ultimate decision will depend on whether the 
students are benefitting from this type of instruction. I don't think there's anyway we can prevent deaf students from coming to our program once we've started it . . unless the students are saying, 'this isn't for us' or unless the teachers start saying, 'well, what we're doing is not helping the students.'

Peter said he felt it was important for deaf ștudents interested in ENNL classes to go through Alice and he wants to see her maintain the screening process. He pointed out that many of the referrals will have taken Alice's Comprehensive English Development for the Deaf class and that in the future she would be able to address issues in that class that might ease the student's transition into ENNL. Peter said that if deaf students came to him inquiring about the ENNL placement test, he would ask them to see Alice first.

I told Peter about my interview with Sharon in the interpreter training program, and asked for his response to Sharon's opinion that ENNL classes were ideal for deaf students because the instructors were used to working with a bilingual population. He was not sure that his definition of bilingual matched hers, but agreed that ENNL instructors did have the experience to work with students who have a first and second language,

but the trick is to convince ENNL instructors that deaf students are that kind of student because none of us that I know in this program have dealt with deaf people very much and none of us really has any expertise in that area. ... But I'm just applying the same logic I would apply to speakers of other languages, but you have to convince the teachers and that wasn't a big struggle, but it was a bit of a struggle because the teachers tend to get hung up on the disability end of it . . . they're not focusing on what the language needs are and that's sort of the second thing, but you have to convince them of both, that the disability is really not a factor in deciding whether they should take these classes or not and then also that it is second language, ESL instruction that those students need. 
Peter did not think ENNL classes were a place for hearing children of deaf parents. He realized that they might have struggles with English but "my own perception is probably by the end of high school, most people in that situation would be bilingual." He conceded that there might be exceptions, "if the person could show that ASL was really their first language and they were not bilingual ...," and would consider those exceptions if they came up.

I asked Peter if after a year or so of deaf students in ENNL classes, there would be any push to make an official policy statement about the program being for deaf as well as non-native speakers. He did not see the need for an official policy change. "I think we will probably just go with the current policy unless there is a movement outside for us to change it." $\mathrm{He}$ explained that to do more would give the impression that the program is completely open and that is not the case even with the non-native students. He noted that many non-native students take the ENNL placement test and are not placed in the program because they are still at the ESL level.

\section{SHARON}

Sharon, an administrator and instructor in the Interpreter Training Program, was interviewed once, for 40 minutes, at the end of the term. Sharon, who communicates with sign language, arranged for an interpreter to be present at the interview. 
I interviewed Sharon to learn more about interpreting and sign language use by interpreters and the kind of training interpreters received in group work. She said that the interpreter's role in the small group was to interpret information and the comments that are being said in the group. It's not to participate in the group discussion. . . They're not supposed to take charge unless it's based on communication. In small groups, you generally get two or three people talking really fast and overlapping and the interpreter will have a hard time following so they have the right to interrupt at that point . . . so the interpreter will sometimes come in to mediate. ... That's the role of the interpreter, to facilitate the communication ... not facilitate the group.

Interpreters range in their ability to sign American Sign Language. In Sharon's program, interpreters are taught ASL but she says that some of them struggle with it. Trainees are exposed to deaf people through field experience, and in these situations the interpreter comes to know his or her own limits with ASL. Sharon explained that when interpreters are not fluent in ASL, "they tend to switch more to the English order which is the 'contact variety'." This is an alternative term for Pidgin Sign English. The responsible interpreter, Sharon said, chooses jobs so that his or her sign language matches that of the client.

Sharon said she strongly supports the idea of deaf students in ENNL classes and believes that ENNL instructors are particularly well suited to teach these students: "The instructor who tends to teach English in ABE or GED tends to look at grammar structure and gets on with it, but doesn't really look at or assess or identify the pattern of somebody with English as a second language." She spoke of her own experience as a student in an English as a second language class years ago: 
We [she and the non-native students] weren't exactly the same but . . it felt safe, it was a safe environment, it was like, 'Oh, O.K. we all have bilingual things going on' . . . but in other English . . . everyone knows the information and it's their language. They're not bilingual and you feel really uncomfortable and you're humiliated and embarrassed." 


\section{CHAPTER VI}

\section{WRITING SAMPLE ANALYSIS}

The ENNL writing placement samples by Susan, Nancy and seven nonnative speakers of English, all of whom received Intermediate Writing assessment on the same testing day, were read and errors were classified according to the system used by Lane and Lange (1993). (See Table 3 in Chapter III.) The results were examined to discover any similarities or differences in the kinds of errors made by the deaf students and the nonnative speakers.

Four in-class essays by Nancy and 15 traditional ENNL students in the Intermediate Writing class were analyzed in the same manner. Detailed definitions of each type of error can be found in the Lane and Lange (1993) text, Writing clearly: An editing guide. Definitions of some error types pertinent to the results of the writing analysis in this study are given.

\section{PLACEMENT SAMPLES}

The placement samples ranged in length from five to twelve sentences. Susan and Nancy's placement samples were seven and eleven sentences long, respectively. 
The classification of errors in the placement samples of nine subjects is shown in Table 4.

Table 4

Classification of Errors of Nine ENNL Intermediate Level Writing Placement Samples

\begin{tabular}{|c|c|c|c|c|c|c|c|c|c|}
\hline ERRORS & Susan & Nancy. & S1: & $\$ 2$. & S3. & S4. & S5. & S6 & S7? \\
\hline \multicolumn{10}{|l|}{ GLOBAL } \\
\hline $\mathrm{vt}$ & 1 & & & 1 & & & & & \\
\hline vf & & & 3 & 1 & 4 & 2 & 4 & & \\
\hline \multicolumn{10}{|l|}{ modal } \\
\hline \multicolumn{10}{|l|}{ cond } \\
\hline ss & 3 & 4 & 1 & 4 & 4 & 6 & 1 & 5 & 2 \\
\hline wo & & & & & & 1 & & & \\
\hline conn & 1 & & & & & & 1 & & \\
\hline \multicolumn{10}{|l|}{ pass } \\
\hline unclear & & 1 & 3 & 1 & & & & 1 & 1 \\
\hline Total & 5 & 5 & 7 & 7 & 8 & 9 & 6 & 6 & 3 \\
\hline \multicolumn{10}{|l|}{ LOCAL } \\
\hline sv & & & & & & & & 2 & \\
\hline art & 3 & & & 1 & 3 & & & & 1 \\
\hline num & & 3 & & 1 & & & & 2 & \\
\hline wc & 2 & 4 & 5 & 1 & 1 & 4 & 4 & 2 & 1 \\
\hline \multicolumn{10}{|l|}{ wf } \\
\hline nonidiom & & & 1 & & & & & & \\
\hline Total & 5 & 7 & 6 & 3 & 4 & 4 & 4 & 6 & 2 \\
\hline
\end{tabular}

Note. The definitions of the errors can be found in Table III in Chapter III. 
Sentence structure errors (ss) and word choice errors (wc) were found in all of the samples. A sentence structure error, according to Lane and Lange (1993), "is an error in which some aspect of the grammatical structure of a sentence is incorrect" (p. 88). Missing sentence parts, problems in the formation of relative or noun clauses, unnecessary repetition of the subject of a sentence, an incorrect structure after a given verb, or problems with parallel structure are examples of sentence structure errors. A sentence structure error a global one because it can affect the reader's ability to understand the text. Word choice errors occur when a wrong word is used in a sentence and are considered a local error, because they usually do not affect the intelligibility of the text.

Samples of five non-native speakers contained verb form errors (vf). Lane and Lange (1993) place verb-form errors made with modals, the conditional, the passive, and present and past participles used as adjectives in other categories. They reserve the verb-form error category for errors made in the formation of a main verb, some portion of a verb phrase, a verbal following a verb, an infinitive, a gerund, and verbs that require prepositions. These errors are considered global. The placement samples of Nancy and Susan did not contain any verb-form errors.

Placement samples of four non-native speakers had errors known as unclear sentences (unclear). "In an unclear sentence, the reader cannot understand the message the writer wants to convey. The error is global 
because it affects more than a clause and may affect whole parts of a text" ( $p$. 164). Nancy's placement essay had one unclear sentence error. Susan's essay had no unclear sentences.

Susan's placement sample had one connector error (conn), described as one "in which the connection between words, clauses, sentences, or paragraphs is either unclear or illogical because of a doubled, missing, incorrect, or misplaced connector" (p. 128). This type of global error was uncommon in the placement samples. Only one non-native speaker essay had a connector error.

Susan's placement sample had one verb tense error (vt) which is caused by choosing the wrong verb tense within a sentence or shifting verb tenses inappropriately within a paragraph. This global error was also uncommon in the placement samples. One non-native speaker also made this error.

Article errors (art) occurred in the samples of three non-native speakers. This is a local error and includes the omission of an article, the unnecessary use of an article or the wrong choice of article. Susan's placement sample contains article errors. Nancy's sample did not have any article errors.

Nancy's placement sample contained number errors (num), a local error found in only two of the seven non-native speaker essays. A number error occurs when a singular form of a noun is used instead of the plural or a 
plural form is used instead of the singular. Susan's sample did not contain number errors. Other errors such as word order errors (wo), subject-verb agreement errors (sv), and nonidiomatic expression errors (nonidiom) occurred only once in all nine placement samples.

The total number of global and local errors in each subject's placement sample as well as the most frequent global and local error of each student are shown in Table 5. Nancy made more local errors than global errors. Susan and one non-native speaker made the same number of global as local errors.

The other non-native speakers made more global than local errors.

Table 5

Global and Local Errors in Nine ENNL Intermediate Writng Placement Samples

\begin{tabular}{|c|c|c|c|c|}
\hline Students: & $\begin{array}{l}\text { Tolal i of? } \\
\text { Glohat Errors }\end{array}$ & $\begin{array}{l}\text { Tolal \# or ? } \\
\text { Local Errors. }\end{array}$ & 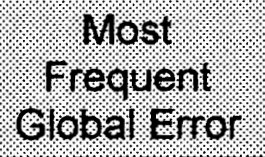 & 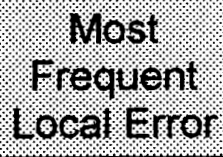 \\
\hline Susan & 5 & 5 & ss & art \\
\hline Nancy & 5 & 7 & ss & wc \\
\hline S1 & 7 & 6 & wf/unclear & wc \\
\hline S2 & 7 & 3 & ss & art/num/wc \\
\hline S3 & 8 & 4 & $v f / s s$ & art \\
\hline S4 & 9 & 4 & ss & wc \\
\hline S5 & 6 & 4 & vf & wc \\
\hline S6 & 6 & 6 & ss & sv/num/wc \\
\hline S7 & 3 & 2 & ss & art/wc \\
\hline
\end{tabular}


The most frequent global error of four of the seven non-native speakers was sentence structure. An additional non-native speaker had an equal number of the global errors of sentence structure and verb-form. Sentence structure was also the most frequent global error made by both Susan and Nancy.

The most frequent local error of three of the non-native speakers was word choice error. Three additional non-native speaker samples also had word choice errors as the most frequent local error, but had an equal number of other local errors as well. Word choice was the most frequent local error made by Nancy. The most frequent local error in Susan's sample was article error.

Table 4 reveals that some of the types of errors found in samples by the deaf students and the non-native speakers are similar. There are also errors that non-native speakers make that the deaf students do not make, and errors that the deaf students make that very few non-native speakers make. Table V, however, shows that when the types of errors are tabulated into most frequent giobal and local errors, the most frequent global and local errors made in the ENNL placement sample by the deaf students were similar to those made by the non-native speakers. 


\section{IN-CLASS ESSAYS}

The classification of errors of four in-class paragraphs of Nancy and fifteen traditional ENNL students in Intermediate Writing are given in Appendix D. The total number of global and local errors found in each student's four paragraphs as well as the most frequent types of global and local error made by each student are shown in Table 6 .

The most frequent global error in the paragraphs of nine traditional ENNL students was sentence structure error. Nancy's most frequent global error was also sentence structure. Word choice was the most frequent local error of eight of the traditional ENNL students. The most frequent local error of all the others was article error. Nancy's most frequent local error was equally divided between article and number.

Table 6 also reveals that the deaf student's most frequent global error was the same as that of more than half of the traditional ENNL students. One of the most frequent local errors of the deaf student was the same as the most frequent local error of nearly half of the traditional ENNL students. The deaf student's other most frequent local error was not a common error found in the paragraphs of the traditional ENNL students. 
Table 6

Global and Local Errors in 64 Intermediate Writing In-class Paragraphs

\begin{tabular}{|c|c|c|c|c|c|c|c|c|c|c|}
\hline \multirow[t]{2}{*}{ Student } & \multicolumn{2}{|c|}{ Essay I: } & \multicolumn{2}{|c|}{ Essay? 2 . } & \multicolumn{2}{|c|}{ Essay 3 : } & \multicolumn{2}{|c|}{ fossay 4} & \multicolumn{2}{|c|}{$\begin{array}{l}\text { Most Trequent: } \\
\text { Type of Error: }\end{array}$} \\
\hline & g & 1 & 9 & 1 & 9 & 1 & 9 & 1 & global & local \\
\hline Nancy & 4 & 7 & 11 & 11 & 20 & 7 & 5 & 2 & ss & art/num \\
\hline W1 & 9 & 19 & 13 & 3 & 30 & 19 & 13 & 5 & vf & art \\
\hline W2 & 9 & 17 & 11 & 2 & 12 & 8 & 12 & 5 & ss & art \\
\hline W3 & 2 & 11 & 11 & 7 & 10 & 8 & 10 & 8 & ss & wc \\
\hline W4 & 6 & 3 & 20 & 3 & 15 & 4 & 10 & 1 & ss & wc \\
\hline W5 & 6 & 10 & 9 & 13 & 6 & 2 & 15 & 4 & ss & wc \\
\hline W6 & 3 & 11 & 11 & 3 & 10 & 1 & 15 & 12 & ss & wc \\
\hline W7 & 5 & 10 & 7 & 2 & 13 & 9 & 14 & 9 & vf & art \\
\hline W8 & 0 & 4 & 10 & 7 & 9 & 7 & 6 & 3 & ss & art \\
\hline w9 & 3 & 8 & 7 & 2 & 7 & 10 & 7 & 8 & ss & art \\
\hline W10 & 3 & 16 & 7 & 3 & 11 & 11 & 9 & 8 & ss & wc \\
\hline W11 & 4 & 7 & 6 & 6 & 10 & 7 & 4 & 6 & vf/ss & wc \\
\hline W12 & 4 & 7 & 12 & 19 & 7 & 13 & 3 & 9 & ss & art \\
\hline W13 & 4 & 6 & 5 & 9 & 12 & 7 & 8 & 6 & $v f$ & wc \\
\hline W14 & 6 & 4 & 14 & 5 & 7 & 10 & 12 & 0 & $\mathrm{vt} / \mathrm{vf}$ & wc \\
\hline W15 & 1 & 10 & 12 & 10 & 6 & 11 & 8 & 7 & vf & art \\
\hline
\end{tabular}

In summary, the writing errors made by the deaf students and the nonnative speakers were found to be similar, confirming that some deaf students may benefit from English as a second language instruction. Both Nancy and Susan have trouble with sentence structure when writing English. Sentence 
patterns are one of the topics outlined in the course curriculum guidelines for Intermediate Writing and students review and learn new phrase and clause structures. Nancy's paragraphs exhibit problems with the use of articles.

Article errors are common in ESL and ENNL student writing and are addressed in the Intermediate Writing class. 
CHAPTER VII

\section{DISCUSSION}

The questions that guided this research are discussed in the first section of this chapter. This is followed by a discussion of additional issues that arose during the observations and interviews. Sections covering limitations of this study and suggestions for future research, implications for teaching, and conclusions round out the chapter.

\section{A RETURN TO THE GUIDING QUESTIONS}

Eleven questions were used to guide this descriptive study. The guiding questions are discussed with both students in mind when it is appropriate. However, because one of the two deaf students, Susan, dropped out of the two ENNL classes before the end of the term, whereas Nancy completed and passed both Intermediate Writing and Upper Intermediate Reading, many apply only to Nancy.

How do the ENNL placement test writing samples of the deaf students compare to those of non-native speakers of English?

The ENNL placement writing samples of seven non-native speakers of English that were judged to be at the Intermediate Writing level were 
compared with placement samples by the two deaf students, also judged to be at the Intermediate Writing level. All of the samples are relatively short (5 to 14 sentences) and written in the form of a letter, so there was not a lot of writing to examine. Each of the nine writing placement samples is different in terms of the types and number of errors made, but all of the samples, including those of the deaf students, contain sentence structure errors and word choice errors. The placement samples by Susan and Nancy contain the same most frequently made global and local errors as the samples by the nonnative speakers.

It is interesting to note the length of the writing samples by Susan and Nancy. Were they "native-users" of English, one might have expected longer samples given the twenty minutes that were allowed for writing. Susan's sample, however, is one of the shortest at seven sentences while Nancy wrote eleven sentences. It is possible that the difference in length between the writing sample of Nancy and that of Susan is related to the difference in age of onset of deafness and educational background, but there is too little data to confirm this.

What modifications, if any, in teaching methodology, style, materials, and testing do ENNL instructors report they make to accommodate American deaf students in the classroom?

Maya reported more fundamental changes to her methodology than Paula did as the result of the presence of deaf students in class. Paula had 
trouble with the first spelling test she gave in Intermediate Writing. In Pidgin Sign English, the sign language used by George, words that have no American Sign language sign or words that the interpreter does not know the ASL sign for are finger spelled. George, hearing the words for the first time during the first spelling test, was not prepared with an ASL sign or an alternative way to present the words to the deaf students. He was concerned that he was giving the students the answer by finger spelling. This problem was solved by giving George the test words in advance so he could identify and practice signs. Since Paula always read a sentence with the spelling word in it, George was able to use a synonym for the word if it had no sign and Nancy did well on all her spelling tests. It could be argued that guessing a word from the sentence and a synonym sign tested more than her spelling skill.

Maya changed the way she taught sound/symbol correspondence and cut back on the amount of reading aloud usually done by traditional ENNL students in the Upper Intermediate Reading class. Though she was able to present the sound/symbol correspondence lessons in shorter chunks over an extended period, the need to stop and transcribe words that students had trouble pronouncing occurred throughout the term. Time taken to do this was essentially "down time" for the deaf students and Maya struggled with the need to provide something she thought that the traditional ENNL students required and her concern that the deaf students would be bored during this 
time. It was necessary to excuse deaf students from portions of an exam that tested knowledge of sound/symbol correspondence.

Maya's use of music and video in the classroom was affected by the presence of deaf students in the classroom and she was very concerned about this change. Maya was especially concerned with the possibility of offending deaf students by involving music or video in a lesson. Alice, the rehabilitation counselor, has suggested that instructors who are concerned about using music and video in classes with deaf students should discuss these matters directly with those students.

Alice pointed out that music with lyrics can be interpreted for the students. The music Maya had planned to use had no lyrics so she decided not to use it, but she did inform her students that the music was available in the library. While there are some videos with closed captioning available at the college library, the one that Maya showed did not have this feature. Although she was not entirely comfortable with the idea, Maya decided to excuse Nancy from the two-day viewing of the movie rather than eliminate it from the lesson.

Sharon, the instructor/administrator in the sign language studies and interpreter training programs at the college thinks that an ENNL instructor with sign language capabilities would be an ideal addition to the department. Though it would certainly help, the ability to communicate in sign language is not a skill that ENNL instructors need to teach American deaf students in their 
classrooms. Instructors do need to be aware of problems that may arise and changes that may have to be made to accomodate these students and it is essential for ENNL instructors such as Maya and Paula who have had deaf students in their class to share their experiences with their collegues.

How much, if any, of the American culture incorporated in the content of the ENNL classes is new to the deaf students?

Before the decision to allow deaf students to take ENNL classes was made, it was argued that deaf students would be bored with the American history and culture that makes up a portion of the content in ENNL reading classes. Neither of the deaf students in this study reported feeling bored in the reading class. Both Susan and Nancy complained of feeling frustrated in Developmental Education Reading classes because it seemed to them that the other students knew so much more about current events and politics than they did.

Alice suggested that there are gaps in the social experience and education of many deaf students that would not make the content of ENNL reading classes a problem. It does seem possible that the situation of some American deaf students more closely resembles that of the traditional ENNL student in terms of the schemata they possess. Successful readers bring background knowledge of the world to the task of reading. According to Rumelhart and Ortony (1977), this knowledge, in the form of general concepts, 
is organized systematically into interrelated mental structures known as schemata.

Reading involves the use of both "bottom-up" and "top-down" processing skills. Bottom-up processing involves deciphering the graphic code of the text and using textual information for comprehension. Top-down processing draws upon schemata, the prior knowledge that brings meaning to the text. A lack of schemata or schemata different from that which the writer assumes the reader possesses can lead to an over-reliance on bottom-up processing skills.

Traditional ENNL students bring their own cultural values, beliefs, and knowledge of the world and, therefore, different schemata to the English texts they read. Some of these students rely more heavily on bottom-up processing skills and believe that defining and understanding every word they come across in reading is essential to comprehension, and they may even translate unknown words into their first language. Some deaf students may have gaps in their schemata or, if raised in the Deaf culture, possess different schemata from someone of the majority hearing population. Susan, like some of the traditional ENNL students in Maya's class, used an electronic dictionary frequently in class. Some of her extensive dialogues with the interpreter were about defining a new word precisely. As far as observation can be used to determine the use of reading processes, Susan appeared to rely more on bottom-up processing than Nancy did. In addition, Alice reported that Susan 
was very enthusiastic about the fable that the reading class read, because she had never understood what a fable was. Her vocabulary of types of texts included the word fable, but she had no previous schema for a fable. This is ironic because most traditional ENNL students probably have a strong schema for fables that translates well to their second language because fables are so universal in cultures.

Maya, one of the people to voice the original concern about the appropriateness of the reading class content for deaf students, found that while Nancy was familiar with much of the material, she did indeed have gaps in her knowledge of American history. Observations revealed that several traditional ENNL students in the reading class were more conversant on topics such as FDR, Martin Luther King and the civil rights movement than Nancy. There were also many traditional ENNL students who appeared to be less knowledgeable about these topics than Nancy.

It should also be noted that although the focus of the content of the Upper Intermediate Reading class is American culture, history and politics, there is an emphasis on providing multi-cultural readings. Alice pointed out that both students reported they enjoyed learning about other cultures both within and outside the U.S. The Upper Intermediate Reading class read a story about Vietnamese refugees living in the United States. It is possible that "Deaf" students who see themselves as part of a minority culture in America would find such readings about other minority cultures interesting. 
Does the ENNL reading and writing curriculum meet some or all of the needs of the two American deaf students who need developmental education in these skill areas?

This question is somewhat difficult to answer on the basis of only one term and one deaf student, but there are several points to note. The ENNL department has a course content guide for each of the ENNL courses in the program (summaries of these were provided in Chapter IV). There is nothing in either the Intermediate Writing or Upper Intermediate Reading Course content guide instructional objectives that would be inappropriate for a class with students whose main channel of communication is visual. Although Paula listed the sound-spelling system of English as a class topic in Intermediate Writing, this is not mandated by the course content guide (None of the Intermediate Writing class periods observed included the sound-spelling system of English in the lesson). There is also nothing in the Upper Intermediate Reading course content guide about sound/symbol correspondence, though it does appear in the guide for speaking classes. It was Maya's choice to include this as one of the topics to be learned in Upper Intermediate Reading. Theoretically, lessons involving any part of the sound system of English could be eliminated from these classes.

The placement samples by Nancy and Susan showed the need for the review of basic grammar and the work with sentence patterns covered in Intermediate Writing. There was a heavy focus on pattern practice in the 
writing class. As mentioned in Chapter II, some deaf educators think that deaf students learning English need extra written grammar practice that is not always provided in ENNL and ESL classes. They received this practice in the Intermediate Writing class.

There is still debate among ENNL faculty members as to whether or not American deaf students need the American culture and history provided in the reading classes. No definitive answer can be given on the basis of one student's experience, but Nancy and Susan would not be in the ENNL program if they had reading levels that matched their age and years of schooling. It is possible that the main benefit for deaf students in ENNL reading classes will be the development of a wide range of skills (identifying topics, main ideas, summarizing, paraphrasing, previewing, skimming, scanning, making inferences, distinguishing rhetorical styles, etc.) that they did not previously possess. Perhaps for American deaf students, the subject matter used in ENNL reading classes is more of a means to developing better reading skills than an end in itself.

\section{What similarities and differences exist in the writing errors of the American} deaf students and other ENNL students?

Susan dropped out of the ENNL program before she had produced enough writing to make a comparison with the traditional ENNL students. The paragraphs by Nancy and fifteen traditional ENNL students show individual patterns of mistakes for each person but an overall look at errors shows that 
Nancy's most frequently made global error is the same as ten of the traditional ENNL students. One of Nancy's most frequently made local errors is the same as seven of the traditional ENNL students. Nancy's other most frequent local error, number error, while present in almost all of the paragraphs, is found in high numbers in only one other student's paragraphs. It is possible that this error has something to do with transfer from American Sign Language or Pidgin Sign English (both of which are used by Nancy), but more analysis of a larger amount of writing and a knowledge of sign language would be needed to confirm this. Nancy's writing errors were more similar to than different from the errors of her traditional ENNL classmates.

What difference, if any, does the interpreter for the deaf students find in interpreting in ENNL classes as opposed to other classes, such as biology. math, or literature?

George, the interpreter for the deaf students, had previously interpreted in an English grammar class (not an ENNL class), a math lab and a computer assisted design class, so he could only compare those classes to the ENNL classes. He found the ENNL classes to be much more interactive than other classes. This meant that he had to interpret much more teacher-student communication than he had experienced in the other classes, which were mostly lectures.

George, used to interpreting in classes made up of native speakers of English, had trouble understanding many of the traditional ENNL students. 
Unless the instructor repeated or paraphrased what the traditional ENNL student said, he did not interpret the questions, answers and comments of those students for the deaf students. It was more difficult in the reading class where students were more likely to talk in a reflective manner for an extended period of time, making repetition or paraphrasing less practical and larger chunks of language unavailable to the deaf students.

Group work in the Upper Intermediate Reading class was more challenging than group work in other classes George had interpreted for. $\mathrm{He}$ was used to group members facilitating the group. He spoke of the silence in the Upper Intermediate reading groups he was in and how everyone was reluctant to take on the role of facilitator or be the first to speak. George decided he had no choice but to take over and facilitate the group, coax dialogue, and draw out answers from the students.

Do the writing and reading skills of the deaf students improve by the end of the term?

At the beginning of this study, Alice had plans to re-adminster a reading test, grammar test, and writing sample to both Susan and Nancy. By the end of the quarter, Susan had dropped out and Alice decided to postpone re-testing of Nancy until she has completed two or three quarters of ENNL. What follows are qualitative assessments based primarily on information provided by the ENNL instructors. 
Student writing in the Upper Intermediate reading class was primarily done at the sentence level. Although students in the Intermediate Writing class produced five paragraphs during the term, this study began after the first one had been written and returned and it was difficult to collect it from all sixteen students. It is difficult to judge the progress of Nancy's writing skills on the basis of only four paragraphs. Paula reported that while Nancy improved at sentence level grammar exercises, found in quizzes as well as homework assignments, she did not always transfer that improvement to her paragraph writing. By her fourth paragraph, Nancy made fewer kinds of errors than she did in her first three paragraphs and made less errors overall in that paragraph than most of the fifteen traditional ENNL students. The analysis of student paragraphs in this study did not invlove the use of an instrument and therefore cannot be discussed in terms of the reliability and validity of such instruments.

Maya, though positive about her experience teaching Nancy and Susan, began questioning the placement of American deaf students in reading classes after the quarter had ended. She thought that Nancy might have been placed too low because she appeared to read faster than anyone else in the class and appeared to easily comprehend what she was reading. What writing Nancy did produce in the reading class was classified as somewhat immature by Maya. Maya thought that this reflected Nancy's sheltered life and limited experiences. She also thought that Nancy's problems in the reading class 
might stem from an inability to accurately reflect her reading comprehension because of her lower writing level.

Is there any classroom interaction between the deaf students and the other ENNL students and what is the nature of this interaction?

Classroom interaction between the traditional ENNL students and Susan and Nancy was limited in the Intermediate Writing class, but as there was no pair or group work observed in this class, this was not surprising. All of the traditional ENNL students in the Upper Intermediate reading class had an opportunity to work with Susan and Nancy in small groups, and communication was primarily through the interpreter, although several students reported that they had written notes to the deaf students.

There appeared to be more social interaction between the deaf students and the traditional ENNL students before and after the reading class than there was in the writing class, and this was probably a result of the contact in small group work. Towards the end of the term, several traditional ENNL students in the reading class would join the conversation George and Nancy usually engaged in before class. It is also possible that the discussion that Maya had with the traditional ENNL students about communication with the deaf students when both Nancy and Susan were absent one day fostered an atmosphere of curiosity and willingness to try to communicate. 
How does the presence of American students in the classroom impact the other ENNL students?

Preliminary informal discussions with traditional Intermediate Writing ENNL students revealed a reluctance to participate in formal interviews or surveys about the American students in the class. Poor English ability was the reason most of the students gave for this reticence. Traditional ENNL students in the Upper Intermediate Reading class, initially reluctant to address this topic, began to volunteer their thoughts and feelings as the quarter progressed, but did not want their comments tape recorded. For these reasons, direct polling of the traditional ENNL students was beyond the scope of this study. Although there were no formal interviews with traditional ENNL students, observations and informal discussions revealed no impact of American students on traditional ENNL students in the Intermediate Writing class and only slight impact on the traditional ENNL students in the Upper Intermediate Reading class.

Observations of group work in the Upper Intermediate Reading class revealed that many of the traditional ENNL students assumed that Nancy and Susan, as Americans, knew the answers to questions about American history and culture. By midterm, traditional ENNL students in small groups with Nancy considered her a native culture informant, especially after George stopped participating in the group discussion, but Nancy often told them that she really did not know as much as they thought she did. 
When six of the traditional ENNL students in the Upper intermediate Reading class informally discussed the presence of Nancy and Susan in the classroom, they focused on them as being deaf students rather than Americans. They talked about being interested in sign language. Some of them knew a little sign language from their own countries and they compared it to the sign language they saw in the classroom. They also discussed their desire to communicate with the deaf students and talked about seeing them on campus and waving and gesturing and writing notes.

How will the ENNL department chair and the Office of Students with Disabilities counselor evaluate the experience of having American deaf students in the ENNL program?

Peter and Alice had no plans for formal evaluation at the end of Spring quarter. Alice plans formal assessment of the deaf students after they have been in ENNL classes for two or three quarters. She will readminister a reading test to Susan and Nancy at the end of Fall quarter 1995 or Winter quarter 1996. She will also have them write an essay. At this point, Alice is more interested in what the students themselves have to say about the experience. She was struck by the lack of frustration exhibited by Nancy and Susan while taking ENNL classes. They did not seek her out for help as they had when they were in Developmental Education classes. When she did see them, they had only positive things to say about the classes and their experiences. 
Peter, the ENNL department chair, expressed disappointment in the number of absences Susan and Nancy had and the way that Susan handled her withdrawal from school. Peter has no immediate plans for formal evaluation. He is interested in the adaptations that are made as issues raised in the Spring quarter classes, this study and future classes arise. He stressed the importance of instructor input and opinion as they experience deaf students in their classes to help in future decisions concerning deaf students in ENNL classes.

What criteria will be used to determine whether ENNL classes be recommended for American deaf students in the future?

The answer to this question is contingent on the future evaluation discussed above. At this point, Alice feels that she needs more time and more deaf students in ENNL classes to adequately gauge which students are appropriate candidates for the ENNL program. Alice plans to continue her role as gatekeeper of deaf students entering the ENNL program and make recommendations as to which students should take the ENNL placement exam. Peter will continue to admit those deaf students who pass the reading and writing portion of the exam into the program.

Classes in the ENNL program are generally very interactive and consequently it might become necessary to limit the number of deaf students per class or increase the number of interpreters. Maya and Paula did not find the idea of more than one interpreter appealing. At some point, the ENNL 
department and Office of Students with Disabilities will have to determine how many deaf students can be adequately served by one interpreter in an ENNL class and decide whether to limit students or increase interpreters.

\section{OTHER ISSUES}

The instructors in this study had never had deaf students in their classes before. The interpreter, though fluent in sign language and knowledgeable about deafness, had no formal interpreter training and had only been interpreting for nine months. Paula, Maya and George shared an eagerness to make things work but their inexperience may have led to certain problems.

George, though he meant well, had his own ideas about what was best for the deaf students and took on roles above and beyond that of interpreter which he was unable or unwilling to sustain throughout the term. When George decided to handle all of Susan's questions and clarification requests himself without voicing them to the instructors, Maya and Paula did not realize how much of this Susan was doing. At midterm, when he abruptly decided to stop handling Susan's requests and started voicing each and every thing that she communicated to him, the instructors were overwhelmed with the disruption. Though it was not her reason for dropping the classes, Susan's last days in the program were difficult because of this change in interpreting, which could have been avoided if George had communicated his change in 
strategy to the instructors. In his second interview, George said he no longer thought that he was acting in Susan's best interests and wanted the instructors to do something about the problem of her excess interrupting, but the instructors were unaware that there had ever been a problem.

After realizing what was happening, Paula assessed Susan's interruptions as a classroom management problem and felt that it could have been cleared up by simply talking to Susan or having Sharon talk to Susan. A more experienced interpreter would probably have drawn the instructor's attention to the problem earlier in the term.

George, who at times seemed to question the value of group work, had trouble interpreting in the small groups in the Upper Intermediate Reading class. As a native-speaker of English, he was often drawn into the discussion by the traditional ENNL students, who saw him as a possible tutor. He also decided that facilitating the small group was in the best interests of the deaf students because when he did not facilitate, they tended to do the work on their own. In fairness to George, it should be noted that Maya admitted to feeling ambivalent about his role as facilitator of the groups when they discussed it early in the term. She suggested that George do whatever he felt comfortable doing.

It was not until George spoke with other interpreters in the Office of Students with Disabilities that he came to the decision that he was much too involved in the groups. Around midterm he made a significant change in his 
strategy and began to act solely as interpreter in small groups. Maya, who was not apprised of the change, was irritated that he did not discuss it with her first. Sharon, the administrator/instructor in the interpreter training program at the college, Alice, and even George himself in his second interview, said that the majority of interpreters would not take on the roles in a small group that George had. Most interpreters would act only as the conduit for communication between deaf and hearing students.

Though understandable given the newness of the situation, Paula and Maya tended towards an over-reliance on George. Both instructors initially found him extremely helpful and a valuable asset in contending with an unfamiliar experience. He was willing to act as consultant to their queries about deafness, appropriate activities and sensitivity issues. After midterm, however, George appeared to tire of this role and Maya, in particular, felt that he became inaccessible to her. Alice has suggested that instructors should discuss such issues directly with the deaf students. Most interpreters would not take the time to discuss issues beyond the mechanics of interpreting with instructors. Counselors in the Office of Students with Disabilities are also available to talk to instructors.

In the end, perhaps personality is the reigning factor in the relationship between the instructor and the interpreter. When discussing the possibility of more deaf students in future classes, Paula looked forward to the possible return of George as interpreter while Maya would prefer a different interpreter. 
As mentioned before, Alice and the ENNL chair and faculty would like to see Alice play the role of gatekeeper in referring deaf students to the ENNL placement exam. They consider this crucial to the success of future ENNL classes with deaf students. There are already signs, however, that this may not be realistic. During spring quarter, a deaf student interested in taking ENNL classes was advised by Alice that she was not ready for that program. The student, adamant about getting into the program, turned to another counselor who asked Peter to allow the student to take the ENNL placement exam. She was placed at the Intermediate Writing level and plans to take the class Fall Quarter 1995. Non-native speakers of English who want to take the ENNL placement test simply call the college testing center and arrange for a test date. As deaf students at the college learn more about the ENNL program, it may not be possible to maintain the screening process that Alice and the ENNL department have set up.

At the beginning of the term, Paula and Maya expected Susan to be the more successful of the two deaf students. They were both struck by Susan's enthusiasm for what she was learning and her intense engagement in the classroom. During the first interview, both instructors reported that they were unsure about Nancy. They felt that they had not made a connection with her yet. Maya was especially concerned about her lack of bonding with Nancy. Initially, George, the interpreter, thought that Susan was getting more out of the classes than Nancy was. Alice, the rehabilitation counselor, who knew 
both students well was careful to point out that Susan and Nancy are very different people. She characterized Nancy as shyer, less experienced and more reserved than Susan and predicted that Nancy would be harder to get to know.

Both instructors noticed changes in Nancy's involvement in class and their own relationships with her after Susan dropped the classes. It is difficult to say whether the changes were directly linked to Susan's absence. It is possible that it takes time to get to know someone like Nancy. Although everyone involved characterized Susan as the more dominant person, Nancy did not report feeling dominated by her fellow student. It is more likely that Susan's monopoly of the interpreter's and instructors' attention led them to assume that Nancy was less engaged in class.

Instructors who cannot communicate directly with deaf students who use sign language need to develop a way to create as normal a teacherstudent relationship as possible. Paula reported less trouble with this than Maya. This may be due to personality but it also seems that writing instructors who regularly receive student writing assignments that often contain personal information have an advantage in getting to know their students sooner. It is easy to see the interpreter as the instructor's link to the deaf student but perhaps it should be seen as a hindrance as well. Maya thought she made an important breakthrough in her relationship with Nancy on the day that she split the deaf students up and worked with Nancy in a small group without George. 


\section{LIMITATIONS AND SUGGESTIONS FOR FUTURE RESEARCH}

Since only one deaf student completed the term, the conclusions of this study are limited, as it is impossible to generalize from this one case. This is particularly important when one considers the extreme diversity of the deaf population.

The difference in the backgrounds of Susan and Nancy demonstrates the heterogenous nature of the deaf population. Susan, born deaf but not diagnosed until the age of two, had experienced language deficit early in life. Born to a hearing family that did not learn a sign language, Susan changed schools and deaf education methods frequently, dropped out of high school and eventually arrived at the community college expressing a high level of frustration with English. Nancy, deafened at age two and immediately diagnosed, learned sign language along with her hearing family members, who learned it in order to communicate with her. She attended two schools, one of which was a residential school for the deaf. She had successful and positive school experiences and was a recent high school graduate. She arrived at the community college aware that she still needed help with English but reported that her experiences learning English, while difficult, had not been particularly frustrating.

Both Nancy and Susan are considered prelingually deaf because they became deaf before they acquired a spoken language. In this way, the 
students are similar and may be typical of the type of hearing-impaired student the ENNL program is likely to serve in the future. On the other hand, though they are both considered prelingually deaf, their backgrounds are different. Though there are many factors in these backgrounds to consider, it is possible that the age of onset of deafness and the age of language acquisition (whether oral or manual) are key factors in determining the success or failure of American deaf students enrolled in ENNL classes.

Though it was worthwhile to compare errors made by Nancy and traditional ENNL students in the writing class, it would have been more valuable if Susan had remained in the class and her essays analyzed as well. It would have been helpful to have longer writing samples that would enable employing a more sophisticated type of analysis.

A researcher who knows sign language may have uncovered information not readily apparent to one who does not. On the other hand, it might have been difficult for a sign fluent researcher to focus on as much interaction between hearing and deaf people when focusing on the language of the deaf person and the interpreter.

Finally, as an observer and interviewer who often had access to more pieces of the puzzle than individual subjects, it was difficult for this researcher to stay objective and maintain the role of describer.

It would be valuable to follow the progress of Nancy and Susan in the ENNL program. As more deaf students enter the program, it should be 
possible to focus on more quantitative research. Future studies might include a look at the writing samples of deaf students, traditional ENNL students and Developmental Education students of comparable writing ability. It would be interesting to observe Developmental Education reading and writing classes with deaf students and ENNL classes with deaf students to compare them. If students with wider degrees of hearing impairment and time of onset of deafness enter the ENNL program, it would be worthwhile to determine whether the program is more suitable for a particular group of these students, such as the prelingually deaf.

\section{IMPLICATIONS FOR TEACHING ENNL CLASSES WITH} AMERICAN DEAF STUDENTS

It is useful to begin a discussion of implications for teaching ENNL classes with American deaf students by separating issues likely to arise in any mainstream classroom with deaf students from those unique to the ENNL classroom. Adapting to the "intrusion" of the interpreter, realizing that for the first few days all student eyes will be on the interpreter, adjusting to the lack of eye contact with deaf students during class, and deciding how to proceed when the interpreter is late or does not show are situations that Maya and Paula, the ENNL instructors, had to deal with and all instructors would face.

The use of multimedia in lessons, while popular with many ENNL instructors, is not limited to those classes. All instructors who bring music and 
video into their classrooms will face decisions about their use when deaf students are present.

The relationship between the instructor and the interpreter for the deaf students is a crucial one in any classroom and whether it is a successful one or not will often hinge on personalities, perspectives, communication, and experience. Well-trained interpreters are essentially conduits for the exchange of language between people who use an aural-oral language and those who use a visual-gestural language. This is all an instructor should expect from an interpreter in the classroom.

The concept of cooperative learning, currently a very popular component of TESOL methodology, is also incorporated in methodology when teaching other disciplines. Small group and other communicative activities involving deaf students, hearing students and interpreters, can be challenging to the instructor who sets them up and the students and interpreters who participate in them. What is unique to ENNL classes is the fact that many traditional ENNL students come from cultures with educational systems that do not use these methods. Students used to teacher-fronted classrooms in which questions and opinions are not encouraged often find small group work unfamiliar and unsettling. Some students even question whether they are engaged in "real learning" when they participate in such activities. Instructors need to set the ground rules for small group work with interpreters at the beginning of the term. As the instructor begins to identify natural facilitators 
among the traditional ENNL students, it may be necessary to move one of these students into the small group with deaf students to get things moving. Interpreters used to interpreting in classes made up of native-speakers of English may find it difficult to understand non-native speakers. It is possible that this might pose less of a problem in higher level classes where speaking ability is generally, though not always, higher. This is a serious problem that instructors need to be aware of and requires instructors and interpreters to decide on a strategy to prevent deaf students from sitting for long periods without receiving any classroom communication.

There may be a tendency by ENNL instructors to assume that deaf students have been placed too low in the program. Paula initially thought that Susan and Nancy had been placed too low. She was impressed by their vocabulary which was more advanced than that of the traditional ENNL students but quickly realized that their control of grammatical structures did not match their vocabulary level. Paula and Maya reported a general sense of comprehension on the part of Nancy when they were teaching and sometimes a tendency to relate this to a feeling that the material was too simple for her. But it should be noted that the deaf students, unlike the traditional ENNL students were receiving instruction in their primary language. It is possible that the look of comprehension on Nancy's face had more to do with her understanding the language of instruction than the subject matter itself. 


\section{CONCLUSION}

Despite the differences in their background, Susan and Nancy both reported frustration with their Developmental Education classes and satisfaction with their ENNL classes. Both students described feeling out of place in Developmental Education classes and thought that they belonged in ENNL classes. Sharon, the deaf administrator/instructor in the college's sign language studies and interpreter training programs, shares their opinion because of her own positive experience in ESL classes years ago. She suggested that despite the differences in background, deaf students and nonnative speakers of English need a safe, comfortable environment in which to learn and practice English, and ENNL provides that place. Alice, the rehabilitation counselor, who had often been called upon by Nancy and Susan when they were enrolled in Developmental Education classes, was impressed by the lack of academic problems either student had in the ENNL classes. Paula and Maya, the ENNL instructors, had reservations at the beginning of the term but believed that because of the nature of language learning and deafness, Nancy and Susan belonged in ENNL classes. Their experience during the term confirmed this belief.

One prelingual, profoundly deaf student in this study had a successful quarter in two ENNL classes and earned the grade of B in both classes. Her rehabilitation counselor, her ENNL instructors and the student herself consider the experience a positive one. This deaf student is encouraged by her 
experience and plans to enroll in Upper Intermediate Writing this fall quarter. She is not sure she will continue with the reading class. The other prelingual, profoundly deaf student had to drop out of the ENNL classes for personal reasons, but reported that she was very satisfied with them and plans to return fall quarter and re-enroll in the classes.

The ENNL program does appear to be an appropriate place for both of these deaf students. Nancy and Susan both thought they were getting the kind of help that they needed in English. Though there were problems to overcome, Maya and Paula both believed that they were providing the kind of instruction that Susan and Nancy needed.

The instructors felt that teaching Upper Intermediate Reading with deaf students in the class posed more challenges than teaching Intermediate Writing did. Techniques used in the reading class were more communicative than those used in the writing class and this led to problems involving small group work, interpreting non-native speaker dialogue, and the use of music and video in lessons For some of these issues, there were no clear solutions. Maya simply adapted to each problem as it arose.

Enroliment of American deaf students in ENNL classes at the community college featured in this study is based on an agreement between two departments at that college. It is far from official policy on that particular campus or any other campus in the system. Some ENNL faculty remain skeptical about this type of placement. In some ways, this situation parallels 
that of ESL and international students mainstreamed into K-12 and secondary education settings many years ago. Instructors of classes of American nativespeaking English students often saw the placement of ESL and international students into their classrooms as inappropriate. Many instructors focused on what the experience would take way from their instruction or the other (nativespeaking) students. TESOL professionals recognized this tendency to look upon non-native students as problems rather than resources to the classroom and many became involved in the struggle to change this attitude, an attitude that American deaf students may now face when entering ENNL classes.

However, it is interesting to note that Peter, the ENNL department chair has changed the information sheet the ENNL department uses to explain the program objectives and goals. It now reads "ENNL serves the needs of refugees, U.S. citizens, permanent residents, professional personnel working and training in the U.S., international students, and international visitors. Some Americans born deaf or hard-of-hearing students may also take ENNL classes if their first language is American Sign Language."

\section{EPILOGUE}

At this writing, Fall quarter 1995 has begun at the community college with five deaf students enrolled in the ENNL program. Nancy has returned and is taking Upper Intermediate Writing and Advanced Reading. Susan has also returned and is taking Intermediate Writing and Upper Intermediate 
Reading again. The student who took the ENNL placement test last spring is enrolled in Intermediate Writing. Two new students who have not taken the Comprehensive English Development for the Deaf class took the ENNL placement test during the summer. One is now enrolled in Intermediate Writing and Upper Intermediate Reading. The other is taking Advanced Writing and Upper Intermediate Reading. One additional deaf student is currently waiting to take the ENNL placement test for Winter quarter 1996.

At the beginning of the first week of classes there were five deaf students enrolled in five different classes taught by four instructors and interpreted by five interpreters. Paula is one of the instructors. The other three are experiencing deaf students in their classes for the first time. By the end of the week some of the deaf students had moved up a level in reading and there are now five instructors with deaf students in their classes.

Diagnostic tests are given during the first week of class and although it is not unusual for some traditional ENNL students to move up or down a level if their original placement does not seem suitable, the movement of the deaf students appears to be motivated by opinion on the part of some of the ENNL faculty that American deaf students do not belong in the lower levels of ENNL reading. This is unfortunate because it seems to be based on the perceived experience of only one deaf student (Nancy) who has successfully completed one term of ENNL classes. 
Some instructors in the department remain somewhat resistant to the idea of deaf students in ENNL classes. There is probably no single reason for this. Some instructors may not have read the research material about language learning and deafness provided by Peter. Others who are unused to observation may view the interpreter as a potential observer of their teaching. Some are concerned that Americans whether they are interpreters or deaf students will be bored in their classrooms. Part-time adjunct faculty who are not paid for preparation or office time may be concerned that extensive conferencing with deaf students and or counselors in the Office of Students with Disabilities will be an imposition on their already limited time.

Time and experience are needed to see if some these concerns can be overcome. For the third term in a row, Alice will not be teaching the Comprehensive English Development for the Deaf class because she lacks the minimum number of students. It remains to be seen whether this will have an impact on the number of deaf students entering the ENNL program. 


\section{REFERENCES}

Allen, T. (1986). Patterns of academic achievement among hearing impaired students: 1974-1983. In A. Schildroth \& M. Karchmer (Eds.), Deaf children in America, 161-206. San Diego: College Hill/Little Brown.

Andersson, Y. (1990). Who should make decisions on communication among deaf people? In M.D. Garretson (Ed.), Eyes, hands, voices: Communication issues among deaf people, 1-4. Silver Spring: National Association of the Deaf.

Berent, G. (1983a). Second language acquisition and acquisition of English by the deaf. TESOL Newsletter, 17, 11-12.

Berent, G. (1983b). Control judgements by deaf adults and by second language learners. Language Learning, $33(1)$.

Bohannon, J. N., Warren-Leubecker, A. (1985). Theoretical approaches to language acquisition. In J. B. Glison (Ed. ), The development of language, 173-226. Columbus: Charles E. Merrill.

Bosso, E. (1990). Ethics in Deaf America: Education and language. In M.D. Garretson (Ed.), Eyes, hands, voices: Communication issues among deaf people, 9-14. Silver Spring: National Association of the Deaf.

Bragg, B. (1990). Communication and the deaf community: Where do we go from here? In M.D. Garretson (Ed.), Eyes, hands, voices: Communication issues among deaf people, 9-14. Silver Spring: National Association of the Deaf.

Cannon, B. \& Polio, C. (1989). An analysis of input and interaction in the dialogue journals of deaf community college students. Teaching English to Deaf and Second Language Students, 7 , (1) 12-21.

Chomsky, N. (1972). Language and mind. New York: Harcourt Brace Jovanovich. 
Christensen, K. (1989). ASL/ESL: A bilingual approach to education of children who are deaf. Teaching English to Deaf and Second Lanquage Students. 7 , (2), 9-14.

Christensen, K. (1990). American Sign Language and English: Parallel bilingualism. In Garretson, M. (Ed.), Communication issues among deaf people: A deaf monograph. Washington, D.C.: St. Mary's Press.

Christensen, K., Goodstein, A., Humphries, T., Kuntze, M., Titus, A. \& Strong, M. (1990). Teaching English to deaf students and English as a second language: Psychological considerations. An academic panel discussion. Teaching English to Deaf and Second Language Students. $\underline{8},(1), 5-19$.

Cornett, O. R. (1990). The complete deaf person. In M. D. Garretson (Ed.), Eyes, hands, voices: Communication issues among deaf people, 43-46. Silver Spring: National Association of the Deaf.

DiFrancesca, S. (1972). Academic achievement test results of a national testing program for hearing impaired students-United States: Spring, 1971 (Series D, No. 9). Washington, D.C.: Gallaudet College, Office of Demographic Studies.

Evans, L. (1982). Total communication: Structure and strategy. Washington, D.C.: Gallaudet College Press.

Finocchario, M. \& Brumfit, C. J. (1983). The functional-notional approach: From small theory to practice. Oxford: Oxford University Press.

Goldberg, J.P., \& Bordman, M. (1975). The ESL approach to teaching English to hearing-impaired students. American Annals of the Deaf, 120, (1), 22-7.

Goldberg, J. P., Ford, C.K. \& Silverman, A. (1984). Deaf student in ESL composition classes: Challenges and strategies. Teaching English to Deaf and Second Language Students, 2, (2), 4-9.

Goodstein, A. (1983). Have you ever had a deaf student in your ESL class? Teaching English to Deaf and Second Language Students. 1, (3), 2426.

Goodstein, H. (1990). American sign language. In M. D. Garretson (Ed.), Eyes, hands, voices: Communication issues among deaf people, 47-49. Silver Spring: National Association of the Deaf. 
Hoffmeister, R. \& Wilbur, R. (1980). The acquisition of sign language. In Lane, H., \& F. Grosjean (Eds.), Recent Perspectives on American Sign Lanquage, 61-78, NJ: Erlbaum.

Johnson, R. \& Liddell, S. (1990). The value of ASL in the education of deaf children. In M. D. Garretson (Ed.), Eyes, hands, voices: Communication issues among deaf people, 59-63. Silver Spring: National Association of the Deaf.

King, C.M., \& Quigley, S.P. (1985). Reading and deafness. San Diego: College-Hill Press.

Klima, E. S. \& Bellugi, V. (1979). The signs of language. Cambridge: Harvard University Press.

Kuntze, M. (1990). ASL: Unity and power. In M. D. Garretson (Ed.), Eyes, hands, voices: Communication issues among deaf people, 75-78. Silver Spring: National Association of the Deaf.

Lane, H. (1990). Bilingual education for ASL-using children. In M. D. Garretson (Ed.), Eyes, hands, voices: Communication issues among deaf people, 79-85. Silver Spring: National Association of the Deaf.

Lane, H. (1984). When the mind hears. New York: Random House.

Lane, J. And Lang, E. (1993). Writing clearly: An editing guide. Boston: Heinle and Heinle Publishers.

Langston, C., \& Maxwell, M. (1988). Holistic judgement of texts by deaf and ESL students. Sign Language Studies, $\underline{60}, 295-312$.

Lou, M. W. (1988). The history of language use of the Deaf in the United States. In. M. Strong (Ed.), Language learning and deafness, 75-98. NY: Cambridge University Press.

Magrath, D. (1985). ESL and deaf education: mutual needs. Foreign Language Annals, 18, 497-499.

Mather, S. (1990). Is America really a free country for us all? In M. D. Garretson (Ed.), Eyes, hands, voices: Communication issues among deaf people, 87-89. Silver Spring: National Association of the Deaf.

McAnally, P. L., Rose, S. \& Quigley, S. D. (1987). Language learning practices with deaf children. Boston: College-Hill Press. 
Meath-Lang, B. \& Albertini, J. A. (1984). Teaching English to Deaf and Second Language Students, 2 , (3), 4-11.

Moores, D. F. \& Meadow-Orlans, K. P. (1990). Educational and developmental aspects of deafness. Washington, D.C.: Gallaudet University Press.

Newell, W. (1990). ASL is not a four-letter word: Deaf education can dance with the boogieman. In M. D. Garretson (Ed.), Eyes, hands, voices: Communication issues among deaf people, 97-102. Silver Spring: National Association of the Deaf.

Paul, P. \& Jackson, D. (1993). Toward a psychology of deafness: Theoretical and empirical perspectives. Needham Heights: Allyn \& Bacon

Paul, P. (1990). ASL to English. In M. D. Garretson (Ed.), Eyes, hands, voices: Communication issues among deaf people, 107-113. Silver Spring: National Association of the Deaf.

Quigley, S. P. \& Paul, P. (1984a). Language and deafness. San Diego: College-Hill Press.

Quigley, S.P., \& Paul, P. (1984b). ASL and ESL? Topics in Early Childhood Special Education, 3 , (4), 17-26.

Quigley, S. P. \& Paul, P. (1987). Deafness and language development. In S. Rosenberg (Ed.), Advances in applied psycholinguistics, Volume 1: Disorders of first language development, 180-219. Cambridge: Cambridge University Press.

Quigley, S.P., \& King, C. M. (1980). An invited article: Syntactic performance of hearing impaired and normal hearing individuals. Applied Psycholinguistics, 4, 142.

Rawlings, B., \& Jensema, C. (1977). Two studies of the families of hearing impaired children. Gallaudet College, Office of Demographic Studies, ser. R, no. 5. Washington, D.C.

Rodda, M. \& Grove, C. (1987). Language cognition and deafness. Hillsdale: Lawrence Erlbaum Associates

Rumelhart, D. E. \& Ortony, A. (1977). The representation of knowlege in memory. In R. C. Anderson, R. J Spiro, \& W. E. Montague (eds.), 
Schooling and the acquisition of knowledge. Hillsdale: Lawrence Erlbaum Associates.

Sacks, O. (1989). Seeing voices: A journey into the world of the deaf. Berkeley: University of California Press.

Scheetz, N. A. (1993). Orientation to deafness. Needham Heights: Allyn \& Bacon.

Snow, C. (1977). The development of conversations between mothers and babies. Journal Child Language, 4 , (1), 1-22.

Stewart, D. (1990). Directions in bilingual education for deaf children. Teaching English to Deaf and Second Language Students. $\underline{8}$, (2), 4-9.

Stewart, L. 1990. Sign language: Some thoughts of a deaf American. In M. D. Garretson (Ed.), Eyes, hands, voices: Communication issues among deaf people, 117-124. Silver Spring: National Association of the Deaf.

Stokoe, W. (1960). Sign language structure: An outline of the visual communication systems of the American Deaf. Studies in Linguistics: Occasional Papers 8, Revised 1978, Silver Spring: Linstok Press.

Streng, A. H., Kretschmer, Jr., R. R., \& Kretschmer, L. W. (1978). Language learning and deafness: Theory, application and classroom management. NY: Grune and Stratton.

Strong, M., Woodward, J., \& Burdett, J. (1987). A bilingual/ESL approach to the education of deaf children. Teaching English to Deaf and Second Language Students. $\underline{5}$, (1), 9-15.

Strong, M. (Ed.). (1988). Learning language and deafness. NY: Cambridge University Press.

Strong, M. (1990). Bilingualism and deaf children. In M. D. Garretson (Ed.), Eyes, hands, voices: Communication issues among deaf people, 125127. Silver Spring: National Association of the Deaf.

Swisher, V. (1989). The language-learning situation of deaf students. TESOL Quarterly, 23, 239-257.

Trybus, R., \& Karchmer, M. (1977). School achievement scores of hearing impaired children: National data on achievement status and growth patterns. American Annals of the Deaf, 122, 62-69. 
Valli, C. 1990. A taboo exposed: Using ASL in the classroom. In M. D. Garretson (Ed.), Eyes, hands, voices: Communication issues among deaf people, 129-131. Silver Spring: National Association of the Deaf.

Walworth, M. (1989). ASL and bilingual education. Teaching English to Deaf and Second Language Students, $\underline{7}$, (1), 27-30. 
APPENDIX A

SAMPLE OBSERVATION FIELD NOTES 


\section{ENNL INTERMEDIATE WRITING $\quad 4 / 20$}

11:50 Ten students and I enter class as last students from other class leave. Susan and Nancy are among us. Susan and Nancy sit down and start signing to each other. Other students drift in up until 12:00. Some are talking to their neighbor. Others are looking at papers or books. Susan and Nancy continue conversing.

12:00 Paula enters the room greeting the class as she walks to the front of the room. The interpreter for the deaf students has not arrived yet. Paula sees Susan and asks her if she is O.K. because she was absent yesterday. Susan looks puzzled. Paula says "Are you better?" Susan smiles and nods her head. Paula starts addressing the whole class and tells them what they will be doing today. The deaf students look at each other. They look puzzled and sign to each other briefly. Paula moves directly in front of Susan and Nancy and repeats the plan for the day. Each student will go to the board and write a sentence from their homework assignment. Susan signs to Nancy. Both Susan and Nancy look at Paula and nod.

12:05 The interpreter arrives. She is substituting for George and explains to Paula that she will not be able to stay for the entire period. She signs this as she says it. Paula says, "That's O.K. We've done this before without an interpreter, right?" She looks at Nancy and Susan. The interpreter has signed this. Nancy and Susan both nod. From now until the interpreter leaves, all communication between Paula and the deaf students is interpreted. While students go in groups to the board to write sentences, Paula gives some homework back to Susan and tells her that she (Susan) is missing one page. Paula gives Susan the inclass handouts and extra homework exercises that were given out yesterday. Susan has a question about one of the handouts.

12:10 Paula explains to Susan that she doesn't have time to go over her it with her now. Paula asks Nancy if she can explain to Susan what she (Susan) missed. Nancy looks confused. Paula then suggests that Susan meet with her (Paula) outside of class but says "Maybe you can try it first." "Try what?", the interpreter voices for Susan. Paula points to the exercises. Then Paula asks "Can you meet with me tomorrow?" They discuss several times but none of them work out. Paula again suggests that Nancy meet with Susan and try explaining the assignment. Paula says, "Susan, if you need more explanation after talking to Nancy, I can meet with you next week." Susan explains that the problem with tomorrow is that there is not enough time to reserve 
an interpreter. While all this is going on, students have been writing sentences on the board.

12:15 Paula announces that the class is ready to look at the sentences. The assignment involved labeling the different parts of sentences and identifying whether the verbs in the sentence are transitive or intransitive. Before Paula starts reviewing the sentences, she tells Susan that she will review briefly the lesson from yesterday. She discusses three sentence patterns: S + Intr.V, S + Trans.V + DO, S + Linking V + Subject Complement.

12:20 Paula looks at first sentence on board and asks the class if it has been labeled correctly. "No, no, no, no ..." Many students calling out and interpreter seems to capture this multiple answering in her signing. Susan and Nancy turn around to look at the class. Susan starts to sign to the interpreter. Interpreter does not voice what she signs. Paula starts to read another sentence and misreads first word, "Fire storks Fire storks? - oops, Five storks - oh that's better". Class laughs. (Interpreter seems to mimic Paula's facial expressions perfectly. Have not noticed that George does this). Nancy and Susan laugh a few seconds later. Sentence reads: Five storks stand on a tree. Paula asks students to think of a better way to say this. A traditional ENNL student says, "Birds stand in a tree." Susan signs, "Maybe they are sitting on the very top of the tree." She says this as a joke because she agrees that the preposition should be "in" not "on."

12:25 Susan signs to the interpreter. The interpreter smiles but does not voice what Susan signed. Paula continues to read each sentence that is on the board and ask for the student's confirmation that the sentence has been labeled correctly. Susan is very active in participating in this and the interpreter seems much more forceful in voicing Susan's contributions than George is. This interpreter calls out Susan's comments quite loudly, the way the traditional ENNL students call out when a question is addressed to the whole class.

12:30 Susan signing to interpreter. Interpreter does not voice her signing. *(What is Susan doing - asking questions, making comments??- ask in interviews). Paula continues to read sentences.

12:31 Interpreter leaves. *(Ask Paula about teaching the deaf students without an interpreter. Ask the deaf students about being in class without an interpreter). Paula moves to stand directly in front of the deaf students. She continues to read sentences from the board. Her speech is slowing down somewhat and she is speaking very clearly, almost 
exaggerated. She is using lots of hand gestures. One of the sentences has the word wrinkle in it. One of the traditional ENNL students asks what the word wrinkle means. Paula says it is when there are lines in the face but she says it again in front of the deaf students while running her fingers in squiggly lines down her face. "I have many," she says. The class, including the deaf students, laughs. Paula continues reading sentences, focusing on speaking in front of the deaf students. Susan and Nancy nod often. One sentence reads: "He shakes his hand." The sentence comes from a story and it is clear that this is not what happens. To demonstrate, Paula shakes her own hand and says, "Is this what you mean?" Several traditional ENNL students call out that the word "shakes" should be replaced with "waves." "Big difference," says Paula, demonstrating shaking one's own hand and waving one's hand. The deaf students and the rest of the class laugh.

12:43 Paula hands out a short quiz. There are 10 sentences and students are to label them according to the three sentence patterns discussed yesterday and reviewed today. The instructions are written on the quiz paper. Nancy appears to understand. Susan begins to vocalize to Paula. I cannot understand her and Paula does not seem to either. She tells Susan to just try. Susan signs to Nancy. Appears to be looking for help. Nancy signs briefly but returns to working on the quiz. Paula puts the homework assignment on the board as the students work.

12:45 Paula asks for the class' attention. She stands directly in front of the deaf students and points out the homework assignment, repeating it verbally. Susan and Nancy nod. Paula makes another joke about shaking and waving. Everyone laughs. Susan appears to be confused about what is to be done now - "the quiz or the homework assignment." She vocalizes this and both Paula and I can understand her. Paula points to the quiz and says, "For now."

12:57 The first students to be done turn in their quiz. Susan and Nancy are in the second round of students turning the quiz in. They begin signing to each other. Susan stops on the way out and says to me, "I'm sorry." She missed an appointment for an interview yesterday. I tell her not to worry about it. She leaves. Nancy smiles at me as she leaves. I leave the room while some traditional ENNL students are still working on their quiz. 
APPENDIX B

SAMPLES OF INTERVIEW TRANSCRIPTS 
Interview with Susan (Alice interpreting)

Me: $\quad$ Were you born deaf?

Susan: $\quad$ Yes I was born deaf. When my Mom was pregnant - she was about four months into her pregnancy when she got rubella, the German measles. When I was born, my mom didn't know I was deaf until I was two years old and then she discovered that I couldn't hear. When I was about three and a half years old I went to a public school for oral training and I was very young when they tried to start teaching me speech and as I was growing up - I was about ten years old - then I started learning sign language $-I$ was about ten and then they started using what's called total communication where it's part speech, part signing but they didn't teach me much about English. I was very confused. It was different education and I was moved a lot. My Mom divorced and we moved and it was just all the instruction that I got was so different. I was very confused and it was - I had lousy writing and I just wasn't learning English very well. And then I went to high school and I never studied until - I was about 22 years old I started kind of learning how to read and I had missed so much reading development when I was little. After six months I got my GED, I got that diploma and I worked in a hotel cleaning rooms and I just kind of worked in that environment for a long time and $I$ also went to a tavern and $I$ worked as a dancer for a short time and stopped and then I came to PCC and now I want to major in computer information systems. My parents never taught me writing English when I was growing up. I really learned all my communication from school because they taught me how to communicate but English is a non-native language because other foreign people - they heard their own language but I've never heard English because I'm deaf I've never heard English and English has never made sense to me. So really it's like a foreign language.

First interview with Nancy (OSD interpreter)

Me: Were you born deaf?

Nancy: No, I wasn't born deaf. I was born hearing and then when I was about 23 months old I became sick with a really high fever and it popped the nerve inside my ear and that's why I became deaf. 
Me: $\quad$ And so they knew at that time that you were deaf?

Nancy: $\quad$ Yes

Me: What happened then in terms of - did you go into some kind of special school or when did you learn sign language

Nancy: Honestly, I don't remember learning sign language. At some point my mother put me in a hearing school and I think I began learning sign maybe at two or three years old - I really don't know.

First interview with Paula

Me: $\quad$ And what about - do you find that you have made any modifications at all in your teaching methodology, style, etc.?

Paula: It think in the beginning I did. I think I was more cautious. I think I was more careful about my choice of words - I - I would trip on my words sometimes and again I think that's nerves because I'm dealing with an interpreter - he's not only a student, he's a graduate - of a - of a university. He is-so he's well versed in what I'm teaching. When he told me - it must have been about three or four days into the class that he was - that he wished he'd taken ENNL classes because his punctuation is just atrocious. So I thought oh good well then he gains - you know? - No, I don't think he's- I don't think he's an intrusion and the students have now sort of seen - seen that happening and they don't pay much attention anymore. 


\section{APPENDIX C}

WRITING SAMPLES FROM ENNL PLACEMENT TEST AND INTERMEDIATE WRITING CLASS 


\section{ENNL PLACEMENT TEST WRITING SAMPLES}

\section{Susan}

$\mathrm{Hi}$, finally l'm writing the letter to you. How are you doing? I'm fine. I received your letter a few days ago, and you wanted that me to come and visit with you in Hermiston, Oregon in summertime.

I want to let you know about summertime that I can't come and visit with you. Because I will still have gone to college in summer term, I'm sorry about not coming and visiting with you in summertime. I guess I'm done now, and I will hear you from the letter again.

\section{Nancy}

$\mathrm{Hi}$, How are you? I'm glad that I got your letter early so I can know what is more information you telling about the trip. I would be glad to go with you for the trip. I was wondering if we'll be traveling for the whole three months or not? And will we be able to communicate to any foreign people? We surely need a inperter. Do we have to hire a inperter to go with us for the trip or just for only us? I really need to know more speific information about the inperter and money too.

Please write me back when you have complete information for me to know. We'll talk more after this when we see each other OK? Thanks for inviting me!

\section{$\underline{\text { S1 }}$}

I writt this letter tilling you, that I can't go with you in this trip. Because my son is in the hospital and he will going to have an operation. And I have to be with him. I am sorry I wish that I am with you in this trip. I think I am going to do it next year and I want you to be ready to this trip. But I want you to have fun in your trip and I am so sorry that I am not you in this trip. Also, I wish that we can make it next time.

Finaley and not the end take care of your selfe and I hope to you every thing okay and you are not being on troble.

$\underline{\mathrm{S}}$

I had received your letter few days ago. I'm very glad when you want me to take a trip around the world with you. I really want to come with you. Please let me know some information about this trip such as: airplane ticket, date and time, which places we will come and how long it take? Will you go only with me or any other family members? I will take a trip with my younger sister, you. How do you think?

I look forward to hear from you. Please call me as soon as possible, so I can have plenty of time to prepare for this wonderful trip. I hope that, I will see you soon. 
$\underline{\text { 53 }}$

I received your letter which you write you are going to take a trip around the world. I am shure it will great trip. Thank you for invited. You know it is my dream. But at this time I can't joined to you. I have a very busy time. First I will take test for my English, how do you know I need study English as much as I can. It is very important for my life. Second I am waiting my father-in-law. He has to come to us. I mean, he has to come to America for good. I need time to help him. I hope you will have a great time, and I will wait your letter about trip. I wish you fun, new friends and many happy days.

$\underline{54}$

I recived your letter about your trip, you had asked me about my idea. The first time I must tanks of you, and then I would be very glad. If I know more about your program. At the present I am very busy, if you can wait for next month, I will come with you and I hope we could have a good trip and could enjoy very much, please after this letter you write for me that I know, what would be your schudle and your program. In the end I want to know, we will go by family or alone and we will go by fly or car.

\section{ENNL INTERMEDIATE WRITING IN-CLASS PARAGRAPHS}

\section{$\underline{W-1} \# 1$}

\section{My Favorite Room in the House}

My favorite room in my house can't be too big, but must have everything what I need. To the right of the door is a niece couch with two pillows. In front of the couch is a table. On a table is a dish with candes. Behind the couch in the corner is a bookshelf with many books. On the side wall in front of the door is nice fireplace. Above the fireplace is big picture with my family. In front of the couch it is big windows with a curtain. Nearby the window is TV. On the middle of the room is the rug. Above the rug, on the middle roof is lamp. There are many floures, and many detail like: a crystals, pictures. There are small lamps in the every corner. The room look like a room what I had in my country. I mostly relaxing in this room, watching TV, or nice view when is nice weather. This room make me feel so good and comfortable.

\section{Nancy \#2}

My Three Favorite Activities

There are three interesting activities outside of school. They are aeroboric, ride bike, and study homework.

Every morning I take an aeroboric class to help me in shape and muscle. It's good for me to keep in fitness then lazy person. It helps my body to gain my weight a little and more muscle good-looking. Also, I ride my bike 
once or twice a week afterschool. I used to ride bike since my childhood. I love to ride bike, and it makes me enjoyable. Then, usually every night, 1 study homework at the same time watching T.V. Sometimes homework makes it difficult for me. I do exercise every day and study homework to helps me keep busy.

$\underline{W-5 \# 2}$

\section{Three Interesting Activities}

There are three most interesting activities to me outside of school, working, going to movie and shopping. The most important activity to me is working. I work just part-time. Some people don't like to work, but I am very interesting to me because I meet somebody and talk with them. I know about their character and hobbies. Also, I learn speaking English. It is good for me. The second most important activity to me is going movie. I like to see movies. In the weekend, sometime I go to see a movie with my friends. I like to see anything kinds of movie. Finally, the last important activity to me is shopping because when I am looking around during the shopping I'm feeling happy. So my problems are solved by the shopping, so I can spend good time next week. I usually spend a time for working, I don't spend a time for shopping and going to a movie. I try to spend the time for them every weekend, so I will enjoy the time for me.

\section{Nancy \#4}

\section{Have Had a Busy Life}

I have had a busy life this year. I have had a lot to do. After school is over, I plan to work full-time to earn more money. There are four weddings that I'll attend this summer, a plan to have a suprise 25th anniversary party for my parents in Aug. I don't have much of vacation. While my parents are gone vacation on cruise in Aug., I'm going to take care of the house for them. Then I probably will have a little time my vacation to visit my sister in Seattle for a while. My cousin will come out to visit me in Aug. Because I haven't seen him for $9 \mathrm{yrs}$. It would be nice for him to come visit us this summer. I have a lot of things to do with my busy schedule. It'll be busy and fun for me to do this summer. 
APPENDIX D

PARAGRAPH ERROR ANALYSIS TABLES 


\begin{tabular}{|c|c|c|c|c|c|}
\hline \multicolumn{6}{|c|}{$\begin{array}{c}\text { Table D1 } \\
\text { Nancy }\end{array}$} \\
\hline & \multicolumn{4}{|c|}{ Paragraph } & \multirow[b]{2}{*}{ Total } \\
\hline Errors & 1 & 2 & 3 & 4 & \\
\hline \multicolumn{6}{|l|}{ Global } \\
\hline$v t$ & & 1 & 1 & 1 & 3 \\
\hline vf & 1 & 2 & 3 & & 6 \\
\hline \multicolumn{6}{|l|}{ modal } \\
\hline \multicolumn{6}{|l|}{ cond } \\
\hline ss & 2 & 6 & 13 & 4 & 26 \\
\hline wo & 1 & 1 & & & 2 \\
\hline conn & & 1 & 2 & & 3 \\
\hline \multicolumn{6}{|l|}{ pass } \\
\hline unclear & & & 1 & & 1 \\
\hline Total & 4 & 11 & 20 & 5 & \\
\hline \multicolumn{6}{|l|}{ Local } \\
\hline sv & 1 & & & & 1 \\
\hline art & & 4 & 2 & 2 & 8 \\
\hline num & 2 & 5 & 1 & & 8 \\
\hline wc & 1 & 2 & 1 & & 4 \\
\hline wf & & & 2 & & 2 \\
\hline nonidiom & 3 & & 1 & & 4 \\
\hline Total & 7 & 11 & 7 & 2 & \\
\hline
\end{tabular}

Table D3
W2
\begin{tabular}{|l|c|c|c|c|c|}
\hline & \multicolumn{5}{c|}{ Paragraph } \\
\hline Errors & 1 & 2 & 3 & 4 & Total \\
\hline \hline Giobal & & & & & \\
\hline vt & & & 1 & 2 & 3 \\
\hline vf & 4 & & 2 & & 6 \\
\hline modal & & & & & \\
\hline cond & & & & & \\
\hline ss & 1 & 9 & 7 & 5 & 22 \\
\hline wo & 2 & & 2 & & 4 \\
\hline conn & & 1 & & 2 & 3 \\
\hline pass & & & & & \\
\hline unclear & 2 & 1 & & 3 & 6 \\
\hline Total & 9 & 11 & 12 & 12 & \\
\hline \hline Local & & & & & \\
\hline sv & 2 & & & & 2 \\
\hline art & 12 & 1 & 4 & 3 & 20 \\
\hline num & 2 & 1 & & 1 & 4 \\
\hline wc & 1 & & 4 & 1 & 6 \\
\hline wf & & & & & \\
\hline nonidiom & & & & & \\
\hline Total & 17 & 2 & 8 & 5 & \\
\hline
\end{tabular}

Table D2

\begin{tabular}{|l|c|c|c|c|c|}
\hline \multicolumn{5}{|c|}{ W1 } \\
\hline Errors & \multicolumn{4}{|c|}{ Paragraph } & \\
\hline \hline Global & 1 & 2 & 3 & 4 & Total \\
\hline vt & & & & & \\
\hline vf & & 4 & 2 & 2 & 8 \\
\hline modal & 1 & & 1 & & 2 \\
\hline cond & & & & & \\
\hline ss & 4 & 2 & 10 & 2 & 18 \\
\hline wo & & & 1 & & 1 \\
\hline conn & 2 & 1 & 3 & 1 & 7 \\
\hline pass & & & & & \\
\hline unclear & & & 1 & & 1 \\
\hline Total & 9 & 13 & 30 & 13 & \\
\hline \hline Local & & & & & 28 \\
\hline sv & 2 & & & & 2 \\
\hline art & 9 & 1 & 10 & 2 & 22 \\
\hline num & 3 & & & 3 & 6 \\
\hline wc & 4 & 2 & 7 & & 13 \\
\hline wf & & & 2 & & 2 \\
\hline nonidiom & 1 & & & & 1 \\
\hline Total & 19 & 3 & 19 & 5 & \\
\hline
\end{tabular}

Table D4

\begin{tabular}{|l|c|c|c|c|c|}
\hline \multicolumn{5}{|c|}{ W3 } \\
\hline Errors & 1 & 2 & 3 & 4 & Total \\
\hline Global & & & & & \\
\hline vt & & & 3 & 4 & 7 \\
\hline vf & 1 & 3 & 2 & & 6 \\
\hline modal & & & & & \\
\hline cond & & 1 & & & 1 \\
\hline ss & & 5 & 4 & 2 & 11 \\
\hline wo & & & & 1 & 1 \\
\hline conn & 1 & 2 & 1 & 3 & 7 \\
\hline pass & & & & & \\
\hline unclear & & & & & \\
\hline Total & 2 & 11 & 10 & 10 & \\
\hline \hline Local & & & & & \\
\hline sv & 1 & & & & 1 \\
\hline art & 3 & 2 & 2 & 3 & 10 \\
\hline num & 1 & 2 & & & 3 \\
\hline wc & 3 & 3 & 6 & 5 & 17 \\
\hline wf & & & & & \\
\hline nonidiom & 3 & & & & 3 \\
\hline Total & 11 & 7 & 8 & 8 & \\
\hline
\end{tabular}


Table D5

W4

\begin{tabular}{|c|c|c|c|c|c|}
\hline & \multicolumn{4}{|c|}{ Paragraph } & \multirow[b]{2}{*}{ Total } \\
\hline Errors & 1 & 2 & 3 & 4 & \\
\hline \multicolumn{6}{|l|}{ Global } \\
\hline$v t$ & & 6 & 1 & 1 & 8 \\
\hline$v f$ & & 5 & 2 & & 7 \\
\hline \multicolumn{6}{|l|}{ modal } \\
\hline cond & & & & 1 & 1 \\
\hline ss & 4 & 6 & 11 & 5 & 26 \\
\hline wo & & & & 1 & 1 \\
\hline \multicolumn{6}{|l|}{ conn } \\
\hline \multicolumn{6}{|l|}{ pass } \\
\hline unclear & 2 & 3 & 1 & 2 & 7 \\
\hline Total & 6 & 20 & 15 & 10 & \\
\hline \multicolumn{6}{|l|}{ Local } \\
\hline \multicolumn{6}{|l|}{ sv } \\
\hline art & & & 2 & & 2 \\
\hline num & 2 & 2 & & & 4 \\
\hline wc & 1 & 1 & 2 & 1 & 5 \\
\hline \multicolumn{6}{|l|}{ wf } \\
\hline \multicolumn{6}{|l|}{ nonidiom } \\
\hline Total & 3 & 3 & 4 & 1 & \\
\hline
\end{tabular}

Table D6

\begin{tabular}{|l|c|c|c|c|c|}
\hline \multicolumn{5}{|c|}{ W5 } \\
\hline Errors & \multicolumn{5}{|c|}{ Paragraph } \\
\hline Global & 1 & 2 & 3 & 4 & Total \\
\hline vt & & & & & \\
\hline vf & 1 & 1 & 2 & 2 & 6 \\
\hline modal & 2 & & & & 2 \\
\hline cond & 1 & & & & 1 \\
\hline ss & 1 & 5 & 3 & 5 & 14 \\
\hline wo & 1 & 1 & & 1 & 3 \\
\hline conn & & 1 & & 1 & 2 \\
\hline pass & & & & & \\
\hline unclear & & 1 & & 1 & 2 \\
\hline Total & 6 & 9 & 6 & 15 & \\
\hline \hline Local & & & & & \\
\hline sv & 1 & & & & 1 \\
\hline art & 4 & 4 & & 2 & 10 \\
\hline num & & 4 & & & 4 \\
\hline wc & 4 & 5 & 2 & 2 & 13 \\
\hline wf & & & & & \\
\hline nonidiom & 1 & & & & 1 \\
\hline Total & 10 & 13 & 2 & 4 & \\
\hline
\end{tabular}

Table D7 W6

\begin{tabular}{|l|c|c|c|c|c|}
\hline & \multicolumn{5}{|c|}{ Paragraph } \\
\hline Errors & 1 & 2 & 3 & 4 & Total \\
\hline Global & & & & & \\
\hline$v t$ & & & 1 & 1 & 2 \\
\hline vf & & 1 & & 3 & 4 \\
\hline modal & & & & & \\
\hline cond & & & & & \\
\hline ss & 2 & 9 & 8 & 5 & 24 \\
\hline wo & & & & & \\
\hline conn & & & & 6 & 6 \\
\hline pass & & & & & \\
\hline unclear & 1 & 1 & 1 & & 3 \\
\hline Total & 3 & 11 & 10 & 15 & \\
\hline Local & & & & & \\
\hline sv & 1 & 1 & & & 2 \\
\hline art & 3 & & 1 & 2 & 6 \\
\hline num & & & & & \\
\hline wc & 4 & 1 & & 6 & 11 \\
\hline wf & & & & 2 & 2 \\
\hline nonidiom & & 1 & & 2 & 3 \\
\hline Total & 11 & 3 & 1 & 12 & \\
\hline
\end{tabular}

Table D8 W7

\begin{tabular}{|l|c|c|c|c|c|}
\hline & \multicolumn{5}{|c|}{ Paragraph } \\
\hline Errors & 1 & 2 & 3 & 4 & Total \\
\hline \hline Global & & & & & \\
\hline $\mathrm{vt}$ & & & 2 & & 2 \\
\hline $\mathrm{vf}$ & 2 & 2 & 7 & 7 & 18 \\
\hline modal & & & & & \\
\hline cond & & & & & \\
\hline ss & 2 & 5 & 2 & 4 & 13 \\
\hline wo & & & 1 & 3 & 4 \\
\hline conn & & & 1 & & 1 \\
\hline pass & & & 2 & & 2 \\
\hline unclear & 1 & & & & 1 \\
\hline Total & 5 & 7 & 13 & 14 & \\
\hline \hline Local & & & & & \\
\hline sv & & & & & \\
\hline art & 7 & 1 & 5 & 2 & 15 \\
\hline num & & & & 3 & 3 \\
\hline wc & & 1 & 3 & 1 & 5 \\
\hline wf & & & 1 & 3 & 4 \\
\hline nonidiom & 3 & & & & 3 \\
\hline Total & 10 & 2 & 9 & 9 & \\
\hline & & & & & \\
\hline
\end{tabular}


Table D9

W8

\begin{tabular}{|l|c|c|c|c|c|}
\hline & \multicolumn{5}{|c|}{ Paragraph } \\
\hline Errors & 1 & 2 & 3 & 4 & Total \\
\hline Global & & & & & \\
\hline vt & & & & & \\
\hline vf & & 2 & 1 & 1 & 4 \\
\hline modal & & & & & \\
\hline cond & & & & & \\
\hline ss & & 7 & 7 & 3 & 17 \\
\hline wo & & & & & \\
\hline conn & & 1 & & & 1 \\
\hline pass & & & & & \\
\hline unclear & & & 1 & 2 & 3 \\
\hline Total & 0 & 10 & 9 & 6 & \\
\hline Local & & & & & \\
\hline sv & & 2 & & & 2 \\
\hline art & 1 & 3 & 5 & & 9 \\
\hline num & & & & 1 & 1 \\
\hline wc & 2 & 1 & 1 & 1 & 5 \\
\hline wf & & & & & \\
\hline nonidiom & 1 & 1 & 1 & 1 & 4 \\
\hline Total & 4 & 7 & 7 & 3 & \\
\hline
\end{tabular}

\section{Table D10}

W9

\begin{tabular}{|l|c|c|c|c|c|}
\hline & & \multicolumn{3}{|c|}{ Paragraph } & \\
\hline Errors & 1 & 2 & 3 & 4 & Total \\
\hline Global & & & & & \\
\hline vt & & & & 1 & 1 \\
\hline vf & 1 & 1 & & 1 & 3 \\
\hline modal & & & & & \\
\hline cond & & 1 & & & 1 \\
\hline ss & & 4 & 6 & 5 & 15 \\
\hline wo & 1 & & 2 & & 3 \\
\hline conn & 1 & & & & 1 \\
\hline pass & & & & & \\
\hline unclear & & 1 & & & 1 \\
\hline Total & 3 & 7 & 7 & 7 & \\
\hline Local & & & & & \\
\hline sv & 1 & & & 2 & 3 \\
\hline art & 4 & & 5 & & 9 \\
\hline num & 1 & & 1 & 5 & 7 \\
\hline wc & 1 & & 2 & 1 & 4 \\
\hline wf & & 2 & 2 & & 4 \\
\hline nonidiom & 1 & & & & 1 \\
\hline Total & 8 & 2 & 10 & 8 & \\
\hline
\end{tabular}

Table D11

W10

\begin{tabular}{|l|c|c|c|c|c|}
\hline & \multicolumn{5}{|c|}{ Paragraph } \\
\hline Errors & 1 & 2 & 3 & 4 & Total \\
\hline \hline Global & & & & & \\
\hline$v t$ & & & & & \\
\hline$v f$ & & 1 & 1 & 2 & 4 \\
\hline modal & 2 & & 1 & 2 & 5 \\
\hline cond & & & & & \\
\hline ss & 1 & 5 & 6 & 5 & 17 \\
\hline wo & & & 1 & & 1 \\
\hline conn & & 1 & 2 & & 3 \\
\hline pass & & & & & \\
\hline unclear & & & & & \\
\hline Total & 3 & 7 & 11 & 9 & \\
\hline \hline Local & & & & & \\
\hline sv & 1 & & & & 1 \\
\hline art & 5 & & 3 & 2 & 10 \\
\hline num & & & 1 & 3 & 4 \\
\hline wc & 2 & 3 & 6 & 1 & 12 \\
\hline wf & 2 & & & 1 & 3 \\
\hline nonidiom & 6 & & 1 & 1 & 8 \\
\hline Total & 16 & 3 & 11 & 8 & \\
\hline
\end{tabular}

Table D12

W11

\begin{tabular}{|l|c|c|c|c|c|}
\hline & \multicolumn{3}{|c|}{ Paragraph } & & \\
\hline Errors & 1 & 2 & 3 & 4 & Total \\
\hline Global & & & & & \\
\hline vt & & & & 2 & 2 \\
\hline vf & 1 & 1 & 4 & & 7 \\
\hline modal & 2 & & & & 2 \\
\hline cond & & & & & \\
\hline ss & 1 & & 4 & 2 & 7 \\
\hline wo & & 1 & & & 1 \\
\hline conn & & 4 & 2 & & 6 \\
\hline pass & & & & & \\
\hline unclear & & & & & \\
\hline Total & 4 & 6 & 10 & 4 & \\
\hline \hline Local & & & & & \\
\hline sv & & & & & \\
\hline art & 1 & & 1 & 4 & 6 \\
\hline num & & & 1 & & 1 \\
\hline wc & 6 & 5 & 5 & 2 & 18 \\
\hline wf & & & & & \\
\hline nonidiom & & 1 & & & 1 \\
\hline Total & 7 & 6 & 7 & 6 & \\
\hline
\end{tabular}




\begin{tabular}{|c|c|c|c|c|c|}
\hline \multicolumn{6}{|c|}{$\begin{array}{c}\text { Table D13 } \\
\text { W12 }\end{array}$} \\
\hline & \multicolumn{4}{|c|}{ Paragraph } & \multirow[b]{2}{*}{ Tota } \\
\hline Errors & 1 & 2 & 3 & 4 & \\
\hline \multicolumn{6}{|l|}{ Global } \\
\hline vt & & 1 & 2 & & 3 \\
\hline vf & 1 & 4 & 2 & 1 & 8 \\
\hline modal & 1 & & & & 1 \\
\hline \multicolumn{6}{|l|}{ cond } \\
\hline ss & 1 & 4 & 3 & 2 & 10 \\
\hline wo & & 2 & & & 2 \\
\hline conn & & 1 & 1 & & 2 \\
\hline \multicolumn{6}{|l|}{ pass } \\
\hline unclear & 1 & & & & 1 \\
\hline Total & 4 & 12 & 7 & 3 & \\
\hline \multicolumn{6}{|l|}{ Local } \\
\hline sv & & 1 & & & 1 \\
\hline art & 2 & 10 & 6 & 6 & 24 \\
\hline num & & 2 & & & 2 \\
\hline wc & 3 & 6 & 5 & 1 & 15 \\
\hline wf & & & & 1 & 1 \\
\hline nonidiom & 2 & & 2 & 1 & 5 \\
\hline Total & 7 & 19 & 13 & 9 & \\
\hline
\end{tabular}

\begin{tabular}{|c|c|c|c|c|c|}
\hline \multirow[b]{2}{*}{ Errors } & \multicolumn{4}{|c|}{ Paragraph } & \multirow[b]{2}{*}{ Total } \\
\hline & 1 & 2 & 3 & 4 & \\
\hline \multicolumn{6}{|l|}{ Global } \\
\hline$v t$ & 3 & 1 & 2 & 4 & 10 \\
\hline vf & & 5 & 3 & 2 & 10 \\
\hline modal & & & & 1 & 1 \\
\hline cond & & & & 1 & 1 \\
\hline ss & 1 & 5 & 1 & 1 & 8 \\
\hline \multicolumn{6}{|l|}{ wo } \\
\hline conn & & 2 & 1 & 3 & 6 \\
\hline \multicolumn{6}{|l|}{ pass } \\
\hline unclear & 2 & 1 & & & 3 \\
\hline Total & 6 & 14 & 7 & 12 & \\
\hline \multicolumn{6}{|l|}{ Local } \\
\hline sv & & 1 & & & 1 \\
\hline art & & 1 & 1 & & 2 \\
\hline num & 1 & 2 & & & 3 \\
\hline wc & 2 & 1 & 7 & & 10 \\
\hline \multicolumn{6}{|l|}{ wf } \\
\hline nonidiom & 1 & & 2 & & 3 \\
\hline Total & 4 & 5 & 10 & & \\
\hline
\end{tabular}

\begin{tabular}{|c|c|c|c|c|c|}
\hline \multirow[b]{2}{*}{ Errors } & \multicolumn{4}{|c|}{ Paragraph } & \multirow[b]{2}{*}{ Total } \\
\hline & 1 & 2 & 3 & 4 & \\
\hline \multicolumn{6}{|l|}{ Global } \\
\hline vt & & 2 & & & 2 \\
\hline vf & 2 & & 5 & 4 & 11 \\
\hline \multicolumn{6}{|l|}{ modal } \\
\hline \multicolumn{6}{|l|}{ cond } \\
\hline ss & 2 & 2 & 3 & 3 & 10 \\
\hline wo & & 1 & 1 & 1 & 3 \\
\hline conn & & & 1 & & 1 \\
\hline \multicolumn{6}{|l|}{ pass } \\
\hline unclear & & & 2 & & 2 \\
\hline Total & 4 & 5 & 12 & 8 & \\
\hline \multicolumn{6}{|l|}{ Local } \\
\hline \multicolumn{6}{|l|}{ sv } \\
\hline art & 1 & 4 & 2 & 2 & 9 \\
\hline num & 1 & & & 1 & 2 \\
\hline wc & 2 & 5 & 4 & 2 & 13 \\
\hline wf & & & & 1 & 1 \\
\hline nonidiom & 2 & & 1 & & 3 \\
\hline Total & 6 & 9 & 7 & 6 & \\
\hline
\end{tabular}

\begin{tabular}{|c|c|c|c|c|c|}
\hline \multirow[b]{2}{*}{ Errors } & \multicolumn{4}{|c|}{ Paragraph } & \multirow[b]{2}{*}{ Total } \\
\hline & 1 & 2 & 3 & 4 & \\
\hline \multicolumn{6}{|l|}{ Global } \\
\hline$v t$ & 1 & & 1 & 3 & 5 \\
\hline vf & & 6 & 2 & 4 & 12 \\
\hline \multicolumn{6}{|l|}{ modal } \\
\hline \multicolumn{6}{|l|}{ cond } \\
\hline ss & & 5 & 3 & 1 & 9 \\
\hline \multicolumn{6}{|l|}{ wo } \\
\hline \multicolumn{6}{|l|}{ conn } \\
\hline \multicolumn{6}{|l|}{ pass } \\
\hline unclear & & 1 & & & 1 \\
\hline Total & 1 & 12 & 6 & 8 & \\
\hline \multicolumn{6}{|l|}{ Local } \\
\hline sv & & 1 & & & 1 \\
\hline art & 8 & 5 & 4 & 5 & 22 \\
\hline num & & 2 & 1 & 1 & 4 \\
\hline wc & 1 & 2 & 5 & 1 & 9 \\
\hline$w f$ & 1 & & 1 & & 2 \\
\hline \multicolumn{6}{|l|}{ nonidiom } \\
\hline Total & 10 & 10 & 11 & 7 & \\
\hline
\end{tabular}

